\title{
Integrated Risk and Uncertainty Assessment of Climate Change Response Policies
}

Coordinating Lead Authors:

Howard Kunreuther (USA), Shreekant Gupta (India)

Lead Authors:

Valentina Bosetti (Italy), Roger Cooke (USA), Varun Dutt (India), Minh Ha-Duong (France), Hermann Held (Germany), Juan Llanes-Regueiro (Cuba), Anthony Patt (Austria/Switzerland), Ekundayo Shittu (Nigeria/USA), Elke Weber (USA)

\section{Contributing Authors:}

Hannes Böttcher (Austria/Germany), Heidi Cullen (USA), Sheila Jasanoff (USA)

Review Editors:

Ismail Elgizouli (Sudan), Joanne Linnerooth-Bayer (Austria/USA)

Chapter Science Assistants:

Siri-Lena Chrobog (Germany), Carol Heller (USA)

This chapter should be cited as:

Kunreuther H., S. Gupta, V. Bosetti, R. Cooke, V. Dutt, M. Ha-Duong, H. Held, J. Llanes-Regueiro, A. Patt, E. Shittu, and E. Weber, 2014: Integrated Risk and Uncertainty Assessment of Climate Change Response Policies. In: Climate Change 2014: Mitigation of Climate Change. Contribution of Working Group III to the Fifth Assessment Report of the Intergovernmental Panel on Climate Change [Edenhofer, O., R. Pichs-Madruga, Y. Sokona, E. Farahani, S. Kadner, K. Seyboth, A. Adler, I. Baum, S. Brunner, P. Eickemeier, B. Kriemann, J. Savolainen, S. Schlömer, C. von Stechow, T. Zwickel and J.C. Minx (eds.)]. Cambridge University Press, Cambridge, United Kingdom and New York, NY, USA. 


\section{Contents}

Executive Summary.

$2.1 \quad$ Introduction

2.2 Metrics of uncertainty and risk

2.3 Risk and uncertainty in climate change.

2.3.1 Uncertainties that matter for climate policy choices

2.3.2 What is new on risk and uncertainty in AR5

2.4 Risk perception and responses to risk and uncertainty 160

2.4.1 Considerations for design of climate change risk reduction policies $\ldots \ldots \ldots \ldots \ldots \ldots \ldots \ldots \ldots \ldots \ldots \ldots \ldots \ldots \ldots \ldots \ldots \ldots$

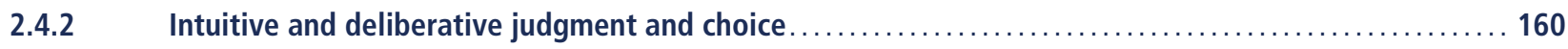

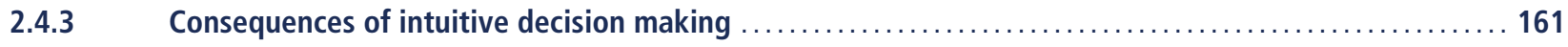

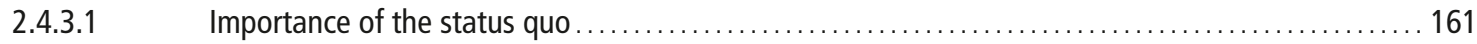

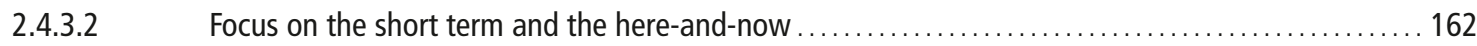

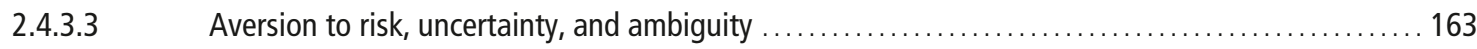

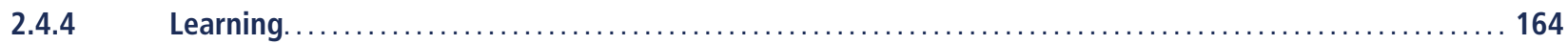

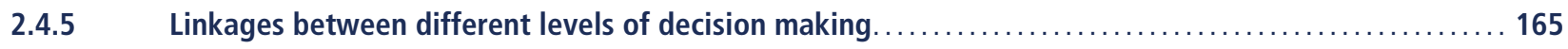

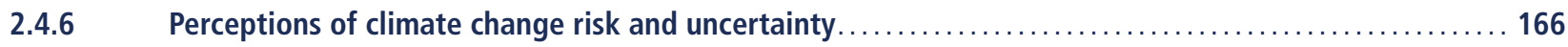

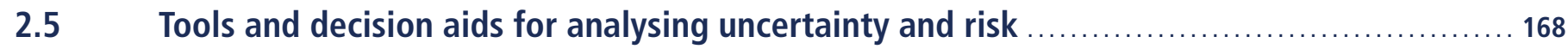

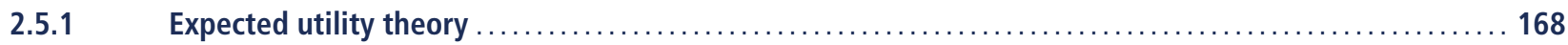

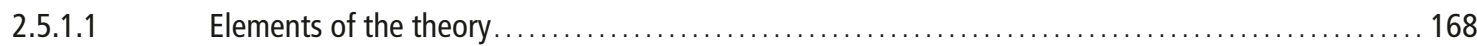

2.5.1.2 How can expected utility improve decision making? ................................ 169

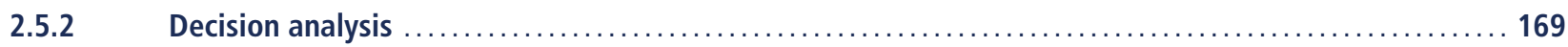

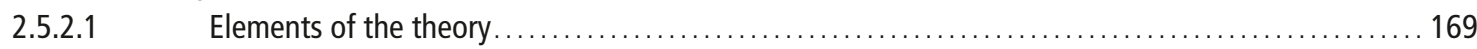

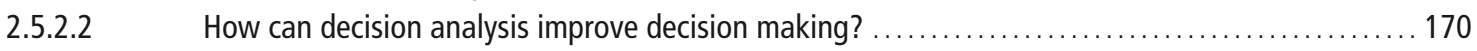

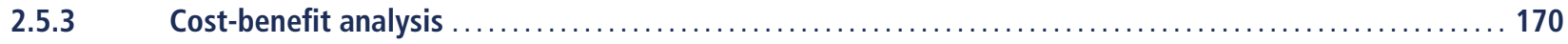

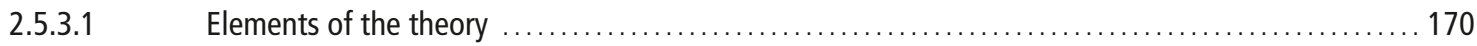

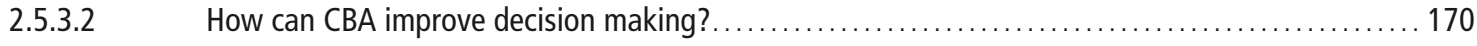

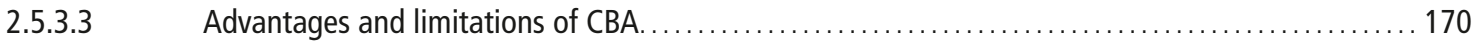




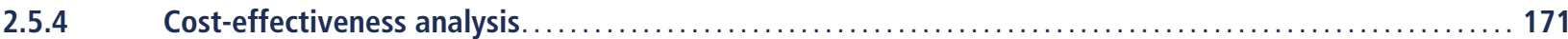

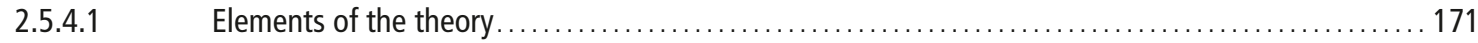

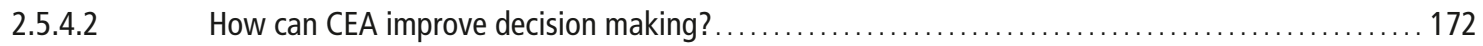

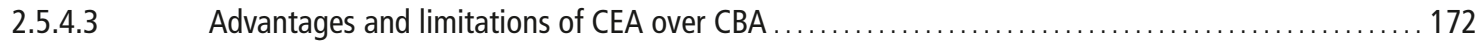

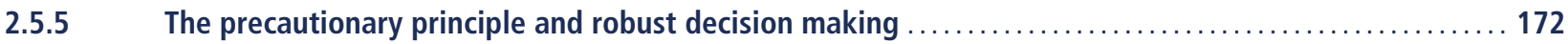

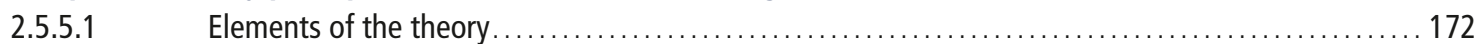

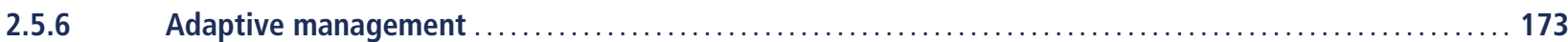

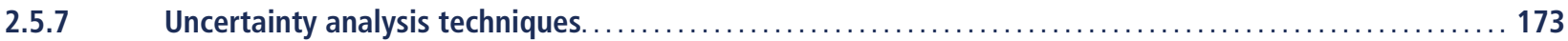

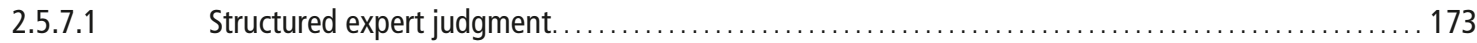

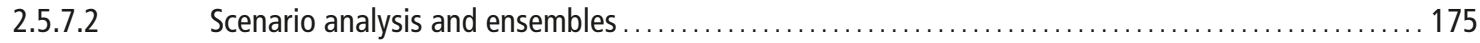

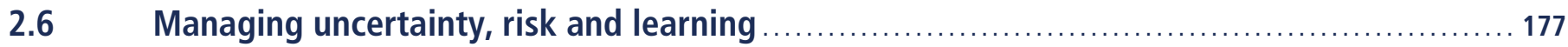

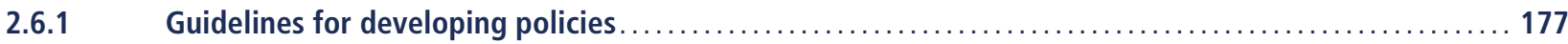

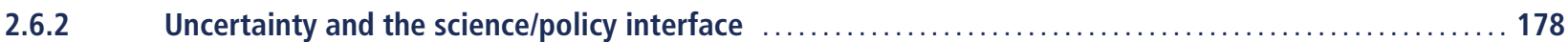

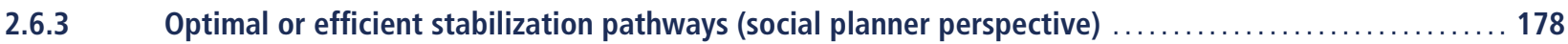

2.6.3.1 Analyses predominantly addressing climate or damage response uncertainty............... 178

2.6.3.2 Analyses predominantly addressing policy response uncertainty $\ldots \ldots \ldots \ldots \ldots \ldots \ldots \ldots \ldots \ldots$

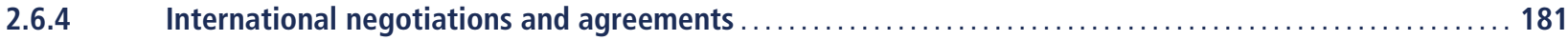

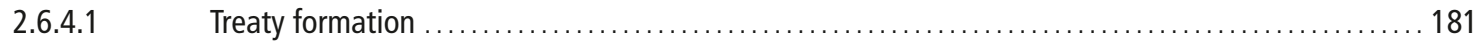

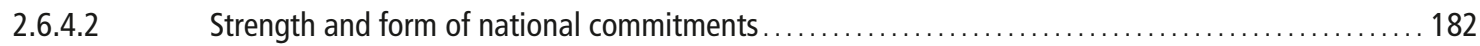

2.6.4.3 Design of measurement, verification regimes, and treaty compliance ...................... 182

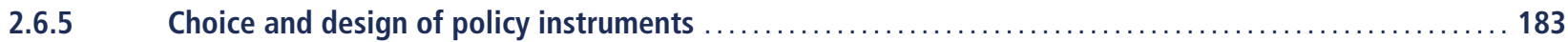

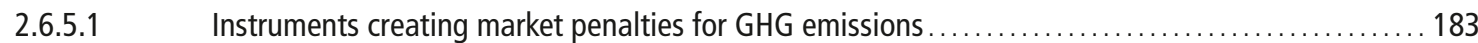

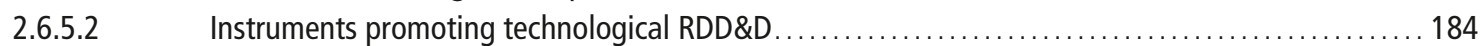

2.6.5.3 Energy efficiency and behavioural change. . . . . . .

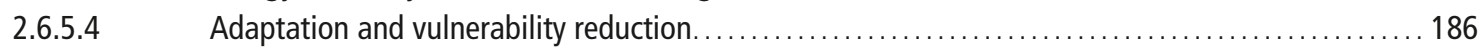

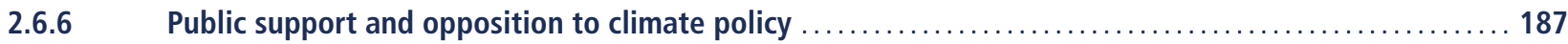

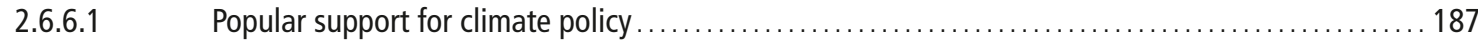

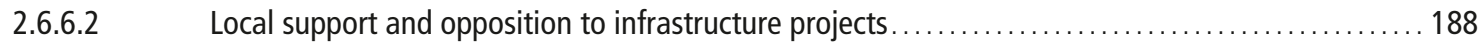

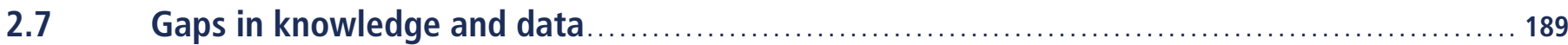

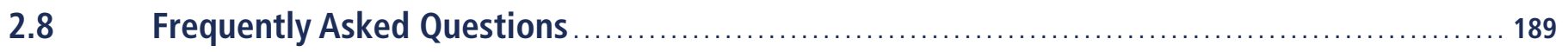

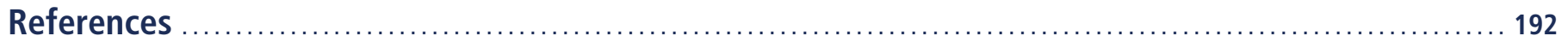




\section{Executive Summary}

The scientific understanding of climate change and the impact it has on different levels of decision-making and policy options has increased since the publication of the Intergovernmental Panel on Climate Change (IPCC) Fourth Assessment Report (AR4). In addition, there is a growing recognition that decision makers often rely on intuitive thinking processes rather than undertaking a systematic analysis of options in a deliberative fashion. It is appropriate that climate change risk management strategies take into account both forms of thinking when considering policy choices where there is risk and uncertainty.

Consideration of risk perception and decision processes can improve risk communication, leading to more effective policies for dealing with climate change. By understanding the systematic biases that individuals utilize in dealing with climate change problems, one can more effectively communicate the nature of the climate change risk. An understanding of the simplified decision rules employed by decision makers in making choices may be helpful in designing policies that encourage the adoption of mitigation and adaptation measures. [Section 2.4]

Decision processes often include both deliberative and intuitive thinking. When making mitigation and adaptation choices, decision makers sometimes calculate the costs and benefits of their alternatives (deliberative thinking). They are also likely to utilize emotion- and rule-based responses that are conditioned by personal past experience, social context, and cultural factors (intuitive thinking). [2.4.2]

Laypersons tend to judge risks differently than experts. Laypersons' perceptions of climate change risks and uncertainties are often influenced by past experience, as well as by emotional processes that characterize intuitive thinking. This may lead them to overestimate or underestimate the risk. Experts engage in more deliberative thinking than laypersons by utilizing scientific data to estimate the likelihood and consequences of climate change. [2.4.6]

Cost-benefit analysis (CBA) and cost-effectiveness analysis (CEA) can enable decision makers to examine costs and benefits, but these methodologies also have their limitations. Both approaches highlight the importance of considering the likelihood of events over time and the importance of focusing on long-term horizons when evaluating climate change mitigation and adaptation policies. CBA enables governments and other collective decision-making units to compare the social costs and benefits of different alternatives. However, CBA cannot deal well with infinite (negative) expected utilities arising from low probability catastrophic events often referred to as 'fat tails'. CEA can generate cost estimates for stabilizing greenhouse gas (GHG) concentrations without having to take into account the uncertainties associated with cost estimates for climate change impacts. A limitation of CEA is that it takes the long-term stabilization as a given without considering the economic efficiency of the target level. [2.5.3, 2.5.4]

Formalized expert judgment and elicitation processes improve the characterization of uncertainty for designing climate change strategies (high confidence). Experts can quantify uncertainty through formal elicitation processes. Their judgments can characterize the uncertainties associated with a risk but not reduce them. The expert judgment process highlights the importance of undertaking more detailed analyses to design prudent climate policies. [2.5.6]

Individuals and organizations that link science with policy grapple with several different forms of uncertainty. These uncertainties include absence of prior agreement on framing of problems and ways to scientifically investigate them (paradigmatic uncertainty), lack of information or knowledge for characterizing phenomena (epistemic uncertainty), and incomplete or conflicting scientific findings (translational uncertainty). [2.6.2]

The social benefit from investments in mitigation tends to increase when uncertainty in the factors relating GHG emissions to climate change impacts are considered (medium confidence). If one sets a global mean temperature (GMT) target, then normative analyses that include uncertainty on the climate response to elevated GHG concentration, suggest that investments in mitigation measures should be accelerated. Under the assumption of nonlinear impacts of a GMT rise, inclusion of uncertainty along the causal chain from emissions to impacts suggests enhancing mitigation. [2.6.3]

The desirability of climate policies and instruments are affected by decision makers' responses to key uncertainties. At the national level, uncertainties in market behaviour and future regulatory actions have been shown to impact the performance of policy instruments designed to influence investment patterns. Both modelling and empirical studies have shown that uncertainty as to future regulatory and market conditions adversely affects the performance of emission allowance trading markets [2.6.5.1]. Other studies have shown that subsidy programmes (e.g., feed-in tariffs, tax credits) are relatively immune to market uncertainties, but that uncertainties with respect to the duration and level of the subsidy program can have adverse effects [2.6.5.2]. In both cases, the adverse effects of uncertainty include less investment in low-carbon infrastructure, increasing consumer prices, and reducing the pressure for technological development.

Decision makers in developing countries often face a particular set of challenges associated with implementing mitigation policies under risk and uncertainty (medium confidence). Managing risk and uncertainty in the context of climate policy is of particular importance to developing countries that are resource constrained and face other pressing development goals. In addition, institutional capacity in these countries may be less developed compared to advanced economies. Therefore, decision makers in these countries (governments and economic agents such as firms, farmers, households, to name a 
few) have less room for 'error' (uncertain outcomes and/or wrong or poorly implemented policies). The same applies to national, regional and local governments in developed countries who can ill afford to waste scarce resources through policy errors. [Box 2.1]

\section{$2.1 \quad$ Introduction}

This framing chapter considers ways in which risk and uncertainty can affect the process and outcome of strategic choices in responding to the threat of climate change.

'Uncertainty' denotes a cognitive state of incomplete knowledge that results from a lack of information and/or from disagreement about what is known or even knowable. It has many sources ranging from quantifiable errors in the data to ambiguously defined concepts or terminology to uncertain projections of human behaviour. The Guidance Note for Lead Authors of the IPCC Fifth Assessment Report on Consistent Treatment of Uncertainties (Mastrandrea et al., 2010) summarizes alternative ways of representing uncertainty. Probability density functions and parameter intervals are among the most common tools for characterizing uncertainty.

'Risk' refers to the potential for adverse effects on lives, livelihoods, health status, economic, social and cultural assets, services (including environmental), and infrastructure due to uncertain states of the world. To the extent that there is a detailed understanding of the characteristics of a specific event, experts will normally be in agreement regarding estimates of the likelihood of its occurrence and its resulting consequences. Risk can also be subjective in the sense that the likelihood and outcomes are based on the knowledge or perception that a person has about a given situation. There may also be risks associated with the outcomes of different climate policies, such as the harm arising from a change in regulations.

There is a growing recognition that today's policy choices are highly sensitive to uncertainties and risk associated with the climate system and the actions of other decision makers. The choice of climate policies can thus be viewed as an exercise in risk management (Kunreuther et al., 2013a). Figure 2.1 suggests a risk management framework that serves as the structure of the chapter.

After defining risk and uncertainty and their relevant metrics (Section 2.2), we consider how choices with respect to climate change policy options are sensitive to risk and uncertainty (Section 2.3). A taxonomy depicts the levels of decision making ranging from international agreements to actions undertaken by individuals in relation to climate change policy options under conditions of risk and uncertainty that range from long-term global temperature targets to lifestyle choices. The goals and values of the different stakeholders given their immediate and long-term agendas will also influence the relative attractive- ness of different climate change policies in the face of risk and uncertainty.

Sections 2.4, 2.5 and 2.6 characterize descriptive and normative theories of decision-making and models of choice for dealing with risk and uncertainty and their implications for prescriptive analysis. Descriptive refers to theories of actual behaviour, based on experimental evidence and field studies that characterize the perception of risk and decision processes. Normative in the context of this chapter refers to theories of choice under risk and uncertainty based on abstract models and axioms that serve as benchmarks as to how decision makers should ideally make their choices. Prescriptive refers to ways of improving the decision process and making final choices (Kleindorfer et al., 1993).

A large empirical literature has revealed that individuals, small groups and organizations often do not make decisions in the analytic or rational way envisioned by normative models of choice in the economics and management science literature. People frequently perceive risk in ways that differ from expert judgments, posing challenges for risk communication and response. There is a tendency to focus on short time horizons, utilize simple heuristics in choosing between alternatives, and selectively attend to subsets of goals and objectives.

To illustrate, the voting public in some countries may have a waitand-see attitude toward climate change, leading their governments to postpone mitigation measures designed to meet specified climate targets (Sterman, 2008; Dutt and Gonzalez, 2011). A coastal village may decide not to undertake measures for reducing future flood risks due to sea level rise (SLR), because their perceived likelihood that SLR will cause problems to their village is below the community council's level of concern.

Section 2.4 provides empirical evidence on behavioural responses to risk and uncertainty by examining the types of biases that influence individuals' perception of the likelihood of an event (e. g., availability, learning from personal experience), the role that emotional, social, and cultural factors play in influencing the perception of climate change risks and strategies for encouraging decision makers to undertake cost-effective measures to mitigate and adapt to the impacts of climate change.

A wide range of decision tools have been developed for evaluating alternative options and making choices in a systematic manner even when probabilities are difficult to characterize and/or outcomes are uncertain. The relevance of these tools for making more informed decisions depends on how the problem is formulated and framed, the nature of the institutional arrangements, and the interactions between stakeholders (Hammond et al., 1999; Schoemaker and Russo, 2001).

Governments debating the merits of a carbon tax may turn to costbenefit analysis or cost-effectiveness analysis to justify their positions. They may need to take into account that firms who utilize formal 
approaches, such as decision analysis, may not reduce their emissions if they feel that they are unlikely to be penalized because the carbon tax will not be well enforced. Households and individuals may find the expected utility model or decision analysis to be useful tools for evaluating the costs and benefits of adopting energy efficient measures given the trajectory of future energy prices.

Section 2.5 delineates formal methodologies and decision aids for analysing risk and uncertainty when individuals, households, firms, communities and nations are making choices that impact their own wellbeing and those of others. These tools encompass variants of expected utility theory, decision analysis, cost-benefit analyses or cost-effectiveness analyses that are implemented in integrated assessment models (IAMs). Decision aids include adaptive management, robust decision making and uncertainty analysis techniques such as structured expert judgment and scenario analysis. The chapter highlights the importance of selecting different methodologies for addressing different problems.

Developing robust policy response strategies and instruments should take into account how the relevant stakeholders perceive risk and their behavioural responses to uncertain information and data (descriptive analysis). The policy design process also needs to consider the methodologies and decision aids for systematically addressing issues of risk and uncertainty (normative analysis) that suggest strategies for improving outcomes at the individual and societal level (prescriptive analysis).

Section 2.6 examines how the outcomes of particular options, in terms of their efficiency or equity, are sensitive to risks and uncertainties and affect policy choices. After examining the role of uncertainty in the science/policy interface, it examines the role of integrated assessment models (IAMs) from the perspective of the social planner operating at a global level and the structuring of international negotiations and paths to reach agreement. Integrated assessment models combined with an understanding of the negotiation process for reaching international agreements may prove useful to delegates for justifying the positions of their country at a global climate conference. The section also examines the role that uncertainty plays in the performance of different technologies now and in the future as well as how lifestyle decisions such as investing in energy efficient measures can be improved.

Impact of Risk and Uncertainty on

Climate Change Policy Choices

[Sections 2.2 and 2.3]

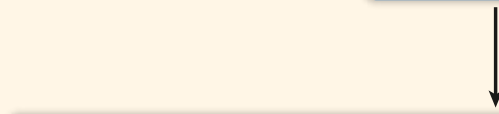

Risk Perception and Responses to Risk and Uncertainty

(Descriptive Analysis)

[Section 2.4]
Tools and Decisions Aids for

Analysing Uncertainty and Risk

(Normative Analysis)

[Section 2.5]

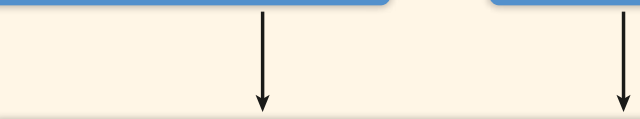

Managing Uncertainty, Risk and Learning

(Prescriptive Analysis)

[Section 2.6]

Figure 2.1 | A risk management framework. Numbers in brackets refer to sections where more information on these topics can be found. 
The section concludes by examining the roles that risk and uncertainty play in support of or opposition to climate policies.

The way climate change is managed will have an impact on policy choices as shown by the feedback loop in Figure 2.1, suggesting that the risk management process for addressing climate change is iterative. The nature of this feedback can be illustrated by the following examples. Individuals may be willing to invest in solar panels if they are able to spread the upfront cost over time through a long-term loan. Firms may be willing to promote new energy technologies that provide social benefits with respect to climate change if they are given a grant to assist them in their efforts. National governments are more likely to implement carbon markets or international treaties if they perceive the short-term benefits of these measures to be greater than the perceived costs. Education and learning can play key roles in how climate change is managed through a reconsideration of policies for managing the risks and uncertainties associated with climate change.

\section{$2.2 \quad$ Metrics of uncertainty and risk}

The IPCC strives for a treatment of risk and uncertainty that is consistent across all three Working Groups based the Guidance Note (GN) for Lead Authors of the IPCC Fifth Assessment Report on Consistent Treatment of Uncertainties (Mastrandrea et al., 2010). This section summarizes key aspects of the GN that frames the discussion in this chapter.

The GN indicates that author teams should evaluate the associated evidence and agreement with respect to specific findings that involve risk and uncertainty. The amount of evidence available can range from small to large, and can vary in quality and consistency. The GN recommends reporting the degree of certainty and/or uncertainty of a given topic as a measure of the consensus or agreement across the scientific community. Confidence expresses the extent to which the IPCC authors do in fact support a key finding. If confidence is sufficiently high, the GN suggests specifying the key finding in terms of probability. The evaluation of evidence and degree of agreement of any key finding is labelled a traceable account in the GN.

The GN also recommends taking a risk-management perspective by stating that "sound decision making that anticipates, prepares for, and responds to climate change depends on information about the full range of possible consequences and associated probabilities." The GN also notes that, "low-probability outcomes can have significant impacts, particularly when characterized by large magnitude, long persistence, broad prevalence, and/or irreversibility." For this reason, the GN encourages the presentation of information on the extremes of the probability distributions of key variables, reporting quantitative estimates when possible and supplying qualitative assessments and evaluations when appropriate.

\subsection{Risk and uncertainty in climate change}

Since the publication of AR4, political scientists have documented the many choices of climate policy and the range of interested parties concerned with them (Moser, 2007; Andonova et al., 2009; Bulkeley, 2010; Betsill and Hoffmann, 2011; Cabré, 2011; Hoffmann, 2011; Meckling, 2011; Victor, 2011).

There continues to be a concern about global targets for mean surface temperature and GHG concentrations that are discussed in Chapter 6 of this report. This choice is normally made at the global level with some regions, countries, and sub-national political regions setting their own targets consistent with what they believe the global ones should be. Policymakers at all levels of decision making face a second-order set of choices as to how to achieve the desired targets. Choices in this vein that are assessed in Chapters 7-12 of this report, include transition pathways for various drivers of emissions, such as fossil fuels within the energy system, energy efficiency and energy-intensive behavioural patterns, issues associated with land-use and spatial planning, and/or the emissions of non- $\mathrm{CO}_{2}$ greenhouse gases.

The drivers influencing climate change policy options are discussed in more detail in Chapters 13-16 of this report. These options include information provision, economic instruments (taxes, subsidies, fines), direct regulations and standards, and public investments. At the same time, individuals, groups and firms decide what actions to take on their own. These choices, some of which may be in response to governmental policy, include investments, lifestyle and behaviour.

Decisions for mitigating climate change are complemented by climate adaptation options and reflect existing environmental trends and drivers. The policy options are likely to be evaluated with a set of criteria that include economic impacts and costs, equity and distributional considerations, sustainable development, risks to individuals and society and co-benefits. Many of these issues are discussed in Chapters 3 and 4.

\subsubsection{Uncertainties that matter for climate policy choices}

The range and number of interested parties who are involved in climate policy choices have increased significantly in recent years. There has been a widening of the governance forums within which climate 
policies and international agreements are negotiated at the global level (Victor, 2011), across multiple networks within national governments (Andonova et al., 2009; Hoffmann, 2011), and at the local, regional and/or interest group level (Moser, 2007; Bulkeley, 2010). At the same time, the number of different policy instruments under active discussion has increased, from an initial focus on cap-and-trade and carbon tax instruments (Betsill and Hoffmann, 2011; Hoffmann, 2011), to feed-in tariffs or quotas for renewable energy (Wiser et al., 2005; Mendonça, 2007), investments in research and development (Sagar and van der Zwaan, 2006; De Coninck et al., 2008; Grubler and Riahi, 2010), and reform of intellectual property laws (Dechezleprêtre et al., 2011; Percival and Miller, 2011).

Choices are sensitive to the degree of uncertainty with respect to a set of parameters that are often of specific importance to particular climate policy decisions. Here, and as shown in Figure 2.2, we group these uncertainties into five broad classes, consistent with the approach taken in Patt and Weber (2014):

- Climate responses to greenhouse gas (GHG) emissions, and their associated impacts. The large number of key uncertainties with respect to the climate system are discussed in Working Group I (WGI). There are even greater uncertainties with respect to the impacts of changes in the climate system on humans and the ecological system as well as their costs to society. These impacts are assessed in WGII.

- Stocks and flows of carbon and other GHGs. The large uncertainties with respect to both historical and current GHG sources and sinks from energy use, industry, and land-use changes are assessed in Chapter 5. Knowledge gaps make it especially difficult to estimate how the flows of greenhouse gases will evolve in the future under conditions of elevated atmospheric $\mathrm{CO}_{2}$ concentrations and their impact on climatic and ecological processes.

- Technological systems. The deployment of technologies is likely to be the main driver of GHG emissions and a major driver of climate vulnerability. Future deployment of new technologies will depend on how their price, availability, and reliability evolve over time as a result of technological learning. There are uncertainties as to how fast the learning will take place, what policies can accelerate learning and the effects of accelerated learning on deployment rates of new technologies. Technological deployment also depends on the degree of public acceptance, which in turn is typically sensitive to perceptions of health and safety risks.

- Market behaviour and regulatory actions. Public policies can create incentives for private sector actors to alter their investment behaviour, often in the presence of other overlapping regulations. The extent to which firms change their behaviour in response to the policy, however, often depends on their expectations about other highly uncertain market factors, such as fossil fuel prices. There are also uncertainties concerning the macro-economic effects of the aggregated behavioural changes. An additional factor influencing the importance of any proposed or existing policy-driven incentive is the likelihood with which regulations will be enacted and enforced over the lifetime of firms' investment cycles.

- Individual and firm perceptions. The choices undertaken by key decision makers with respect to mitigation and adaptation measures are impacted by their perceptions of risk and uncertainties, as well as their perceptions of the relevant costs and expected benefits over time. Their decisions may also be influenced by the actions undertaken by others.

Section 2.6 assesses the effects of uncertainties of these different parameters on a wide range of policy choices, drawing from both empirical studies and the modelling literature. The following three examples illustrate how uncertainties in one or more of the above factors can influence choices between alternative options.

Example 1: Designing a regional emissions trading system (ETS). Over the past decade, a number of political jurisdictions have designed and implemented ETSs, with the European ETS being the one most studied. In designing the European system, policymakers took as their starting point pre-defined emissions reduction targets. It was unclear whether these targets would be met, due to uncertainties with respect to national baseline emissions. The stocks and flows of greenhouse gas emissions were partly determined by the uncertainty of the performance of the technological systems that were deployed. Uncertainties in market behaviour could also influence target prices and the number of emissions permits allocated to different countries (Betsill and Hoffmann, 2011).

Example 2: Supporting scientific research into solar radiation management (SRM). SRM may help avert potentially catastrophic temperature increases, but may have other negative impacts with respect to global and regional climatic conditions (Rasch et al., 2008). Research could reduce the uncertainties as to these other consequences (Robock et al., 2010). The decision to invest in specific research activities requires an assessment as to what impact SRM will have on avoiding catastrophic temperature increases. Temperature change will be sensitive to the stocks and flows of greenhouse gases (GHG) and therefore to the responses by key decision makers to the impacts of GHG emissions. The decision to invest in specific research activities is likely to be influenced by the perceived uncertainty in the actions undertaken by individuals and firms (Blackstock and Long, 2010).

Example 3: Renting an apartment in the city versus buying a house in the suburbs. When families and households face this choice, it is likely to be driven by factors other than climate change concerns. The decision, however, can have major consequences on $\mathrm{CO}_{2}$ emissions as well as on the impacts of climate change on future disasters such as damage from flooding due to sea level rise. Hence, governments may seek to influence these decisions as part of their portfolio of climate change policies through measures such as land-use regulations or the 
pricing of local transportation options. The final choice is thus likely to be sensitive to uncertainties in market behaviour as well as actions undertaken by individuals and firms.

To add structure and clarity to the many uncertainties that different actors face for different types of problems, we introduce a taxonomy shown in Figure 2.2 that focuses on levels of decision making (the rows) that range from international organizations to individuals and households, and climate policy options (the columns) that include long-term targets, transition pathways, policy instruments, resource allocation and lifestyle options. The circles that overlay the cells in Figure 2.2 highlight the principal uncertainties relevant to decision-making levels and climate policy choices that appear prominently in the literature associated with particular policies. These are reviewed in Section 2.6 of this chapter and in many of the following chapters of WGIII. The literature appraises the effects of a wide range of uncertainties, which we group according to the five types described above.

\subsubsection{What is new on risk and uncertainty in AR5}

Chapter 2 in WGIII AR4 on risk and uncertainty, which also served as a framing chapter, illuminated the relationship of risk and uncertainty to decision making and reviewed the literature on catastrophic or abrupt climate change and its irreversible nature. It examined three pillars for dealing with uncertainties: precaution, risk hedging, and crisis prevention and management. The report also summarized the debate in the economic literature about the limits of cost-benefit analysis in situations of uncertainty.

Since the publication of AR4, a growing number of studies have considered additional sources of risk and uncertainties, such as regulatory and technological risks, and examined the role they play in influencing climate policy. There is also growing awareness that risks in the extremes or tail of the distribution make it problematic to rely on historical averages. As the number of political jurisdictions implementing climate policies has increased, there are now empirical findings to supplement earlier model-based studies on the effects of such risks. At the local level, adaptation studies using scenario-based methods have been developed (ECLACS, 2011).

This chapter extends previous reports in four ways. First, rather than focusing solely at the global level, this chapter expands climate-related decisions to other levels of decision making as shown in Figure 2.2. Second, compared to AR4, where judgment and choice were primarily framed in rational-economic terms, this chapter reviews the psychological and behavioural literature on perceptions and responses to risk and uncertainty. Third, the chapter considers the pros and cons of alternative methodologies and decision aids from the point of view of practitioners. Finally, the chapter expands the scope of the challenges associated with developing risk management strategies in relation to

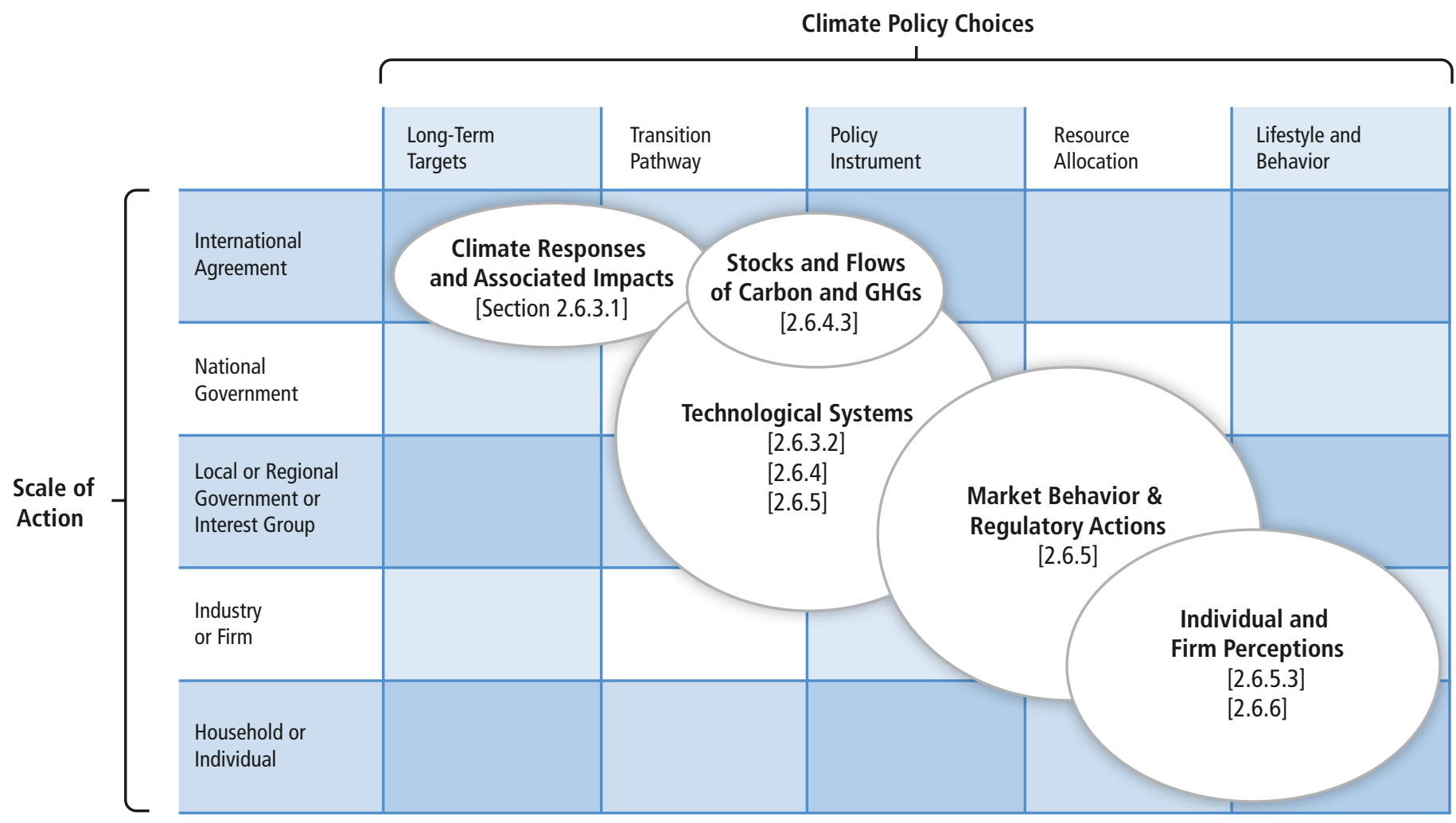

Figure 2.2 | Taxonomy of levels of decision making and climate policy choices. Circles show type and extent of uncertainty sources as they are covered by the literature. Numbers in brackets refer to sections where more information on these uncertainty sources can be found. 
AR4 that requires reviewing a much larger body of published research. To illustrate this point, the chapter references more than 50 publications on decision making under uncertainty with respect to integrated assessment models (IAMs), the first time such a detailed examination of this literature has been undertaken.

\subsection{Risk perception and responses to risk and uncertainty}

\subsubsection{Considerations for design of climate change risk reduction policies}

When stakeholders are given information about mitigation and adaptation measures to reduce climate change risks, they make the following judgments and choices: How serious is the risk? Is any action required? Which options are ruled out because the costs seem prohibitive? Which option offers the greatest net expected benefits?

In designing such measures and in deciding how to present them to stakeholders, one needs to recognize both the strengths and limitations of decision makers at the different levels delineated in Figure 2.2. Decision makers often have insufficient or imperfect knowledge about climate risks, a deficit that can and needs to be addressed by better data and public education. However, cognitive and motivational barriers are equally or more important in this regard (Weber and Stern, 2011).

Normative models of choice described in Section 2.5 indicate how decisions under risk and uncertainty should be made to achieve efficiency and consistency, but these approaches do not characterize how choices are actually made. Since decision makers have limitations in their ability to process information and are boundedly rational (Simon, 1955), they often use simple heuristics and rules of thumb (Payne et al., 1988). Their choices are guided not only by external reality (objective outcomes and their likelihood) but also by the decision makers' internal states (e.g., needs and goals) and their mental representation of outcomes and likelihood, often shaped by previous experience. In other words, a descriptive model of choice needs to consider cognitive and motivational biases and decision rules as well as factors that are considered when engaging in deliberative thinking. Another complicating factor is that when groups or organizations make decisions, there is the potential for disagreement and conflict among individuals that may require interpersonal and organizational facilitation by a third party.

Mitigation and adaptation decisions are shaped also by existing economic and political institutional arrangements. Policy and market tools for addressing climate change, such as insurance, may not be feasible in developing countries that have no history of this type of protection; however, this option may be viewed as desirable in a country with an active insurance sector (see Box 2.1). Another important determinant of decisions is the status quo, because there is a tendency to give more weight to the negative impacts of undertaking change than the equivalent positive impacts (Johnson et al., 2007). For example, proposing a carbon tax to reduce GHG emissions may elicit much more concern from affected stakeholders as to how this measure will impact on their current activities than the expected climate change benefits from reducing carbon emissions. Choices are also affected by cultural differences in values and needs (Maslow, 1954), in beliefs about the existence and causes of climate change (Leiserowitz et al., 2008), and in the role of informal social networks for cushioning catastrophic losses (Weber and Hsee, 1998). By considering actual judgment and choice processes, policymakers can more accurately characterize the effectiveness and acceptability of alternative mitigation policies and new technologies. Descriptive models also provide insights into ways of framing mitigation or adaptation options so as to increase the likelihood that desirable climate policy choices are adopted. Descriptive models, with their broader assumptions about goals and processes, also allow for the design of behavioural interventions that capitalize on motivations such as equity and fairness.

\subsubsection{Intuitive and deliberative judgment and choice}

The characterization of judgment and choice that distinguishes intuitive processes from deliberative processes builds on a large body of cognitive psychology and behavioural decision research that can be traced to William James (1878) in psychology and to Friedrich Nietzsche (2008) and Martin Heidegger (1962) in philosophy. A recent summary has been provided by Kahneman $(2003 ; 2011)$ as detailed in Table 2.1:

Table 2.1 | Intuitive and deliberative process characteristics.

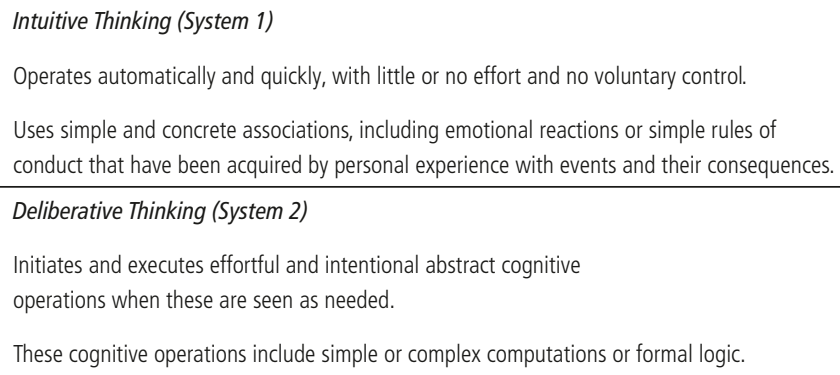

Even though the operations of these two types of processes do not map cleanly onto distinct brain regions, and the two systems often operate cooperatively and in parallel (Weber and Johnson, 2009), the distinction between Systems 1 and 2 helps to clarify the tension in the human mind between the automatic and largely involuntary processes of intuitive decisions, versus the effortful and more deliberate processes of analytic decisions (Kahneman, 2011). 
Many of the simplified decision rules that characterize human judgment and choice under uncertainty utilize intuitive (System 1) processes. Simplification is achieved by utilizing the experiences, expectations, beliefs, and goals of the interested parties involved in the decision. Such shortcuts require much less time and effort than a more detailed analysis of the tradeoffs between options and often leads to reasonable outcomes. If one takes into account the constraints on time and attention and processing capacity of decision makers, these decisions may be the best we can do for many choices under uncertainty (Simon, 1955). Intuitive processes are utilized not only by the general public, but also by technical experts such as insurers and regulators (Kunreuther et al., 2013c) and by groups and organizations (Cyert and March, 1963; Cohen et al., 1972; Barreto and Patient, 2013).

Intuitive processes work well when decision makers have copious data on the outcomes of different decisions and recent experience is a meaningful guide for the future, as would be the case in stationary environments (Feltovich et al., 2006). These processes do not work well, however, for low-probability high-consequence events for which the decision maker has limited or no past experience (Weber, 2011). In such situations, reliance on intuitive processes for making decisions will most likely lead to maintaining the status quo and focusing on the recent past. This suggests that intuitive decisions may be problematic in dealing with climate change risks such as increased flooding and storm surge due to sea level rise, or a surge in fossil fuel prices as a result of an unexpected political conflict. These are risks for which there is limited or no personal experience or historical data and considerable disagreement and uncertainty among experts with respect to their risk assessments (Taleb, 2007).

The formal models and tools that characterize deliberative (System 2) thinking require stakeholders to make choices in a more abstract and systematic manner. A deliberative process focuses on potential shortand long-term consequences and their likelihoods, and evenly evaluates the options under consideration, not favouring the status quo. For the low-probability high-consequence situations for which decision makers have limited experience with outcomes, alternative decision frameworks that do not depend on precise specification of probabilities should be considered in designing risk management strategies for climate change (Charlesworth and Okereke, 2010; Kunreuther et al., 2013a).

The remainder of this section is organized as follows. Section 2.4.3 describes some important consequences of the intuitive processes utilized by individuals, groups, and organizations in making decisions. The predicted effectiveness of economic or technological climate change mitigation solutions typically presuppose rational deliberative thinking and evaluation without considering how perceptions and reactions to climate risks impose on these policy options. Section 2.4.4 discusses biases and heuristics that suggest that individuals learn in ways that differ significantly from deliberative Bayesian updating. Section 2.4.5 addresses how behaviour is affected by social amplification of risk and considers the different levels of decision making in Figure 2.2 by discussing the role of social norms, social comparisons, and social networks in the choice process. Section 2.4.6 characterizes the general public's perceptions of climate change risks and uncertainty and their implications for communicating relevant information.

Empirical evidence for the biases associated with climate change response decisions triggered by intuitive processes exists mostly at the level of the individual. As discussed in Sections 2.5 and 2.6, intuitive judgment and choice processes at other levels of decision making, such as those specified in Figure 2.2, need to be acknowledged and understood.

\subsubsection{Consequences of intuitive decision making}

The behaviour of individuals are captured by descriptive models of choice such as prospect theory (Kahneman and Tversky, 1979) for decisions under risk and uncertainty and the beta-delta model (Laibson, 1997) for characterizing how future costs and benefits are evaluated. While individual variation exists, the patterns of responding to potential outcomes over time and the probabilities of their occurrence have an empirical foundation based on controlled experiments and well-designed field studies examining the behaviour of technical experts and the general public (Loewenstein and Elster, 1992; Camerer, 2000).

\subsubsection{Importance of the status quo}

The tendency to maintain the current situation is a broadly observed phenomenon in climate change response contexts (e.g., inertia in switching to a non-carbon economy or in switching to cost-effective energy efficient products) (Swim et al., 2011). Sticking with the current state of affairs is the easy option, favoured by emotional responses in situations of uncertainty ("better the devil you know than the devil you don't"), by many proverbs or rules ("when in doubt, do nothing"), and observed biases in the accumulation of arguments for different choice options (Weber et al., 2007). Overriding the status quo requires commitment to change and effort (Fleming et al., 2010).

\section{Loss aversion and reference points}

Loss aversion is an important property that distinguishes prospect theory (Tversky and Kahneman, 1992) from expected utility theory (von Neumann and Morgenstern, 1944) by introducing a reference-dependent valuation of outcomes, with a steeper slope for perceived losses than for perceived gains. In other words, people experience more pain from a loss than they get pleasure from an equivalent gain. The status quo is often the relevant reference point that distinguishes outcomes perceived as losses from those perceived as gains. Given loss aversion, the potential negative consequences of moving away from the current 
state of affairs are weighted much more heavily than the potential gains, often leading the decision maker not to take action. This behaviour is referred to as the status quo bias (Samuelson and Zeckhauser, 1988).

Loss aversion explains a broad range of decisions in controlled laboratory experiments and real world choices that deviate from the predictions of rational models like expected utility theory (Camerer, 2000). Letson et al. (2009) show that adapting to seasonal and inter-annual climate variability in the Argentine Pampas by allocating land to different crops depends not only on existing institutional arrangements (e. g., whether the farmer is renting the land or owns it), but also on individual differences in farmers' degree of loss aversion and risk aversion. Greene et al. (2009) show that loss aversion combined with uncertainty about future cost savings can explain why consumers frequently appear to be unwilling to invest in energy-efficient technology such as a more expensive but more fuel-efficient car that has positive expected utility. Weber and Johnson (2009) distinguish between perceptions of risk, attitudes towards risk, and loss aversion that have different determinants, but are characterized by a single 'risk attitude' parameter in expected utility models. Distinguishing and measuring these psychologically distinct components of individual differences in risk taking (e. g., by using prospect theory and adaptive ways of eliciting its model parameters; Toubia et al., 2013) provides better targeted entry points for policy interventions.

Loss aversion influences the choices of experienced decision makers in high-stakes risky choice contexts, including professional financial markets traders (Haigh and List, 2005) and professional golfers (Pope and Schweitzer, 2011). Yet, other contexts fail to elicit loss aversion, as evidenced by the failure of much of the global general public to be alarmed by the prospect of climate change (Weber, 2006). In this and other contexts, loss aversion does not arise because decision makers are not emotionally involved (Loewenstein et al., 2001).

\section{Use of framing and default options for the design of decision aids and interventions}

Descriptive models not only help explain behaviours that deviate from the predictions of normative models of choice but also provide entry points for the design of decision aids and interventions collectively referred to as choice architecture, indicating that people's choices depend in part on the ways that possible outcomes of different options are framed and presented (Thaler and Sunstein, 2008). Prospect theory suggests that changing decision makers' reference points can impact on how they evaluate outcomes of different options and hence their final choice. Patt and Zeckhauser (2000) show, for example, how information about the status quo and other choice options can be presented differently to create an action bias with respect to addressing the climate change problem. More generally, choice architecture often involves changing the description of choice options and the context of a decision to overcome the pitfalls of intuitive (System 1) processes without requiring decision makers to switch to effortful (System 2) thinking (Thaler and Sunstein, 2008).
One important choice architecture tool comes in the form of behavioural defaults, that is, recommended options that will be implemented if no active decision is made (Johnson and Goldstein, 2013). Default options serve as a reference point so that decision makers normally stick with this option due to loss aversion (Johnson et al., 2007; Weber et al., 2007). 'Green' energy defaults have been found to be very effective in lab studies involving choices between different lighting technologies (Dinner et al., 2011), suggesting that environmentally friendly and cost-effective energy efficient technology will find greater deployment if it were to show up as the default option in building codes and other regulatory contexts. Green defaults are desirable policy options because they guide decision makers towards individual and social welfare maximizing options without reducing choice autonomy. In a field study, German utility customers adopted green energy defaults, a passive choice that persisted over time and was not changed by price feedback (Pichert and Katsikopoulos, 2008). Moser (2010) provides other ways to frame climate change information and response options in ways consistent with the communication goal and characteristics of the audience.

\subsubsection{Focus on the short term and the here-and-now}

Finite attention and processing capacity imply that unaided intuitive choices are restricted in their scope. This makes individuals susceptible to different types of myopia or short-sightedness with respect to their decisions on whether to invest in measures they would consider costeffective if they engaged in deliberative thinking (Weber and Johnson, 2009; Kunreuther et al., 2013b).

\section{Present bias and quasi-hyperbolic time discounting}

Normative models suggest that future costs and benefits should be evaluated using an exponential discount function, that is, a constant discount rate per time period (i.e., exponentially), where the discount rate should reflect the decision maker's opportunity cost of money (for more details see Section 3.6.2). In reality, people discount future costs or benefits much more sharply and at a non-constant rate (i.e., hyperbolically), so that delaying an immediate receipt of a benefit is viewed much more negatively than if a similar delay occurs at a future point in time (Loewenstein and Elster, 1992). Laibson (1997) characterized this pattern by a quasi-hyperbolic discount function, with two parameters: (1) present bias, i.e., a discount applied to all non-immediate outcomes regardless how far into the future they occur, and (2) a rational discounting parameter. The model retains much of the analytical tractability of exponential discounting, while capturing the key qualitative feature of hyperbolic discounting.

\section{Failure to invest in protective measures}

In the management of climate-related natural hazards such as flooding, an extensive empirical literature reveals that adoption rates of protective measures by the general public are much lower than if individuals had engaged in deliberative thinking by making relevant tradeoffs between expected costs and benefits. Thus, few people living in 
flood prone areas in the United States voluntarily purchase flood insurance, even when it is offered at highly subsidized premiums under the National Flood Insurance Program (NFIP) (Kunreuther et al., 1978). In the context of climate change mitigation, many efficient responses like investments in household energy efficiency are not adopted because decision makers focus unduly on the upfront costs of these measures (due to hyperbolic discounting amplified by loss aversion) and weight the future benefits of these investments less than predicted by normative models (see Sections 2.6.4.3 and 3.10). The failure of consumers to buy fuel-efficient cars because of their higher upfront costs (Section 8.3.5) is another example of this behaviour.

At a country or community level, the upfront costs of mitigating $\mathrm{CO}_{2}$ emissions or of building seawalls to reduce the effects of sea level rise loom large due to loss aversion, while the uncertain and future benefits of such actions are more heavily discounted than predicted by normative models. Such accounting of present and future costs and benefits on the part of consumers and policymakers might make it difficult for them to justify these investments today and arrive at longterm sustainable decisions (Weber, 2013).

\section{Focus on short-term goals}

Krantz and Kunreuther (2007) emphasize the importance of goals and plans as a basis for making decisions. In the context of climate change, protective or mitigating actions often require sacrificing short-term goals that are highly weighted in people's choices in order to meet more abstract, distant goals that are typically given very low weight. A strong focus on short-term goals (e.g., immediate survival) may have been helpful as humans evolved, but may have negative consequences in the current environment where risks and challenges are more complex and solutions to problems such as climate change require a focus on long time horizons. Weber et al. (2007) succeeded in drastically reducing people's discounting of future rewards by prompting them to first generate arguments for deferring consumption, contrary to their natural inclination to focus initially on rationales for immediate consumption. To deal with uncertainty about future objective circumstances as well as subjective evaluations, one can adopt multiple points of view (Jones and Preston, 2011) or multiple frames of reference (De Boer et al., 2010); a generalization of the IPCC's scenario approach to an uncertain climate future is discussed in Chapter 6.

\section{Mental accounting as a protection against short-term focus}

People often mentally set up separate 'accounts' for different classes of expenditures and do not treat money as fungible between these accounts (Thaler, 1999). Mental accounts for different expenditures serve as effective budgeting and self-control devices for decision makers with limited processing capacity and self-control. A focus on shortterm needs and goals can easily deplete financial resources, leaving not enough for long(er)-term goals. Placing a limit on short-term spending prevents this from happening. But such a heuristic also has a downside by unduly limiting people's willingness to invest in climate change mitigation or adaptation measures (e.g., flood proofing or solar pan- els) that exceed their allocated budget for this account, regardless of future benefits. Such constraints (real or mental) often lead to the use of lexicographic (rather than compensatory) choice processes, where option sets are created or eliminated sequentially, based on a series of criteria of decreasing importance (Payne et al., 1988).

Mental accounting at a nonfinancial level may also be responsible for rebound effects of a more psychological nature, in addition to the economically based rebound effects discussed in Section 8.3.5. Rebound effects describe the increase in energy usage that sometimes follows improvements in household, vehicle, or appliance efficiency. For example, households who weatherize their homes tend to increase their thermostat settings during the winter afterwards, resulting in a decrease in energy savings relative to what is technologically achievable (Hirst et al., 1985). While rebound effects on average equal only $10-30 \%$ of the achievable savings, and therefore do not cancel out the benefits of efficiency upgrades (Ehrhardt-Martinez and Laitner, 2010), they are significant and may result from fixed mental accounts that people have for environmentally responsible behaviour. Having fulfilled their self-imposed quota by a particular action allows decision makers to move on to other goals, a behaviour also sometimes referred to as the single-action bias (Weber, 2006).

\subsubsection{Aversion to risk, uncertainty, and ambiguity}

Most people are averse to risk and to uncertainty and ambiguity when making choices. More familiar options tend to be seen as less risky, all other things being equal, and thus more likely to be selected (Figner and Weber, 2011).

\section{Certainty effect or uncertainty aversion}

Prospect theory formalizes a regularity related to people's perceptions of certain versus probabilistic prospects. People overweight outcomes they consider certain, relative to outcomes that are merely probable-a phenomenon labelled the certainty effect (Kahneman and Tversky, 1979). This frequently observed behaviour can explain why the certain upfront costs of adaptation or mitigation actions are viewed as unattractive when compared to the uncertain future benefits of undertaking such actions (Kunreuther et al., 2013b).

\section{Ambiguity aversion}

Given the high degree of uncertainty or ambiguity in most forecasts of future climate change impacts and the effects of different mitigation or adaptation strategies, it is important to consider not only decision makers' risk attitudes, but also attitudes towards ambiguous outcomes. The Ellsberg paradox (Ellsberg, 1961) revealed that, in addition to being risk averse, most decision makers are also ambiguity averse, that is, they prefer choice options with well-specified probabilities over options where the probabilities are uncertain. Heath and Tversky (1991) demonstrated, however, that ambiguity aversion is not present when decision makers believe they have expertise in the domain of choice. For example, in contrast to the many members of the general 
public who consider themselves to be experts in sports or the stock market, relatively few people believe themselves to be highly competent in environmentally relevant technical domains such as the tradeoffs between hybrid electric versus conventional gasoline engines in cars, so they are likely to be ambiguity averse. Farmers who feel less competent with respect to their understanding of new technology are more ambiguity averse and less likely to adopt farming innovations (in Peru; Engle-Warnick and Laszlo, 2006; and in the USA; Barham et al., 2014). With respect to the likelihood of extreme events, such as natural disasters, insurers feel they do not have special expertise in estimating the likelihood of these events so they also tend to be ambiguity averse and set premiums that are considerably higher than if they had more certainty with respect to the likelihood of their occurrence (Kunreuther et al., 1993; Cabantous et al., 2011).

\subsubsection{Learning}

The ability to change expectations and behaviour in response to new information is an important survival skill, especially in uncertain and non-stationary environments. Bayesian updating characterizes learning when one engages in deliberative thinking. Individuals who engage in intuitive thinking are also highly responsive to new and especially recent feedback and information, but treat the data differently than that implied by Bayesian updating (Weber et al., 2004).

\section{Availability bias and the role of salience}

People's intuitive assessment of the likelihood of an uncertain event is often based on the ease with which instances of its occurrence can be brought to mind, a mechanism called availability by Tversky and Kahneman (1973). Sunstein (2006) discusses the use of the availability heuristics in response to climate change risks and how it differs among groups, cultures, and nations. Availability is strongly influenced by recent personal experience and can lead to an underestimation of low-probability events (e. g., typhoons, floods, or droughts) before they occur, and their overestimation after an extreme event has occurred. The resulting availability bias can explain why individuals first purchase insurance after a disaster has occurred and cancel their policies several years later, as observed for earthquake (Kunreuther et al., 1978) and flood insurance (Michel-Kerjan et al., 2012). It is likely that most of these individuals had not suffered any losses during this period and considered the insurance to be a poor investment. It is difficult to convince insured individuals that the best return on their policy is no return at all. They should celebrate not having suffered a loss (Kunreuther et al., 2013c).

\section{Linear thinking}

A majority of people perceive climate in a linear fashion that reflects two common biases (Sterman and Sweeney, 2007; Cronin et al., 2009; Dutt and Gonzalez, 2011). First, people often rely on the correlation heuristic, which means that people wrongly infer that an accumulation $\left(\mathrm{CO}_{2}\right.$ concentration) follows the same path as the inflow $\left(\mathrm{CO}_{2}\right.$ emissions). This implies that cutting emissions will quickly reduce the con- centration and damages from climate change (Sterman and Sweeney, 2007). According to Dutt (2011) people who rely on this heuristic likely demonstrate wait-and-see behaviour on policies that mitigate climate change because they significantly underestimate the delay between reductions in $\mathrm{CO}_{2}$ emissions and in the $\mathrm{CO}_{2}$ concentration. Sterman and Sweeny (2007) show that people's wait-and-see behaviour on mitigation policies is also related to a second bias whereby people incorrectly infer that atmospheric $\mathrm{CO}_{2}$ concentration can be stabilized even when emissions exceeds absorption.

Linear thinking also leads people to draw incorrect conclusions from nonlinear metrics, like the miles-per-gallon (mpg) ratings of vehicles' gasoline consumption in North America (Larrick and Soll, 2008). When given a choice between upgrading to a $15-\mathrm{mpg}$ car from a $12-\mathrm{mpg}$ car, or to a 50-mpg car from a 29-mpg car, most people choose the latter option. However, for 100 miles driven under both options, it is easily shown that the first upgrade option saves more fuel (1.6 gallons for every 100 miles driven) than the second upgrade option (1.4 gallons for every 100 miles driven).

\section{Effects of personal experience}

Learning from personal experience is well predicted by reinforcement learning models (Weber et al., 2004). Such models describe and predict why the general public is less concerned about low-probability highimpact climate risks than climate scientists would suggest is warranted by the evidence (Gonzalez and Dutt, 2011). These learning models also capture the volatility of the public's concern about climate change over time, for example in reaction to the personal experience of local weather abnormalities (an abnormal cold spell or heat wave) that have been shown to influence belief in climate change (Li et al., 2011).

Most people do not differentiate very carefully between weather, climate (average weather over time), and climate variability (variations in weather over time). People confound climate and weather in part because they have personal experience with weather and weather abnormalities but little experience with climate change, an abstract statistical concept. They thus utilize weather events in making judgments about climate change (Whitmarsh, 2008). This confusion has been observed in countries as diverse as the United States (Bostrom et al., 1994; Cullen, 2010) and Ethiopia (BBC World Service Trust, 2009).

Personal experience can differ between individuals as a function of their location, history, and/or socio-economic circumstances (Figner and Weber, 2011). Greater familiarity with climate risks, unless accompanied by alarming negative consequences, could actually lead to a reduction rather than an increase in the perceptions of its riskiness (Kloeckner, 2011). On the other hand, people's experience can make climate a more salient issue. For example, changes in the timing and extent of freezing and melting (and associated effects on sea ice, flora, and fauna) have been experienced since the 1990s in the American and Canadian Arctic and especially indigenous communities (Laidler, 2006), leading to increased concern with climate change because tra- 
ditional prediction mechanisms no longer can explain these phenomena (Turner and Clifton, 2009).

People's expectations of change (or stability) in climate variables also affect their ability to detect trends in probabilistic environments. For instance, farmers in Illinois were asked to recall growing season temperature or precipitation statistics for seven preceding years. Farmers who believed that their region was affected by climate change recalled precipitation and temperature trends consistent with this expectation, whereas farmers who believed in a constant climate, recalled precipitations and temperatures consistent with that belief (Weber, 1997). Recognizing that beliefs shape perception and memory provides insight into why climate change expectations and concerns vary between segments of the US population with different political ideologies (Leiserowitz et al., 2008).

The evidence is mixed when we examine whether individuals learn from past experience with respect to investing in adaptation or mitigation measures that are likely to be cost-effective. Even after the devastating 2004 and 2005 hurricane seasons in the United States, a large number of residents in high-risk areas had still not invested in relatively inexpensive loss-reduction measures, nor had they undertaken emergency preparedness measures (Goodnough, 2006). Surveys conducted in Alaska and Florida, regions where residents have been exposed more regularly to physical evidence of climate change, show greater concern and willingness to take action (ACl, 2004; Leiserowitz and Broad, 2008; Mozumder et al., 2011).

A recent study assessed perceptions and beliefs about climate change of a representative sample of the Britain public (some of whom had experienced recent flooding in their local area). It also asked whether they would reduce personal energy use to reduce greenhouse gas emission (Spence et al., 2011). Concern about climate change and willingness to take action was greater in the group of residents who had experienced recent flooding. Even though the flooding was only a single and local data point, this group also reported less uncertainty about whether climate change was really happening than those who did not experience flooding recently, illustrating the strong influence of personal experience. Other studies fail to find a direct effect of personal experience with flooding generating concern about climate risks (Whitmarsh, 2008).

Some researchers find that personal experience with ill health from air pollution affects perceptions of and behavioural responses to climate risks (Bord et al., 2000; Whitmarsh, 2008), with the negative effects from air pollution creating stronger pro-environmental values. Myers et al. (2012) looked at the role of experiential learning versus motivated reasoning among highly engaged individuals and those less engaged in the issue of climate change. Low-engaged individuals were more likely to be influenced by their perceived personal experience of climate change than by their prior beliefs, while those highly engaged in the issue (on both sides of the climate issue) were more likely to interpret their perceived personal experience in a manner that strengthens their pre-existing beliefs.
Indigenous climate change knowledge contributions from Africa (Orlove et al., 2010), the Arctic (Gearheard et al., 2009), Australia (Green et al., 2010), or the Pacific Islands (Lefale, 2010), derive from accumulated and transmitted experience and focus mostly on predicting seasonal or interannual climate variability. Indigenous knowledge can supplement scientific knowledge in geographic areas with a paucity of data (Green and Raygorodetsky, 2010) and can guide knowledge generation that reduces uncertainty in areas that matter for human responses (ACl, 2004). Traditional ecological knowledge is embedded in value-institutions and belief systems related to historical modes of experimentation and is transferred from generation to generation (Pierotti, 2011).

\section{Underweighting of probabilities and threshold models of choice}

The probability weighting function of prospect theory indicates that low probabilities tend to be overweighted relative to their objective probability unless they are perceived as being so low that they are ignored because they are below the decision maker's threshold level of concern. Prior to a disaster, people often perceive the likelihood of catastrophic events occurring as below their threshold level of concern, a form of intuitive thinking in the sense that one doesn't have to reflect on the consequences of a catastrophic event (Camerer and Kunreuther, 1989). The need to take steps today to deal with future climate change presents a challenge to individuals who are myopic. They are likely to deal with this challenge by using a threshold model that does not require any action for risks below this level. The problem is compounded by the inability of individuals to distinguish between low likelihoods that differ by one or even two orders of magnitude (e. g., between 1 in 100 and 1 in 10,000) (Kunreuther et al., 2001).

\subsubsection{Linkages between different levels of decision making}

\section{Social amplification of risk}

Hazards interact with psychological, social, institutional, and cultural processes in ways that may amplify or attenuate public responses to the risk or risk event by generating emotional responses and other biases associated with intuitive thinking. Amplification may occur when scientists, news media, cultural groups, interpersonal networks, and other forms of communication provide risk information. The amplified risk leads to behavioural responses, which, in turn, may result in secondary impacts such as the stigmatization of a place that has experienced an adverse event (Kasperson et al., 1988; Flynn et al., 2001). The general public's overall concern about climate change is influenced, in part, by the amount of media coverage the issue receives as well as the personal and collective experience of extreme weather in a given place (Leiserowitz et al., 2012; Brulle et al., 2012).

\section{Social norms and social comparisons}

Individuals' choices are often influenced by other people's behaviour, especially under conditions of uncertainty. Adherence to formal rules 
(e. g., standard operating procedures or best practices in organizations) or informal rules of conduct is an important way in which we intuitively decide between different courses of action (Weber and Lindemann, 2007). "When in doubt, copy what the majority is doing" is not a bad rule to follow in many situations, as choices adopted by others are assumed to be beneficial and safe (Weber, 2013). In fact, such social imitation can lead to social norms. Section 3.10.2 describes the effects of social norms in greater detail. Goldstein et al. (2008) demonstrate the effectiveness of providing descriptive norms ("this is what most people do") versus injunctive norms ("this is what you should be doing") to reduce energy use in US hotels. The application of social norms to encourage investment in energy efficient products and technology is discussed in Section 2.6.5.3.

Social comparisons are another effective way to evaluate and learn about the quality of obtained outcomes (Weber, 2004). It helps, for example, to compare one's own energy consumption to that of neighbours in similar-sized apartments or houses to see how effective efforts at energy conservation have been. Such non-price interventions can substantially change consumer behaviour, with effects equivalent to that of a short-run electricity price increase of $11 \%$ to $20 \%$ (Alcott, 2011). Social comparisons, imitation, and norms may be necessary to bring about lifestyle changes that are identified in Chapter 9 as reducing GHG emissions from the current levels (Sanquist et al., 2012).

\section{Social learning and cultural transmission}

Section 9.3.10 suggests that indigenous building practices in many parts of the world provide important lessons for affordable lowenergy housing design and that developed countries can learn from traditional building practices, transmitted over generations, the socialscale equivalent of 'intuitive' processing and learning at the individual level.

Risk protection by formal (e.g., insurance) and informal institutions (e.g., social networks)

Depending on their cultural and institutional context, people can protect themselves against worst-case and/or potentially catastrophic economic outcomes either by purchasing insurance (Kunreuther et al., 2013c) or by developing social networks that will help bail them out or assist them in the recovery process (Weber and Hsee, 1998). Individualist cultures favour formal insurance contracts, whereas collectivist societies make more use of informal mutual insurance via social networks. This distinction between risk protection by either formal or informal means exists at the individual level and also at the firm level, e.g., the chaebols in Korea or the keiretsus in Japan (Gilson and Roe, 1993).

\section{Impact of uncertainty on coordination and competition}

Adaptation and especially mitigation responses require coordination and cooperation between individuals, groups, or countries for many of the choices associated with climate change. The possible outcomes often can be viewed as a game between players who are concerned with their own payoffs but who may still be mindful of social goals and objectives. In this sense they can be viewed in the context of a pris- oners' dilemma (PD) or social dilemma. Recent experimental research on two-person PD games reveals that individuals are more likely to be cooperative when payoffs are deterministic than when the outcomes are probabilistic. A key factor explaining this difference is that in a deterministic PD game, the losses of both persons will always be greater when they both do not cooperate than when they do. When outcomes are probabilistic there is some chance that the losses will be smaller when both parties do not cooperate than when they do, even though the expected losses to both players will be greater if they both decide not to cooperate than if they both cooperate (Kunreuther et al., 2009).

In a related set of experiments, Gong et al. (2009) found that groups are less cooperative than individuals in a two-person deterministic PD game; however, in a stochastic PD game, where defection increased uncertainty for both players, groups became more cooperative than they were in a deterministic PD game and more cooperative than individuals in the stochastic PD game. These findings have relevance to behaviour with respect to climate change where future outcomes of specific policies are uncertain. Consider decisions made by groups of individuals, such as when delegations from countries are negotiating at the Conference of Parties (COP) to make commitments for reducing GHG emissions where the impacts on climate change are uncertain. These findings suggest that there is likely to be more cooperation between governmental delegations than if each country was represented by a single decision maker.

Cooperation also plays a crucial role in international climate agreements. There is a growing body of experimental literature that looks at individuals' cooperation when there is uncertainty associated with others adopting climate change mitigation measures. Tavoni et al. (2011) found that communication across individuals improves the likelihood of cooperation. Milinski et al. (2008) observed that the higher the risky losses associated with the failure to cooperate in the provision of a public good, the higher the likelihood of cooperation. If the target for reducing $\mathrm{CO}_{2}$ is uncertain, Barrett and Dannenberg (2012) show in an experimental setting that cooperation is less likely than if the target is well specified.

\subsubsection{Perceptions of climate change risk and uncertainty}

Empirical social science research shows that the perceptions of climate change risks and uncertainties depend not only on external reality but also on the observers' internal states, needs, and the cognitive and emotional processes that characterize intuitive thinking. Psychological research has documented the prevalence of affective processes in the intuitive assessment of risk, depicting them as essentially effort-free inputs that orient and motivate adaptive behaviour, especially under conditions of uncertainty that are informed and shaped by personal experience over time (Finucane et al., 2000; Loewenstein et al., 2001; Peters et al., 2006). 


\section{Box 2.1 | Challenges facing developing countries}

One of the key findings on developing countries is that non-state actors such as tribes, clans, castes, or guilds may be of substantial influence on how climate policy choices are made and diffused rather than having the locus of decision making at the level of the individual or governmental unit. For instance, a farming tribe/caste may address the climate risks and uncertainties faced by their community and opt for a system of crop rotation to retain soil fertility or shift cultivation to preserve the nutritious state of farmlands. Research in developing countries in Africa has shown that people may understand probabilistic information better when it is presented in a group where members have a chance to discuss it (Patt et al., 2005; Roncoli, 2006). This underscores why the risks and uncertainty associated with climate change has shifted governmental responsibility to non-state actors (Rayner, 2007).

In this context, methodologies and decision aids used in individualcentred western societies for making choices that rely on uncertain probabilities and uncertain outcomes may not apply to developing countries. Furthermore, methodologies, such as expected utility theory, assume an individual decision maker whereas in developing countries, decisions are often made by clans or tribes. In addition, tools such as cost-benefit analysis, cost-effectiveness analysis and robust decision making may not always be relevant for developing countries since decisions are often based on social norms, traditions, and customs

The adverse effects of climate change on food, water, security, and incidences of temperature-influenced diseases (Shah and Lele, 2011), are further fuelled by a general lack of awareness about climate change in developing countries (UNDP, 2007); conse- quently, policymakers in these countries support a wait-and-see attitude toward climate change (Dutt, 2011). Resource allocation and investment constraints may also lead policy-makers to postpone policy decisions to deal with climate change, as is the case with respect to integration of future energy systems in small island states (UNFCCC, 2007). The delay may prevent opportunities for learning and increase future vulnerabilities. It may also lock in countries into infrastructure and technologies that may be difficult to alter.

The tension between short- and long-term priorities in low income countries is often accentuated by uncertainties in political culture and regulatory policies (Rayner, 1993). This may lead to policies that are flawed in design and/or implementation or those that have unintended negative consequences. For example, subsidies for clean fuels such as liquefied petroleum gas (LPG) in a country like India often do not reach their intended beneficiaries (the poor), and at the same time add a large burden to the exchequer (Government of India, Ministry of Finance, 2012; IISD, 2012).

Other institutional and governance factors impede effective climate change risk management in developing countries. These include lack of experience with insurance (Patt et al., 2010), dearth of data, and analytical capacity. A more transparent and effective civil service would also be helpful, for instance in stimulating investments in renewable energy generation capacities (Komendantova et al., 2012). Financial constraints suggest the importance of international assistance and private sector contribution to implement adaptation and mitigation strategies for dealing with climate change in developing countries.
Two important psychological risk dimensions have been shown to influence people's intuitive perceptions of health and safety risks across numerous studies in multiple countries (Slovic, 1987). The first factor, 'dread risk', captures emotional reactions to hazards like nuclear reactor accidents, or nerve gas accidents, that is, things that make people anxious because of a perceived lack of control over exposure to the risks and because consequences may be catastrophic. The second factor, 'unknown risk', refers to the degree to which a risk (e.g., DNA technology) is perceived as new, with unforeseeable consequences and with exposures not easily detectable.

Perceptions of the risks associated with a given event or hazard are also strongly influenced by personal experience and can therefore differ between individuals as a function of their location, history, and/or socio-economic circumstances (see Box 2.1) (Figner and Weber, 2011). Whereas personal exposure to adverse consequences increases fear and perceptions of risk, familiarity with a risk can lower perceptions of its riskiness unless it is accompanied by alarming negative consequences (Kloeckner, 2011). Seeing climate change only as a simple and gradual change from current to future average temperatures and precipitation may make it seem controllable-the non-immediacy of the danger seems to provide time to plan and execute protective responses (Weber, 2006). These factors suggest that laypersons differ in their perception of climate risks more than experts who engage in deliberative thinking and estimate the likelihood and consequences of climate change utilizing scientific data.

\section{Impact of uncertainties in communicating risk}

If the uncertainties associated with climate change and its future impact on the physical and social system are not communicated accurately, the general public may misperceive them (Corner and Hahn, 2009). Krosnick et al. (2006) found that perceptions of the seriousness of global warming as a national issue in the United States depended on the degree of certainty of respondents as to whether global warming is 
occurring and will have negative consequences coupled with their belief that humans are causing the problem and have the ability to solve it. Accurately communicating the degree of uncertainty in both climate risks and policy responses is therefore a critically important challenge for climate scientists and policymakers (Pidgeon and Fischhoff, 2011).

Roser-Renouf et al. (2011), building upon the work of Krosnick et al. (2006), apply social cognitive theory to develop a model of climate advocacy to increase the attention given to climate change in the spirit of social amplification of risk. They found that campaigns looking to increase the number of citizens contacting elected officials to advocate climate policy action should focus on increasing the belief that global warming is real, human-caused, a serious risk, and solvable. These four key elements, coupled with the understanding that there is strong scientific agreement on global warming (Ding et al., 2011), are likely to build issue involvement and support for action to reduce the impacts of climate change.

The significant time lags within the climate system and a focus on short-term outcomes lead many people to believe global warming will have only moderately negative impacts. This view is reinforced because adverse consequences are currently experienced only in some regions of the world or are not easily attributed to climate change. For example, despite the fact that "climate change currently contributes to the global burden of disease and premature deaths" (IPCC, 2007) relatively few people make the connection between climate change and human health risks.

One challenge is how to facilitate correct inferences about the role of climate change as a function of extreme event frequency and severity. Many parts of the world have seen increases in the frequency and magnitude of heat waves and heavy precipitation events (IPCC, 2012). In the United States, a large majority of Americans believe that climate change exacerbated extreme weather events (Leiserowitz et al., 2012). That said, the perception that the impact of climate change is neither immediate nor local persists (Leiserowitz et al., 2008), leading many to think it rational to advocate a wait-and-see approach to emissions reductions (Sterman, 2008; Dutt and Gonzalez, 2013).

\section{Differences in education and numeracy}

Individual and group differences in education and training and the resulting different cognitive and affective processes have additional implications for risk communication. It may help to supplement the use of words to characterize the likelihood of an outcome recommended by the current IPCC Guidance Note (GN) with numeric probability ranges (Budescu et al., 2009). Patt and Dessai (2005) show that in the IPCC Third Assessment Report (TAR), words that characterized numerical probabilities were interpreted by decision makers in inconsistent and often context-specific ways, a phenomenon with a long history in cognitive psychology (Wallsten et al., 1986; Weber and Hilton, 1990). These context-specific interpretations of probability words are deeply rooted, as evidenced by the fact that the likelihood of using the intended interpretation of TAR probability words did not differ with level of expertise (attendees of a UN COP conference versus students) or as a function of whether respondents had read the TAR instructions that specify how the probability words characterized numerical probabilities (Patt and Dessai, 2005).

Numeracy, the ability to reason with numbers and other mathematical concepts, is a particularly important individual and group difference in this context as it has implications for the presentation of likelihood information using either numbers (for example, $90 \%$ ) or words (for example, "very likely" or "likely") or different graphs or diagrams (Peters et al., 2006; Mastrandrea et al., 2011). Using personal experience with climate variables has been shown to be effective in communicating the impact of probabilities (e.g., of below-, about-, and above-normal rainfall in an El Niño year) to decision makers with low levels of numeracy, for example subsistence farmers in Zimbabwe (Patt et al., 2005).

\subsection{Tools and decision aids for analysing uncertainty and risk}

This section examines how more formal approaches can assist decision makers in engaging in more deliberative thinking with respect to climate change policies when faced with the risks and uncertainties characterized in Section 2.3.

\subsubsection{Expected utility theory}

Expected utility $[E(U)]$ theory (Ramsey, 1926; von Neumann and Morgenstern, 1944; Savage, 1954); remains the standard approach for providing normative guidelines against which other theories of individual decision making under risk and uncertainty are benchmarked. According to the $\mathrm{E}(\mathrm{U})$ model, the solution to a decision problem under uncertainty is reached by the following four steps:

1. Define a set of possible decision alternatives.

2. Quantify uncertainties on possible states of the world.

3. Value possible outcomes of the decision alternatives as utilities.

4. Choose the alternative with the highest expected utility.

This section clarifies the applicability of expected utility theory to the climate change problem, highlighting its potentials and limitations.

\subsubsection{Elements of the theory}

$E(U)$ theory is based on a set of axioms that are claimed to have normative rather than descriptive validity. Based on these axioms, a per- 
son's subjective probability and utility function can be determined by observing preferences in structured choice situations. These axioms have been debated, strengthened, and relaxed by economists, psychologists, and other social scientists over the years. The axioms have been challenged by controlled laboratory experiments and field studies discussed in Section 2.4 but they remain the basis for parsing decision problems and recommending options that maximize expected utility.

\subsubsection{How can expected utility improve decision making?}

$E(U)$ theory provides guidelines for individual choice, such as a farmer deciding what crops to plant or an entrepreneur deciding whether to invest in wind technology. These decision makers would apply $E(U)$ theory by following the four steps above. The perceptions and responses to risk and uncertainty discussed in Section 2.5 provide a rationale for undertaking deliberative thinking before making final choices. More specifically, a structured approach, such as the $E(U)$ model, can reduce the impact of probabilistic biases and simplified decision rules that characterize intuitive thinking. At the same time, the limitations of $E(U)$ must be clearly understood, as the procedures for determining an optimal choice do not capture the full range of information about outcomes and their risks and uncertainties.

\section{Subjective versus objective probability}

In the standard $\mathrm{E}(\mathrm{U})$ model, each individual has his/her own subjective probability estimates. When there is uncertainty on the scientific evidence, experts' probability estimates may diverge from each other, sometimes significantly. With respect to climate change, observed relative frequencies are always preferred when suitable sets of observations are accessible. When these data are not available, one may want to utilize structured expert judgment for quantifying uncertainty (see Section 2.5.7).

\section{Individual versus social choice}

In applying $\mathrm{E}(\mathrm{U})$ theory to problems of social choice, a number of issues arise. Condorcet's voting paradox shows that groups of rational individuals deciding by majority rule do not exhibit rational preferences. Using a social utility or social welfare function to determine an optimal course of action for society requires some method of measuring society's preferences. In the absence of these data the social choice problem is not a simple exercise of maximizing expected utility. In this case, a plurality of approaches involving different aggregations of individual utilities and probabilities may best aid decision makers. The basis and use of the social welfare function are discussed in Section 3.4.6.

\section{Normative versus descriptive}

As noted above, the rationality axioms of $E(U)$ are claimed to have normative as opposed to descriptive validity. The paradoxes of Allais (1953) and Ellsberg (1961) reveal choice behaviour incompatible with $\mathrm{E}(\mathrm{U})$; whether this requires modifications of the normative theory is a subject of debate. McCrimmon (1968) found that business executives willingly corrected violations of the axioms when they were made aware of them. Other authors (Kahneman and Tversky, 1979; Schmeidler, 1989; Quiggin, 1993; Wakker, 2010) account for such paradoxical choice behaviour by transforming the probabilities of outcomes into decision weight probabilities that play the role of likelihood in computing optimal choices but do not obey the laws of probability. However, Wakker (2010, p. 350) notes that decision weighting fails to describe some empirically observed behavioural patterns.

\subsubsection{Decision analysis}

\subsubsection{Elements of the theory}

Decision analysis is a formal approach for choosing between alternatives under conditions of risk and uncertainty. The foundations of decision analysis are provided by the axioms of expected utility theory. The methodology for choosing between alternatives consists of the following elements that are described in more detail in Keeney (1993):

1. Structure the decision problem by generating alternatives and specifying values and objectives or criteria that are important to the decision maker.

2. Assess the possible impacts of different alternatives by determining the set of possible consequences and the probability of each occurring.

3. Determine preferences of the relevant decision maker by developing an objective function that considers attitudes toward risk and aggregates the weighted objectives.

4. Evaluate and compare alternatives by computing the expected utility associated with each alternative. The alternative with the highest expected utility is the most preferred one.

To illustrate the application of decision analysis, consider a homeowner that is considering whether to invest in energy efficient technology as part of their lifestyle options as depicted in Figure 2.2:

1. The person focuses on two alternatives: (A1) Maintain the status quo, and (A2) Invest in solar panels, and has two objectives: (01) Minimize cost, and (02) Assist in reducing global warming.

2. The homeowner would then determine the impacts of $A 1$ and $A 2$ on the objectives 01 and 02 given the risks and uncertainties associated with the impact of climate change on energy usage as well as the price of energy.

3. The homeowner would then consider his or her attitude toward risks and then combine 01 and 02 into a multiattribute utility function.

4. The homeowner would then compare the expected utility of A1 and $A 2$, choosing the one that had the highest expected utility. 


\subsubsection{How can decision analysis improve decision making?}

Decision analysis enables one to undertake sensitivity analyses with respect to the uncertainties associated with the various consequences and to different value structures. Suppose alternative A1 had the highest expected utility. The homeowner could determine when the decision to invest in solar panels would be preferred to maintaining the status quo by asking questions such as:

- What would the minimum annual savings in energy expenses have to be over the next 10 years to justify investing in solar panels?

- What is the fewest number of years one would have to reside in the house to justify investing in solar panels?

- What impact will different levels of global warming have on the expected costs of energy over the next 10 years for the homeowner to want to invest in solar panels?

- How will changing the relative weights placed on minimizing cost (01) and assisting in reducing global warming (02) affect the expected utility of $\mathrm{A} 1$ and $\mathrm{A} 2$ ?

\subsubsection{Cost-benefit analysis}

\subsubsection{Elements of the theory}

Cost-benefit analysis (CBA) compares the costs and benefits of different alternatives with the broad purpose of facilitating more efficient allocation of society's resources. When applied to government decisions, CBA can indicate the alternative that has the highest social net present value based on a discount rate, normally constant over time, that converts future benefits and costs to their present values (Boardman et al., 2005; see also the extensive discussion in Section 3.6). Social, rather than private, costs and benefits are compared, including those affecting future generations (Brent, 2006). In this regard, benefits across individuals are assumed to be additive. Distributional issues may be addressed by putting different weights on specific groups to reflect their relative importance. Under conditions of risk and uncertainty, one determines expected costs and benefits by weighting outcomes by their likelihoods of occurrence. In this sense, the analysis is similar to expected utility theory and decision analysis discussed in Sections 2.5.1 and 2.5.2.

CBA can be extremely useful when dealing with well-defined problems that involve a limited number of actors who make choices among different mitigation or adaptation options. For example, a region could examine the benefits and costs over the next fifty years of building levees to reduce the likelihood and consequences of flooding given projected sea level rise due to climate change.

CBA can also provide a framework for defining a range of global long-term targets on which to base negotiations across countries (see for example Stern, 2007). However, CBA faces major challenges when defining the optimal level of global mitigation actions for the following three reasons: (1) the need to determine and aggregate individual welfare, (2) the presence of distributional and intertemporal issues, and (3) the difficulty in assigning probabilities to uncertain climate change impacts. The limits of CBA in the context of climate change are discussed at length in Sections 3.6 and 3.9. The discussion that follows focuses on challenges posed by risk and uncertainty.

\subsubsection{How can CBA improve decision making?}

Cost-benefit analysis assumes that the decision maker(s) will eventually choose between well-specified alternatives. To illustrate this point, consider a region that is considering measures that coastal villages in hazard-prone areas can undertake to reduce future flood risks that are expected to increase in part due to sea level rise. The different options range from building a levee (at the community level) to providing low interest loans to encourage residents and businesses in the community to invest in adaptation measures to reduce future damage to their property (at the level of an individual or household).

Some heuristics and resulting biases discussed in the context of expected utility theory also apply to cost-benefit analysis under uncertainty. For example, the key decision maker, the mayor, may utilize a threshold model of choice by assuming that the region will not be subject to flooding because there have been no floods or hurricanes during the past 25 years. By relying solely on intuitive processes there would be no way to correct this behaviour until the next disaster occurred, at which time the mayor would belatedly want to protect the community. The mayor and his advisors may also focus on short-time horizons, and hence do not wish to incur the high upfront costs associated with building flood protection measures such as dams or levees. They are unconvinced that that such an investment will bring significant enough benefits over the first few years when these city officials are likely to be held accountable for the expenditures associated with a decision to go forward on the project.

Cost-benefit analysis can highlight the importance of considering the likelihood of events over time and the need to discount impacts exponentially rather than hyperbolically, so that future time periods are given more weight in the decision process. In addition, CBA can highlight the tradeoffs between efficient resource allocation and distributional issues as a function of the relative weights assigned to different stakeholders (e. g., low income and well-to-do households in flood prone areas).

\subsubsection{Advantages and limitations of $C B A$}

The main advantage of CBA in the context of climate change is that it is internally coherent and based on the axioms of expected utility theory. 
As the prices used to aggregate costs and benefits are the outcomes of market activity, CBA is, at least in principle, a tool reflecting people's preferences. Although this is one of the main arguments in favour of CBA (Tol, 2003), this line of reasoning can also be the basis for recommending that this approach not be employed for making choices if market prices are unavailable. Indeed, many impacts associated with climate change are not valued in any market and are therefore hard to measure in monetary terms. Omitting these impacts distorts the costbenefit relationship.

Several ethical and methodological critiques have been put forward with respect to the application of CBA to climate policy (Charlesworth and Okereke, 2010; Caney, 2011). For example, the uncertainty surrounding the potential impacts of climate change, including possible irreversible and catastrophic effects on ecosystems, and their asymmetric distribution around the planet, suggests CBA may be inappropriate for assessing optimal responses to climate change in these circumstances.

A strong and recurrent argument against CBA (Azar and Lindgren, 2003; Tol, 2003; Weitzman, 2009, 2011) relates to its failure in dealing with infinite (negative) expected utilities arising from low-probability catastrophic events often referred to as 'fat tails'. In these situations, CBA is unable to produce meaningful results, and thus more robust techniques are required. The debate concerning whether fat tails are indeed relevant to the problem at hand is still unsettled (see for example Pindyck, 2011). Box 3.9 in Chapter 3 addresses the fat tail problem and suggests the importance of understanding the impacts associated with low probability, high impact climate change scenarios in evaluating alternative mitigation strategies.

One way to address the fat tail problem would be to focus on the potential catastrophic consequences of low-probability, high-impact events in developing GHG emissions targets and to specify a threshold probability and a threshold loss. One can then remove events from consideration that are below these critical values in determining what mitigation and/or adaptation to adopt as part of a risk management strategy for dealing with climate change (Kunreuther et al., 2013c). Insurers and reinsurers specify these thresholds and use them to determine the amount of coverage that they are willing to offer against a particular risk. They then diversify their portfolio of policies so the annual probability of a major loss is below a pre-specified threshold level of concern (e. g., 1 in 1000) (Kunreuther et al., 2013c). This approach is in the spirit of a classic paper by Roy (1952) on safetyfirst behaviour and can be interpreted as an application of probabilistic cost-effectiveness analysis (i. e., chance constrained programming) discussed in the next section. It was applied in a somewhat different manner to environmental policy by Ciriacy-Wantrup (1971) who contended that "a safe minimum standard is frequently a valid and relevant criterion for conservation policy."

One could also view uncertainty or risk associated with different options as one of the many criteria on which alternatives should be evaluated. Multi-criteria analysis (MCA) is sometimes proposed to overcome some of the limitations of CBA (see more on its basic features in Chapter 3 and for applications in Chapter 6). MCA implies that the different criteria or attributes should not be aggregated by converting all of them into monetary units. MCA techniques commonly apply numerical analysis in two stages:

- Scoring: for each option and criterion, the expected consequences of each option are assigned a numerical score on a strength of preference scale. More (less) preferred options score higher (lower) on the scale. In practice, scales often extend from 0 to 100 , where 0 is assigned to a real or hypothetical least preferred option, and 100 is assigned to a real or hypothetical most preferred option. All options considered in the MCA would then fall between 0 and 100 .

- Weighting: numerical weights are assigned to define their relative performance on a chosen scale that will often range from 0 (no importance) to 1 (highest importance) (Dodgson et al., 2009).

\subsubsection{Cost-effectiveness analysis}

\subsubsection{Elements of the theory}

Cost-effectiveness analysis (CEA) is a tool based on constrained optimization for comparing policies designed to meet a pre-specified target. The target can be defined through CBA, by applying a specific guideline such as the precautionary principle (see Section 2.5.5), or by specifying a threshold level of concern or environmental standard in the spirit of the safety-first models discussed above. The target could be chosen without the need to formally specify impacts and their respective probabilities. It could also be based on an ethical principle such as minimizing the worst outcome, in the spirit of a Rawlsian fair agreement, or as a result of political and societal negotiation processes.

Cost-effectiveness analysis does not evaluate benefits in monetary terms. Rather, it attempts to find the least-cost option that achieves a desired quantifiable outcome. In one sense CEA can be seen as a special case of CBA in that the technique replaces the criterion of choosing a climate policy based on expected costs and benefits with the objective of selecting the option that minimizes the cost of meeting an exogenous target (e.g., equilibrium temperature, concentration, or emission trajectory).

Like CBA, CEA can be generalized to include uncertainty. One solution concept requires the externally set target to be specified with certainty. The option chosen is the one that minimizes expected costs. Since temperature targets cannot be met with certainty (den Elzen and van Vuuren, 2007; Held et al., 2009), a variation of this solution concept requires that the likelihood that an exogenous target (e.g., equilibrium temperature) will be exceeded is below a pre-defined threshold probability. This solution procedure, equivalent to chance constrained 
programming (CCP) (Charnes and Cooper, 1959), enables one to use stochastic programming to examine the impacts of uncertainty with respect to the cost of meeting a pre-specified target. Chance constrained programming is a conceptually valid decision-analytic framework for examining the likelihood of attaining climate targets when the probability distributions characterizing the decision maker's state of knowledge is held constant over time (Held et al., 2009).

\subsubsection{How can CEA improve decision making?}

To illustrate how CEA can be useful, consider a national government that wants to set a target for reducing greenhouse gas (GHG) emissions in preparation for a meeting of delegates from different countries at the Conference of Parties (COP). It knows there is uncertainty as to whether specific policy measures will achieve the desired objectives. The uncertainties may be related to the outcomes of the forthcoming negotiation process at the COP and/or to the uncertain impacts of proposed technological innovations in reducing GHG emissions. Costeffectiveness analysis could enable the government to assess alternative mitigation strategies (or energy investment policies) for reducing GHG emissions in the face of these uncertainties by specifying a threshold probability that aggregate GHG emissions will not be greater than a pre-specified target level.

\subsubsection{Advantages and limitations of CEA over CBA}

Cost-effectiveness analysis has an advantage over CBA in tackling the climate problem in that it does not require formalized knowledge about global warming impact functions (Pindyck, 2013). The focus of CEA is on more tangible elements, such as energy alternatives, where scientific understanding is more established (Stern, 2007). Still, CEA does require scientific input on potential risks associated with climate change. National and international political processes specify temperature targets and threshold probabilities that incorporate the preferences of different actors guided by data from the scientific community. The corresponding drawback of CEA is that the choice of the target is specified without considering its impact on economic efficiency. Once costs to society are assessed and a range of temperature targets is considered, one can assess people's preferences by considering the potential benefits and costs associated with different targets. However, if costs of a desirable action turn out to be regarded as too high, then CEA may not provide sufficient information to support taking action now. In this case additional knowledge on the mitigation benefit side would be required.

An important application of CEA in the context of climate change is evaluating alternative transition pathways that do not violate a predefined temperature target. Since a specific temperature target cannot be attained with certainty, formulating probabilistic targets as a CCP problem is an appropriate solution technique to use. However, introducing anticipated future learning so that probability distribu- tions change over time can lead to infeasible solutions (Eisner et al., 1971). Since this is a problem with respect to specifying temperature targets, Schmidt et al. (2011) proposed an approach that that combines CEA and CBA. The properties of this hybrid model (labelled 'cost risk analysis') require further investigation. At this time, CEA through the use of CCP represents an informative concept for deriving mitigation costs for the case where there is no learning over time. With learning, society would be no worse off than the proposed CEA solution.

\subsubsection{The precautionary principle and robust decision making}

\subsubsection{Elements of the theory}

In the 1970s and 1980s, the precautionary principle was proposed for dealing with serious uncertain risks to the natural environment and to public health (Vlek, 2010). In its strongest form the precautionary principle implies that if an action or policy is suspected of having a risk that causes harm to the public or to the environment, precautionary measures should be taken even if some cause and effect relationships are not established. The burden of proof that the activity is not harmful falls on the proponent of the activity rather than on the public. A consensus statement to this effect was issued at the Wingspread Conference on the Precautionary Principle on 26 January 1998.

The precautionary principle allows policymakers to ban products or substances in situations where there is the possibility of their causing harm and/or where extensive scientific knowledge on their risks is lacking. These actions can be relaxed only if further scientific findings emerge that provide sound evidence that no harm will result. An influential statement of the precautionary principle with respect to climate change is principle 15 of the 1992 Rio Declaration on Environment and Development: "where there are threats of serious or irreversible damage, lack of full scientific certainty shall not be used as a reason for postponing cost-effective measures to prevent environmental degradation."

Robust decision making (RDM) is a particular set of methods developed over the last decade to address the precautionary principle in a systematic manner. RDM uses ranges or, more formally, sets of plausible probability distributions to describe uncertainty and to evaluate how well different policies perform with respect to different outcomes arising from these probability distributions. RDM provides decision makers with tradeoff curves that allow them to debate how much expected performance they are willing to sacrifice in order to improve outcomes in worst case scenarios. RDM thus captures the spirit of the precautionary principle in a way that illuminates the risks and benefits of different policies. Lempert et al. (2006) and Hall et al. (2012) review the application of robust approaches to decision making with respect to mitigating or adapting to climate change. 
The tolerable windows approach can also be regarded as a 'robust method'. Temperature targets are specified and the bundle of decision paths compatible with the targets is characterized. Mathematically, the tolerable windows approach incorporates the features of CEA or CCP without optimization. The selection of the relevant targets and the paths to achieving it are left to those making the decision. (See Bruckner and Zickfeld (2008) for an introduction and an overview to peer-reviewed literature on the tolerable windows approach.)

\subsubsection{Adaptive management}

Adaptive management is an approach to governance that that grew out of the field of conservation ecology in the 1970s and incorporates mechanisms for reducing uncertainty over time (Holling, 1978; Walters and Hilborn, 1978). Paraphrasing the IPCC Special Report on Extreme Events (SREX) (IPCC, 2012), adaptive management represents structured processes for improving decision making and policy over time, by incorporating lessons learned. From the theoretical literature, two strands of adaptive management have been developed for improving decision making under uncertainty: passive and active.

Passive adaptive management (PAM) involves carefully designing monitoring systems, at the relevant spatial scales, so as to be able to track the performance of policy interventions and improve them over time in response to what has been learned. Active adaptive management (AAM) extends PAM by designing the interventions themselves as controlled experiments, so as to generate new knowledge. For example, if a number of political jurisdictions were seeking to implement support mechanisms for technology deployment, in an AAM approach they would deliberately design separate mechanisms that are likely to differ across jurisdictions. By introducing such variance into the management regime, however, one would collectively learn more about how industry and investors respond to a range of interventions. All jurisdictions could then use this knowledge in a later round of policymaking, reflecting the public goods character of institutional knowledge.

With respect to the application of PAM, Nilsson (2005) reports on a case study of Sweden, in which policymakers engaged in repetitive ex post analyses of national climate policy, and then responded to the lessons learned by modifying their goals and strategies. There are many documented cases of PAM applications in the area of climate change adaptation (Lawler et al., 2008; Berkes et al., 2000; Berkes and Jolly, 2001; Joyce et al., 2009; Armitage, 2011). The information gathering and reporting requirements of the UNFCCC are also in the spirit of PAM with respect to policy design, as are the diversity of approaches implemented for renewable energy support across the states and provinces of North America and the countries in Europe. The combination of the variance in action with data gathered about the consequences of these actions by government agencies has allowed for robust analysis on the relative effectiveness of different instruments (Blok, 2006; Mendonça, 2007; Butler and Neuhoff, 2008).
Individuals relying on intuitive thinking are unlikely to undertake experimentation that leads to new knowledge, as discussed in Section 2.4.3.1. In theory, adaptive management ought to correct this problem by making the goal of learning through experimentation an explicit policy goal. Lee (1993) illustrates this point by presenting a paradigmatic case of AAM designed to increase salmon stocks in the Columbia River watershed in the western United States and Canada. In this case, there was the opportunity to introduce a number of different management regimes on the individual river tributaries, and to reduce uncertainty about salmon population dynamics. As Lee (1993) documented, policymakers on the Columbia River were ultimately not able to carry through with AAM: local constituencies, valuing their own immediate interests over long-term learning in the entire region, played a crucial role in blocking it. One could imagine such political and institutional issues hindering the application of AAM at a global scale with respect to climate change policies.

To date, there are no cases in the literature specifically documenting climate change policies explicitly incorporating AAM. However, there are a number of examples where policy interventions implicitly follow AAM principles. One of these is promotion of energy research and development (R\&D). In this case the government invests in a large number of potential new technologies, with the expectation that some technologies will not prove practical, while others will be successful and be supported by funding in the form of incentives such as subsidies (Fischer and Newell, 2008).

\subsubsection{Uncertainty analysis techniques}

Uncertainty analysis consists of both qualitative and quantitative methodologies (see Box 2.2 for more details). A Qualitative Uncertainty Analysis (QLUA) helps improve the choice process of decision makers by providing data in a form that individuals can easily understand. QLUA normally does not require complex calculations so that it can be useful in helping to overcome judgmental biases that characterize intuitive thinking. QLUA assembles arguments and evidence and provides a verbal assessment of plausibility, frequently incorporated in a Weight of Evidence (WoE) narrative.

A Quantitative Uncertainty Analysis (QNUA) assigns a joint distribution to uncertain parameters of a specific model used to characterize different phenomena. Quantitative Uncertainty Analysis was pioneered in the nuclear sector in 1975 to determine the risks associated with nuclear power plants (Rasmussen, 1975). The development of QNUA and its prospects for applications to climate change are reviewed by Cooke (2012).

\subsubsection{Structured expert judgment}

Structured expert judgment designates methods in which experts quantify their uncertainties to build probabilistic input for complex 


\section{Box 2.2 | Quantifying uncertainty}

Natural language is not adequate for propagating and communicating uncertainty. To illustrate, consider the U.S. National Research Council 2010 report Advancing the Science of Climate Change (America's Climate Choices: Panel on Advancing the Science of Climate Change; National Research Council, 2010). Using the AR4 calibrated uncertainty language, the NRC is highly confident that (1) the Earth is warming and that (2) most of the recent warming is due to human activities.

What does the second statement mean? Does it mean the NRC is highly confident that the Earth is warming and the recent warming is anthropogenic or that, given the Earth is warming, are they highly confident humans cause this warming? The latter seems most natural, as the warming is asserted in the first statement. In that case the 'high confidence' applies to a conditional statement. The probability of both statements being true is the probability of the condition (Earth is warming) multiplied by the probability of this warming being caused by humans, given that warming is taking place. If both statements enjoy high confidence, then in the calibrated language of AR4 where high confidence implies a probability of 0.8 , the statement that both are true would only be "more likely than not" $(0.8 \times 0.8=0.64)$.

Qualitative uncertainty analysis easily leads the unwary to erroneous conclusions. Interval analysis is a semi-qualitative method in which ranges are assigned to uncertain variables without distribu- tions and can mask the complexities of propagation, as attested by the following statement in an early handbook on risk analysis: "The simplest quantitative measure of variability in a parameter or a measurable quantity is given by an assessed range of the values the parameter or quantity can take. This measure may be adequate for certain purposes (e. g., as input to a sensitivity analysis), but in general it is not a complete representation of the analyst's knowledge or state of confidence and generally will lead to an unrealistic range of results if such measures are propagated through an analysis", (U.S. NRC, 1983, Chapter 12, p.12).

The sum of 10 independent variables each ranging between zero and ten, can assume any value between zero and 100 . The upper (lower) bound can be attained only if ALL variables take their maximal (minimal) values, whereas values near 50 can arise through many combinations. Simply stating the interval $[0,100]$ conceals the fact that very high (low) values are much more exceptional than central values. These same concepts are widely represented throughout the uncertainty analysis literature. According to Morgan and Henrion (1990): "Uncertainty analysis is the computation of the total uncertainty induced in the output by quantified uncertainty in the inputs and models [...] Failure to engage in systematic sensitivity and uncertainty analysis leaves both analysts and users unable to judge the adequacy of the analysis and the conclusions reached", (Morgan and Henrion, 1990, p. 39). decision problems (Morgan and Henrion, 1990; Cooke, 1991; O'Hagan et al., 2006). A wide variety of activities fall under the heading of expert judgment that includes blue ribbon panels, Delphi surveys, and decision conferencing.

\section{Elements}

Structured expert judgment such as science-based uncertainty quantification was pioneered in the Rasmussen Report on risks of nuclear power plants (Rasmussen, 1975). The methodology was further elaborated in successive studies and involves protocols for expert selection and training, elicitation procedures and performance-based combinations that are described in more detail in Goossens et al. (2000). In large studies, multiple expert panels provide inputs to computer models with no practical alternative for combining expert judgments except to use equal weighting. Hora (2004) has shown that equal weight combinations of statistically accurate ('well calibrated') experts loses statistical accuracy. Combinations based on experts' statistical accuracy have consistently given more accurate and informative results (see for example Cooke and Goossens, 2008; Aspinall, 2010).
How can this tool improve decision making under uncertainty? Structured expert judgment can provide insights into the nature of the uncertainties associated with a specific risk and the importance of undertaking more detailed analyses to design meaningful strategies and policies for dealing with climate change in the spirit of deliberative thinking. In addition to climate change (Morgan and Keith, 1995; Zickfeld et al., 2010), structured expert judgment has migrated into many fields such as volcanology (Aspinall, 1996, 2010), dam/dyke safety (Aspinall, 2010), seismicity (Klügel, 2008), civil aviation (Ale et al., 2009), ecology (Martin et al., 2012; Rothlisberger et al., 2012), toxicology (Tyshenko et al., 2011), security (Ryan et al., 2012), and epidemiology (Tuomisto et al., 2008).

The general conclusions emerging from experience with structured expert judgments to date are: (1) formalizing the expert judgment process and adhering to a strict protocol adds substantial value to understanding the importance of characterizing uncertainty; (2) experts differ greatly in their ability to provide statistically accurate and informative quantifications of uncertainty; and (3) if expert judgments must be combined to support complex decision problems, the combination 
method should be subjected to the following quality controls: statistical accuracy and informativeness (Aspinall, 2010).

As attested by a number of governmental guidelines, structured expert judgment is increasingly accepted as quality science that is applicable when other methods are unavailable (U.S. Environmental Protection Agency, 2005). Some expert surveys of economists concerned with climate change examine damages (Nordhaus, 1994) and appropriate discount rates (Weitzman, 2001). Structured expert judgments of climate scientists were recently used to quantify uncertainty in the ice sheet contribution to sea level rise, revealing that experts' uncertainty regarding the 2100 contribution to sea level rise from ice sheets increased between 2010 and 2012 (Bamber and Aspinall, 2013).

Damages or benefits to ecosystems from invasions of non-indigenous species are difficult to quantify and monetize on the basis of historical data. However ecologists, biologists and conservation economists have substantial knowledge regarding the possible impacts of invasive species. Recent studies applied structured expert judgment with a performance-based combination and validation to quantify the costs and benefits of the invasive species introduced since 1959 into the U.S. Great Lakes by opening the St. Lawrence Seaway (Rothlisberger et al., 2009, 2012). Lessons from studies such as these reveal that experts may have applicable knowledge that can be captured in a structured elicitation when historical data have large uncertainties associated with them.

\section{Advantages and limitations of structured expert judgment}

Expert judgment studies do not reduce uncertainty; they merely quantify it. If the uncertainties are large, as indeed they often are, then decision makers cannot expect science to relieve them of the burden of deciding under conditions of ambiguity. Since its inception, structured expert judgment has been met with scepticism in some quarters; it is, after all, just opinions and not hard facts. Its steady growth and widening acceptance over 35 years correlates with the growth of complex decision support models. The use of structured expert judgment must never justify a diminution of effort in collecting hard data.

\subsubsection{Scenario analysis and ensembles}

Scenario analysis develops a set of possible futures based on extrapolating current trends and varying key parameters, without sampling in a systematic manner from an uncertainty distribution. Utilizing sufficiently long time horizons ensures that structural changes in the system are considered. The futurist Herman Kahn and colleagues at the RAND Corporation are usually credited with inventing scenario analysis (Kahn and Wiener, 1967). In the climate change arena, scenarios are currently presented as different emission pathways or Representative Concentration Pathways (RCPs). Predicting the effects of such pathways involves modelling the Earth's response to changes in GHG concentrations from natural and anthropogenic sources. Different climate models will yield different projections for the same emissions scenario.
Model Intercomparison studies generate sets of projections termed 'ensembles' (van Vuuren et al., 2011).

\section{Elements of the theory}

Currently, RCPs are carefully constructed on the bases of plausible storylines while insuring (1) they are based on a representative set of peer-reviewed scientific publications by independent groups, (2) they provide climate and atmospheric models as inputs, (3) they are harmonized to agree on a common base year, and (4) they extend to the year 2100 . The four RCP scenarios, shown in Figure 2.3 relative to the range of baseline scenarios in the literature, roughly span the entire scenario literature, which includes control scenarios reaching $430 \mathrm{ppm} \mathrm{CO}_{2} \mathrm{eq}$ or lower by 2100 . The scenarios underlying the RCPs were originally developed by four independent integrated assessment models, each with their own carbon cycle. To provide the climate community with four harmonized scenarios, they were run through the same carbon cycle/climate model (Meinshausen et al., 2011). Note that a representative set is not a random sample from the scenarios as they do not represent independent samples from some underlying uncertainty distribution over unknown parameters.

Ensembles of model runs generated by different models, called multimodel ensembles or super-ensembles, convey the scatter of the climate response and natural internal climate variability around reference scenarios as sampled by a set of models, but cannot be interpreted probabilistically without an assessment of model biases, model interdependence, and how the ensemble was constructed (see WGI AR5 Section 12.2; Knutti et al., 2010). In many cases the assessed uncertainty is larger than the raw model spread, as illustrated in Figure 2.4. The shaded areas (+/-1 standard deviation) around the time series do not imply that $68 \%$ are certain to fall in the shaded areas, but the modelers' assessed uncertainty (likely ranges, vertical bars on the right) are larger. These larger ranges reflect uncertainty in the carbon cycle and the full range of climate sensitivity (WGI AR4 Section 10.5.4.6 and Box 10.3; Knutti et al., 2008) but do not reflect other possible sources of uncertainty (e. g., ice sheet dynamics, permafrost, or changes in future solar and volcanic forcings). Moreover, many of these models have common ancestors and share parameterizations or code (Knutti et al., 2013) creating dependences between different model runs. Probability statements on global surface warming require estimating the models' bias and interdependence (see WGI AR5 Sections 12.2 and 12.4.1.2). WGI AR5 assigns likelihood statements (calibrated language) to global temperature ranges for the RCP scenarios (WGI AR5 Table SPM.2) but does not provide probability density functions (PDFs), as there is no established formal method to generate PDFs based on results from different published studies.

\section{Advantages and limitation of scenario and ensemble analyses}

Scenario and ensemble analyses are an essential step in scoping the range of effects of human actions and climate change. If the scenarios span the range of possible outcomes, they may be seen as providing support for uncertainty distributions in a formal uncertainty analysis. If specific assumptions are imposed when generating the scenarios, then 

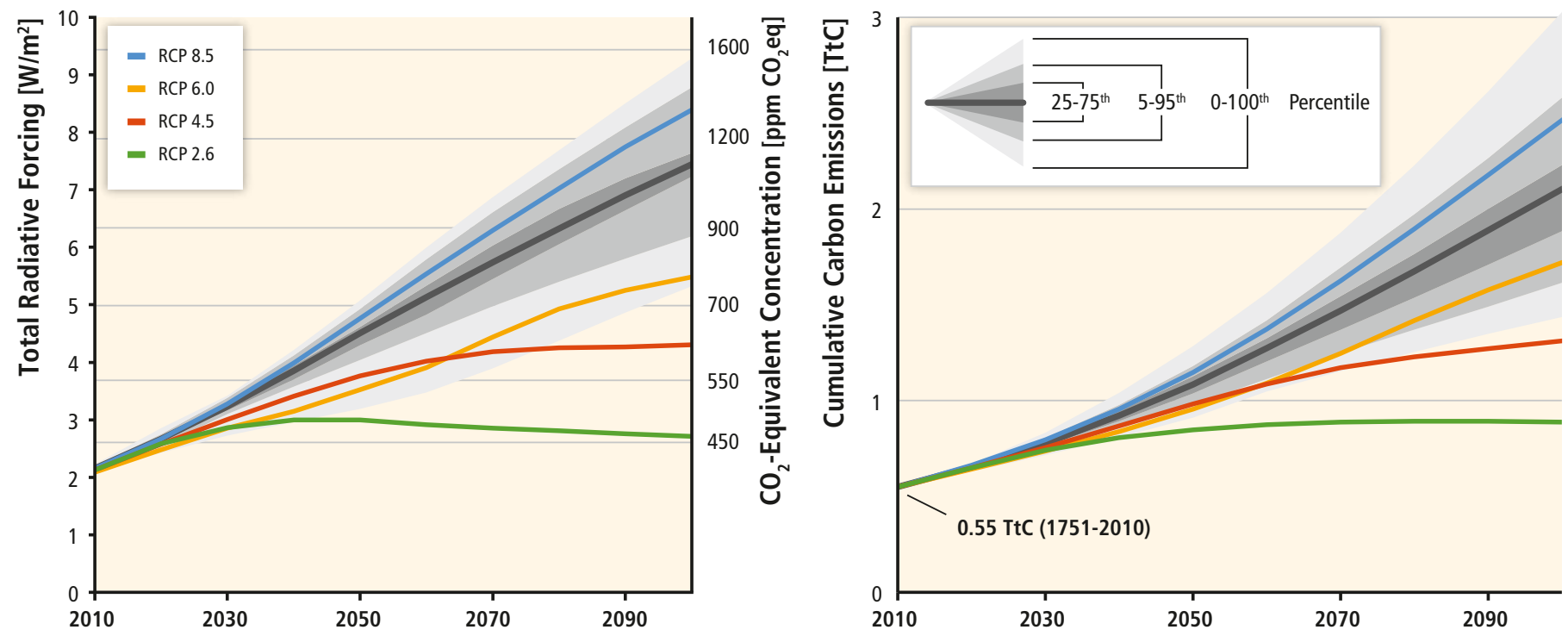

Figure 2.3 Total radiative forcing (left panel) and cumulative carbon emissions since 1751 (right panel) in baseline scenario literature compared to RCP scenarios. Forcing was estimated

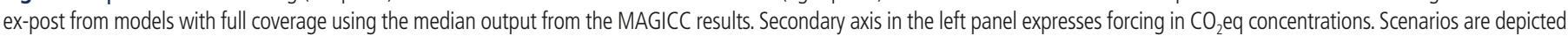
as ranges with median emboldened; shading reflects interquartile range (darkest), 5th-95th percentile range (lighter), and full extremes (lightest). Source: Figure 6.6 from WGIII AR5.
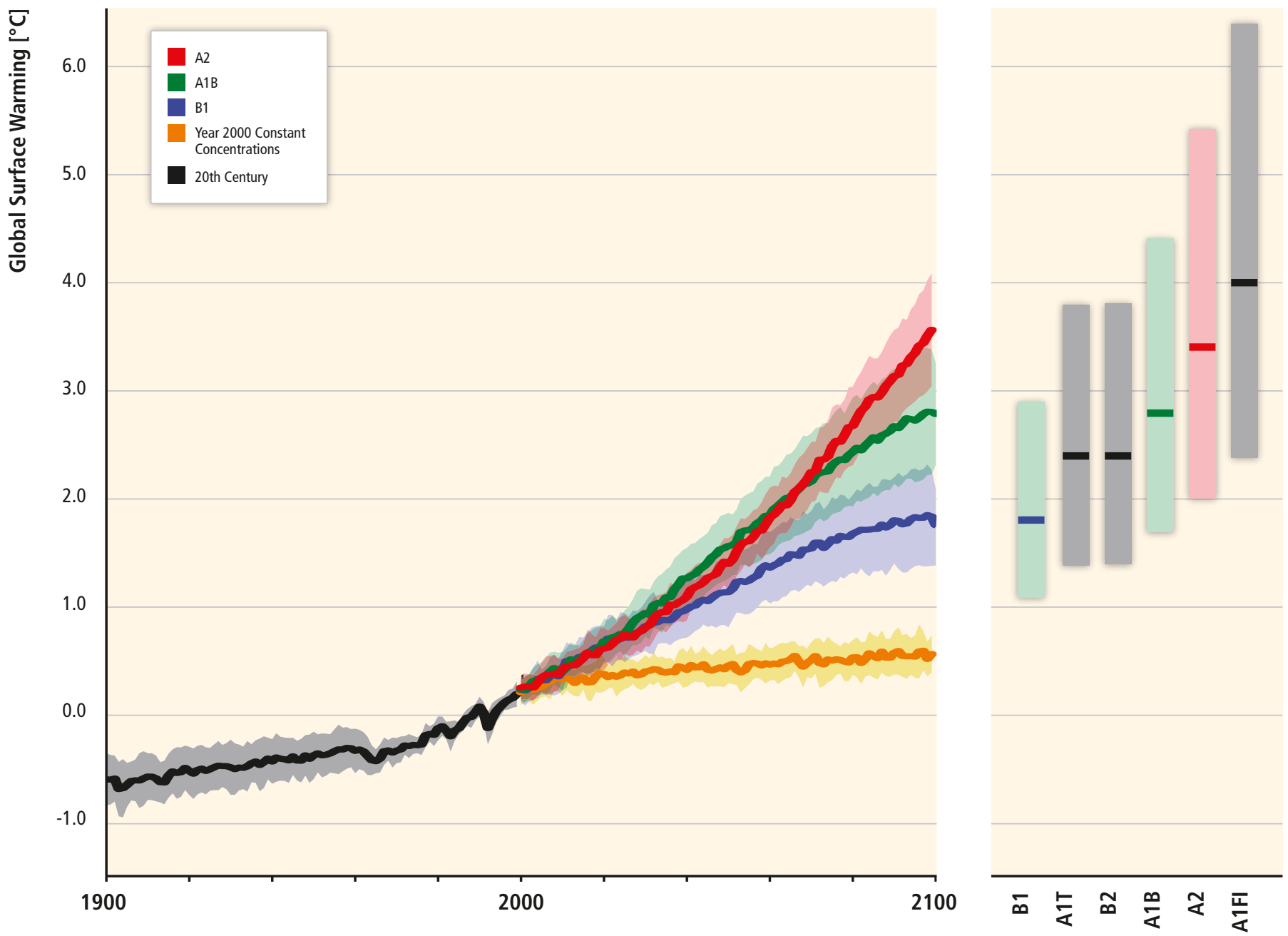

Figure 2.4 | Solid lines are multi-model global averages of surface warming (relative to 1980-1999) for the scenarios A2, A1B and B1, shown as continuations of the 20th century simulations. Shading denotes the \pm 1 standard deviation range of individual model annual averages. The orange line is for the experiment where concentrations were held constant at year 2000 values. The grey bars at right indicate the best estimate (solid line within each bar) and the likely range assessed for the six families of emissions scenarios discussed in the IPCC's Fourth Assessment Report (AR4). The assessment of the best estimate and likely ranges in the grey bars includes the Atmosphere-Ocean General Circulation Models (AOGCMs) in the left part of the figure, as well as results from a hierarchy of independent models and observational constraints. Based on: Figure SPM.5 from WGI AR5. 
the support is conditional on these assumptions (see Section 6.2.3). The advantage of scenario/ensemble analyses is that they can be performed without quantifying the uncertainty of the underlying unknown parameters. On the downside, it is easy to read more into these analyses than is justified. Analysts often forget that scenarios are illustrative possible futures along a continuum. They tend to use one of those scenarios in a deterministic fashion without recognizing that they have a low probability of occurrence and are only one of many possible outcomes. The use of probabilistic language in describing the swaths of scenarios (such as standard deviations in Figure 2.4) may also encourage the misunderstandings that these represent science-based ranges of confidence.

The study of representative scenarios based on probabilistic forecasts have been shown to facilitate strategic planning by professional groups such as military commanders, oil company managers, and policymakers (Schoemaker, 1995; Bradfield et al., 2005). Recent work on ice sheet modelling (Little et al., 2013) points in this direction. Using modelling assumptions and prior distributions on model coefficients, Monte Carlo simulations are used to produce probabilistic predictions. Expert informed modelling is methodologically intermediate between structured expert judgment (Bamber and Aspinall, 2013) and nonprobabilistic scenario sweeps. Structured expert judgment leaves the modelling assumptions to the experts who quantify their uncertainty on future observables.

\subsection{Managing uncertainty, risk and learning}

\subsubsection{Guidelines for developing policies}

This section assesses how the risks and uncertainties associated with climate change can affect choices with respect to policy responses, strategies, and instruments. At the time of the AR4, there was some modelling-based literature on how uncertainties affected policy design, but very few empirical studies. In the intervening years, international negotiations failed to establish clear national emissions reductions targets, but established a set of normative principles, such as limiting global warming to $2^{\circ} \mathrm{C}$. These are now reflected in international, national, and subnational planning processes and have affected the risks and uncertainties that matter for new climate policy development. Greater attention and effort has been given to finding synergies between climate policy and other policy objectives, so that it is now important to consider multiple benefits of a single policy instrument. For example, efforts to protect tropical rainforests (McDermott et al., 2011), rural livelihoods (Lawlor et al., 2010), biodiversity (Jin- nah, 2011), public health (Stevenson, 2010), fisheries (Axelrod, 2011), arable land (Conliffe, 2011), energy security (Battaglini et al., 2009), and job creation (Barry et al., 2008) have been framed as issues that should be considered when evaluating climate policies.

The treatment here complements the examination of policies and instruments in later chapters of this report, such as Chapter 6 (which assesses the results of IAMs) and Chapters 13-15 (which assess policy instruments at a range of scales). Those later chapters provide greater details on the overall tradeoffs to be made in designing policies. The focus here is on the special effects of various uncertainties and risks on those tradeoffs.

- Section 2.6.2 discusses how institutions that link science with policy grapple with several different forms of uncertainty so that they meet both scientific and political standards of accountability.

- Section 2.6.3 presents the results of integrated assessment models (IAMs) that address the choice of a climate change temperature target or the optimal transition pathway to achieve a particular target. IAMs normally focus on a social planner operating at the global level.

- Section 2.6.4 summarizes the findings from modelling and empirical studies that examine the processes and architecture of international treaties.

- Section 2.6.5 presents the results of modelling studies and the few empirical analyses that examine the choice of particular policy instruments at the sovereign state level for reducing GHG emissions. It also examines how the adoption of energy efficiency products and technologies can be promoted at the firm and household levels. Special attention is given to how uncertainties affect the performance and effectiveness of these policy instruments.

- Section 2.6.6 discusses empirical studies of people's support or opposition with respect to changes in investment patterns and livelihood or lifestyles that climate policies will bring about. These studies show people's sensitivity to the impact that climate change will have on their personal health or safety and their perceptions of the health and safety risks associated with the new technologies addressing the climate change problem.

Linking intuitive thinking and deliberative thinking processes for dealing with uncertainties associated with climate change and climate policy should increase the likelihood that instruments and robust policies will be implemented. In this sense, the concepts presented in this section should be viewed as a starting point for integrating descriptive models with normative models of choice for developing risk management strategies. 


\subsubsection{Uncertainty and the science/policy interface}

Science/policy interfaces are defined as social processes which encompass relationships between scientists and other actors in the policy process, and which allow for exchanges, co-evolution, and joint construction of knowledge with the aim of enriching decision making (Van den Hove, 2007). Analysts have called attention to several different forms of uncertainty affecting the science/policy relationship that can be summarized as follows:

- Paradigmatic uncertainty results from the absence of prior agreement on the framing of problems, on methods for scientifically investigating them, and on how to combine knowledge from disparate research traditions. Such uncertainties are especially common in cross-disciplinary, application-oriented research and assessment for meeting policy objectives (Gibbons, 1994; Nowotny et al., 2001).

- Epistemic uncertainty results from lack of information or knowledge for characterizing phenomena. Stirling (2007) further distinguishes between uncertainty (insufficient knowledge to assess probabilities), ambiguity (insufficient knowledge about possible outcomes), and ignorance (insufficient knowledge of likely outcomes and their probabilities). Others have noted that producing more knowledge may exacerbate uncertainty, especially when actors disagree about how to frame a problem for scientific investigation (Beck, 1992; Gross, 2010).

- Translational uncertainty results from scientific findings that are incomplete or conflicting, so that they can be invoked to support divergent policy positions (Sarewitz, 2010). In such circumstances, protracted controversy often occurs, as each side challenges the methodological foundations of the other's claims in a process called 'experimenters' regress' (Collins, 1985).

Institutions that link science to policy must grapple with all of the above forms of uncertainty, often simultaneously. Because their work cuts across conventional lines between science and politics, these institutions have been called 'boundary organizations' (Guston, 2001) and their function has been termed 'hybrid management' (Miller, 2001). Straddling multiple worlds, science-policy institutions are required to meet both scientific and political standards of accountability. Whereas achieving scientific consensus frequently calls for bounding and closing down disagreements, achieving political legitimacy requires opening up areas of conflict in order to give voice to divergent perspectives.

The task of resolving conflicts in policy-relevant science is generally entrusted to multidisciplinary expert bodies. These organizations are best suited to addressing the paradigmatic uncertainties that arise when problems are novel or when synthesis is required across fields with different standards of good scientific practice. Bridging epistemic and translational uncertainties, however, imposes added demands. For expert advisory bodies to be viewed as legitimate they must represent all relevant viewpoints in a politically acceptable manner (Jasanoff, 1990; 2005a). What counts as acceptable varies to some degree across national decision-making cultures. Each culture may place different weights on experts' personal integrity, the reliability of their disciplinary judgments, and their ability to forge agreement across competing values (Jasanoff, 2005b, pp. 209-224).

To achieve legitimacy, institutions charged with linking science to policy must also open themselves up to public input at one or more stages in their deliberations. This process of "extended peer review" (Funtowicz and Ravetz, 1992) is regarded as necessary, though insufficient, for the production of "socially robust knowledge", that is, knowledge that can withstand public scrutiny and scepticism (Gibbons, 1994). Procedures that are sufficient to produce public trust in one political context may not work in others because national political cultures are characterized by different "civic epistemologies", i.e., culturally specific modes of generating and publicly testing policy-relevant knowledge (Jasanoff, 2005a).

International and global scientific assessment bodies confront additional problems of legitimacy because they operate outside longestablished national decision-making cultures and are accountable to publics subscribing to different civic epistemologies (Jasanoff, 2010). The temptation for such bodies has been to seek refuge in the linear model in the hope that the strength of their internal scientific consensus will be sufficient to win wide political buy-in. The recent research on linking science to policy suggests otherwise.

\subsubsection{Optimal or efficient stabilization pathways (social planner perspective)}

Integrated assessment models (IAMs) vary widely in their underlying structure and decision-making processes. IAMs designed for cost-benefit analysis typically simulate the choices of an idealized 'social planner', who by definition is someone who makes decisions on behalf of society, in order to achieve the highest social welfare by weighting the benefits and cost of mitigation measures. In contrast, many IAMs designed for cost-effectiveness analysis (CEA) specify the social planner's objective as identifying the transformation pathway that achieves a pre-defined climate goal at the lowest discounted aggregated costs to society. In both cases, the analyses do not consider distributional effects of policies on different income groups, but instead focus on the effect on total macroeconomic costs. Hence, with these types of IAMs, negotiators that are part of the political process are able to rank the relative desirability of alternative policies to the extent that they share the definition of social welfare embedded in the model (e.g., discounted aggregate cost minimization), and believe that those implementing the policy will do so cooperatively. 
Chapter 6 describes in more detail important structural characteristics of a set of IAMs used to generate transformation pathways. The modelling analyses highlighted in Chapter 6 utilize the scenario approach to represent uncertainty. In this section we instead focus on IAM results where uncertainty is an integral part of the decision-analytic framework.

Climate policy assessment should be considered in the light of uncertainties associated with climate or damage response functions, the costs of mitigation technology and the uncertainty in climate change policy instruments. A key question these analyses address is how uncertainty with respect to the above factors alters the optimal social planner's short-term reactions to climate change. A subset also asks whether adjusting behaviour to uncertainty and designing more flexible policies and technology solutions would induce a significant welfare gain.

Table 2.2 provides an overview of the existing literature on IAMs that examine mitigation actions. The rows classify the literature on the basis of the type of uncertainty: upstream, associated with emission baseline drivers, such as economic and population growth; downstream continuous, associated with climate feedbacks and damages; downstream strongly nonlinear, associated with the possibility of thresholds and irreversibilities; policy responses, associated with the uncertain adoption of policy tools; and multiple sources, when more than one of the sources above are considered simultaneously. The three columns categorize the literature according to the ways introducing uncertainty influence the findings. The theoretical economic literature shows that the effect of including uncertainty in decision making on near-term mitigation is ambiguous (for an overview see e.g., Lange and Treich, 2008; De Zeeuw and Zemel, 2012). However, for most studies that assume downstream strongly nonlinear uncertainties under a social welfare maximization or downstream uncertainties in combination with a temperature target, including uncertainty in the analysis leads to an optimal or efficient level of mitigation that is greater and/or accelerated than under conditions of certainty.

The literature on IAMs incorporating uncertainty uses either Monte Carlo simulations or fully stochastic programming techniques. Monte Carlo studies provide insights regarding the order-of-magnitude effect of multiple model parameter uncertainties for model output (Nordhaus and Popp, 1997; Tol, 1999; Webster et al., 2002; Hope, 2008, p. 200; Ackerman et al., 2010; Dietz, 2011; Pycroft et al., 2011). In this sense they can be interpreted as a preparatory step towards a full-fledged decision analysis under uncertainty.

Table 2.2 | Overview of literature on integrated assessment models examining mitigation actions. (cea) indicates: analysis based on a probabilistic generalization of CEA. Papers that appear several times report different scenarios or assumptions. The few studies highlighted by "*" use non-probabilistic decision criteria under uncertainty (e. g., minimax regret or maximin).

\begin{tabular}{|c|c|c|c|}
\hline \multirow{2}{*}{ Type of Uncertainty Considered } & \multicolumn{3}{|c|}{ Effect on Mitigation Action } \\
\hline & Accelerates/Increases Mitigation Action & Delays/Decreases Mitigation Action & Ambiguous Effect \\
\hline Upstream (emission drivers) & $\begin{array}{l}\text { Reilly et al., 1987; Webster et al., 2002; O'Neill } \\
\text { and Sanderson, 2008; Rozenberg et al., } 2010\end{array}$ & & O'Neill and Sanderson, 2008 \\
\hline $\begin{array}{l}\text { Downstream (climate } \\
\text { and damages)—mildly } \\
\text { nonlinear damages }\end{array}$ & $\begin{array}{l}\text { Chichilnisky and Heal, 1993; Peck and Teisberg, 1994; } \\
\text { Ha-Duong and Treich, 2004; Syri et al., 2008; Athanassoglou } \\
\text { and Xepapadeas, 2011; Kaufman, 2012; Ackerman et al., } 2013\end{array}$ & Kolstad, 1994, 1996a; Baranzini et al., 2003 & $\begin{array}{l}\text { Clarke and Reed, 1994; Kolstad, 1996b; } \\
\text { Tsur and Zemel, 1996; Gollier et al., 2000; } \\
\text { Fisher and Narain, 2003; Ha-Duong and } \\
\text { Treich, 2004; Baker et al., 2006; Lange and } \\
\text { Treich, 2008; Lorenz et al., 2012b; Ulph } \\
\text { and Ulph, 1997; Ackerman et al., } 2013\end{array}$ \\
\hline $\begin{array}{l}\text { Downstream (climate and } \\
\text { damages)—strongly nonlinear } \\
\text { event or temperature target }\end{array}$ & $\begin{array}{l}\text { Ha-Duong, 1998; Gjerde et al., 1999; O'Neill and Oppenheimer, } \\
\text { 2002; Baranzini et al., 2003; Dumas and Ha-Duong, 2005; } \\
\text { Syri et al., 2008(cea); Johansson et al., 2008(cea); Hope, } \\
\text { 2008; Webster, 2008; Tsur and Zemel, 2009; Schmidt et al., } \\
\text { 2011(cea); Funke and Paetz, 2011; Iverson and Perrings, } \\
\text { 2012*; Lorenz et al., 2012b; de Zeeuw and Zemel, } 2012\end{array}$ & Peck and Teisberg, 1995 & Gollier and Treich, 2003 \\
\hline Uncertainty on Policy Response & $\begin{array}{l}\text { Ha-Duong et al., 1997; Blanford, 2009; Bosetti and Tavoni, } \\
\text { 2009; Bosetti et al., 2009; Durand-Lasserve et al., 2010(cea) }\end{array}$ & Baudry, 2000; Baker and Shittu, 2006(cea) ${ }^{2}$ & Farzin and Kort, 2000(cea) \\
\hline Multiple Sources of Uncertainty & $\begin{array}{l}\text { Nordhaus and Popp, 1997; Grubb, 1997; Pizer, 1999; Tol, } \\
\text { 1999; Obersteiner et al., 2001; Yohe et al., 2004; Keller et al., } \\
\text { 2004; Baker and Shittu, 2008; Baker and Adu-Bonnah, 2008; } \\
\text { Bahn et al., 2008; Held et al., 2009; Hope, 2009; Labriet et al., } \\
\text { 2012(cea), 2010; Hof et al., 2010*; Funke and Paetz, 2011* }\end{array}$ & Scott et al., 1999 & $\begin{array}{l}\text { Manne and Richels, 1991; Baker and Shittu, } \\
\text { 2008(4); Baker and Adu-Bonnah, } 2008^{3}\end{array}$ \\
\hline
\end{tabular}

Notes:

In some studies the 'baseline case' is a decision analysis based on a reduced form of uncertainty.

The impact on R\&D investments depend on technology; the most common result is, however, that uncertainty decreases the optimal level of R\&D investments.

In the sense of: increasing damage uncertainty would lead to higher investments in less risky programmes, but the effect depends on the type of technology. 
Table 2.2 also characterizes the effect of the inclusion of uncertainty on early-period mitigation efforts. A decision analysis is generally compared to a baseline-case represented by a deterministic study utilizing average values of uncertain parameters. (In some studies, the baseline case is a decision analysis based on a reduced form of uncertainty.)

It should be noted that, although IAMs mimic decision makers who utilize deliberative processes, in reality social planners might resort to intuitive thinking to simplify their decision processes, leading to biases and inferior choices. To date there is no research that considers such behaviour by decision makers and how it affects the projections of IAMs. We discuss the need for such studies in Section 2.7 on gaps in knowledge and data.

\subsubsection{Analyses predominantly addressing climate or damage response uncertainty}

Although studies differ in their approaches, the case against accelerated or increased mitigation action is the possibility that irreversible sunk cost investments in abatement options outweigh the irreversible effects of climate change. This has been an infrequent finding, with the exception of those studies that have not included catastrophic/threshold damage and give no consideration to the non-climate related benefits of these investments, such as enhancing energy security or local pollution benefits. Indeed, the one set of papers that finds a need for increased or accelerated mitigation action is ambiguous when the social welfare optimum is examined under downstream continuous/mildly nonlinear damages uncertainty. Lorenz et al. (2012a) show that this is due primarily to the fact that damage nonlinearities are often compensated by other nonlinearities such as a concave (i. e., sublinear) concentration-temperature relation.

Studies that cluster in the first column (accelerated or increased mitigation action) assumed strongly non-linear damage functions or temperature targets (3rd row). Cost-effectiveness analysis has been applied to reflect targets when the models have been generalized to include uncertainty. In this regard, Held et al. (2009), utilizing chance constrained programming (CCP) (see Section 2.5.4.1), examine uncertainty in climate and technology response properties. As their reference case they calculated the mitigation effort needed to achieve a $2{ }^{\circ} \mathrm{C}$ temperature target, assuming average values for all uncertain parameters. Given uncertainty, however, it is clear that any given mitigation effort will exceed the target with some probability; for the reference case this is approximately $50 \%$. As the required probability for meeting the target increases, a greater level of mitigation effort is required. (An analogous argument holds for tipping-point derived targets. See McInerney and Keller, 2008). If the required probability is $66.6 \%$ rather than $50 \%$, investments in mitigation technologies need to occur in earlier decades.

The effects on investment in mitigation also depend on whether uncertainty is expected to be reduced. Is a reduction of uncertainty on cli- mate sensitivity and related climate response properties realistic? In an early paper, Kelly and Kolstad (1999) evaluated the amount of time needed to significantly reduce uncertainty about the parameters influencing climate sensitivity by observing global warming. They found the required time to be 90 to 160 years. Leach (2007) conducted a similar analysis that allowed two rather than one independent sources of downstream uncertainty. In that case, the time required to resolve the climate sensitivity parameters is likely to be even longer. These kind of studies assumed that our basic understanding of atmospheric chemistry and physics would remain unchanged over time. If one were to relax this constraint, then one could imagine that learning would progress more rapidly.

Another set of papers examines the 'anticipation effect', namely what it means if we believe we will learn in the future, rather than that our knowledge will remain constant. Lange and Treich (2008) showed that the sign and magnitude of mitigation depend on the particular numerical model and type of uncertainty when introducing the anticipation effect. Using CBA, for example, Lorenz et al. (2012b), Peck and Teisberg (1993), Webster et al. (2008), and Yohe and Wallace (1996) showed the anticipation effect to be negligible when assuming continuous and only weakly non-linear damages. However, Lorenz (2012b) showed slightly less immediate mitigation (compared to no-learning) if one anticipates learning within a given, narrow, time window with respect to threshold-type impacts. Such a mild reduction of early mitigation in response to anticipation was also reported in Keller et al. (2004) in accordance with Ulph and Ulph (1997).

When CEA is used to represent temperature targets in combination with climate response uncertainty, it is difficult to evaluate learning effects (see the discussion in Section 2.5.4.3). One way to allow for numerical solutions in this case is to assume an upper limit on the distribution of climate sensitivity to examine the effect of learning in the presence of a climate target. Under this assumption, more mitigation is called for (Bahn et al., 2008; Syri et al., 2008; Fouquet and Johansson, 2008; Webster, 2008).

A further set of papers considers the impossibility of specifying a precise probability density function for characterizing climate sensitivity as suggested by many climate scientists. This implies that these probabilities are difficult to estimate and decisions have to be made under conditions of ambiguity. Funke and Paetz (2011) account for model structure uncertainty by employing a robust control approach based on a maximin principle. When considering uncertainty on the ecological side of the balance, they conclude that model uncertainty implies a need for more aggressive near-term emissions reductions. Athanassoglou and Xepapadeas (2011) extend this approach to include adaptation. Iverson and Perrings (2012) apply combinations of maximin and/or minimax decision criteria, examining the effects of widening the range of climate sensitivity. Hof et al. (2010), contrast a CBA with a minimax regret approach and find that the minimax regret approach leads to more stringent and robust climate targets for relatively low discount rates if both high climate sensitivity and high damage 
estimates are assumed. What remains unresearched is the possibility of using non-probabilistic methods to evaluate the effects of an unbounded, or 'fat-tails', distribution for climate responses and climate impacts.

Finally, a potentially path-breaking development in economics is the effort of Ackerman et al. (2013), Crost and Traeger (2013), and Kaufman (2012) to disentangle risk aversion (a static effect) from consumption smoothing (an intertemporal effect) (for a conceptual discussion see Ha-Duong and Treich, 2004) in an Integrated Assessment Model. Compared to the results of a standard discounted expected utility model that relates risk aversion to consumption smoothing, Ackerman (2013) as well as Crost and Traeger (2013) find optimal mitigation to be twice as great. Since these are the first papers on this topic, it is too early to tell whether their results represent a robust result that captures society's risk preferences.

\subsubsection{Analyses predominantly addressing policy response uncertainty}

There are two strands of research in the area of policy response uncertainty. The first has focused on examining how the extent and timing of mitigation investments are affected by the uncertainty on the effectiveness of Research, Development, and Demonstration (RD\&D) and/or the future cost of technologies for reducing the impact of climate change. An example of this would be optimal investment in energy technologies that a social planner should undertake, knowing that there might be a nuclear power ban in the near future. Another strand of research looks at how uncertainty concerning future climate policy instruments in combination with climate and/or damage uncertainty affects a mitigation strategy. An example would be the optimal technological mix in the power sector to hedge future climate regulatory uncertainty.

With respect to the first strand, the main challenge is to quantify uncertainty related to the future costs and/or availability of mitigation technologies. Indeed, there does not appear to be a single stochastic process that underlies all (RD\&D) programmes' effectiveness or innovation processes. Thus elicitation of expert judgment on the probabilistic improvements in technology performance and cost becomes a crucial input for numerical analysis. A literature is emerging that uses expert elicitation to investigate the uncertain effects of RD\&D investments on the prospect of success of mitigation technologies (see for example Baker et al., 2008; Curtright et al., 2008; Chan et al., 2010; Baker and Keisler, 2011). In future years, this new body of research will allow the emergence of a literature studying the probabilistic relationship between $R \& D$ and the future cost of energy technologies in IAMs.

The few existing papers reported in Table 2.2 under the Policy Response uncertainty column (see Blanford, 2009; Bosetti and Tavoni, 2009) point to increased investments in energy RD\&D and in early deployment of carbon-free energy technologies in response to uncertainty.
An interesting analysis has been performed in Goeschl and Perino (2009), where the potential for technological 'boomerangs' is considered. Indeed, while studies cited above consider an innovation failure an R\&D project that does not deliver a clean technology at a competitive cost, Goeschl and Perino (2009) define R\&D failure when it brings about a new, environmentally harmful, technology. Under such characterization they find that short-term R\&D investments are negatively affected.

Turning to the second strand of literature reported in the Policy Response or in the Multiple Uncertainty columns of Table 2.2 (see HaDuong et al., 1997; Baker and Shittu, 2006; Durand-Lasserve et al., 2010), most analyses imply increased mitigation in the short term when there is uncertainty about future climate policy due to the asymmetry of future states of nature. In the event of the realization of the 'no climate policy' state, investment in carbon-free capital has low or zero value. Conversely, if a 'stringent climate policy' state of nature is realized, it will be necessary to rapidly ramp up mitigation to reduce the amount of carbon in the atmosphere. This cost is consistently higher, thus implying higher mitigation prior to the realization of the uncertain policy state.

\subsubsection{International negotiations and agreements}

Social planner studies, as reviewed in the previous sub-sections, consider the appropriate magnitude and pace of aggregate global emissions reduction. These issues have been the subject of negotiations about long-term strategic issues at the international level along with the structuring of national commitments and the design of mechanisms for compliance, monitoring, and enforcement.

\subsubsection{Treaty formation}

A vast literature looks at international treaties in general and how they might be affected by uncertainties. Cooper (1989) examined two centuries of international agreements that aimed to control the spread of communicable diseases and concludes that it is only when uncertainty is largely resolved that countries will enter into agreements. Young (1994), on the other hand, suggests that it may be easier to enter into agreements when parties are uncertain over their individual net benefits from an agreement than when that uncertainty has been resolved. Coalition theory predicts that for international negotiations related to a global externality such as climate change, stable coalitions will generally be small and/or ineffective (Barrett, 1994). Recently, De Canio and Fremstad (2013) show how the recognition of the seriousness of a climate catastrophe on the part of leading governments - which increases the incentives for reaching an agreement-could transform a prisoner's dilemma game into a coordination game leading to an increased likelihood of reaching an international agreement to limit emissions. 
Relatively little research has been undertaken on how uncertainty affects the stability of multilateral environmental agreements (MEAs) and when uncertainty and learning has the potential to unravel agreements. Kolstad (2007), using a game theoretic model, looks specifically at environmental agreements. He finds that systematic uncertainty decreases the size of the largest stable coalition of an MEA. Kolstad and Ulph (2011) show that partial or complete learning has a negative impact on the formation of an MEA because as outcomes become more certain, some countries also learn the MEA will reduce their own welfare benefits, which deters them from joining the coalition. Baker (2005), using a model of the impacts of uncertainty and learning in a non-cooperative game, shows that the level of correlation of damages across countries is a crucial determinant of outcome.

Barrett (2013) has investigated the role of catastrophic, low probability events on the likelihood of cooperation with respect to a global climate agreement. By comparing a cooperative agreement with the Nash equilibrium it is possible to assess a country's incentives for participating in such an agreement. Looking at stratospheric ozone as an analogy for climate, Heal and Kunreuther (2013) observed that the signing of the Montreal Protocol by the United States led many other countries to follow suit. The authors in turn suggest how it could be applied to foster an international treaty on greenhouse gas emissions by tipping a non-cooperative game from an inefficient to an efficient equilibrium.

Several analyses, including Victor (2011) and Hafner-Burton et al. (2012), contend that the likelihood of a successful comprehensive international agreement for climate change is low because of the sensitivity of negotiations to uncertain factors, such as the precise alignment and actions of participants. Keohane and Victor (2011), in turn, suggest that the chances of a positive outcome would be higher in the case of numerous, more limited agreements. Developing countries have been unlikely to agree to binding targets in the context of international agreements due in part to the interests of developed countries dominating the negotiation process. For the situation to change, the developing countries would have to enhance their negotiating power in international climate change discussions by highlighting their concerns (Rayner and Malone, 2001).

The above analyses all assume that the agents are deliberative thinkers, each of whom has the same information on the likelihood and consequences of climate change. Section 2.7 indicates the need for future research that examines the impact of intuitive thinking on behaviour on international negotiations and processes for improving the chances of reaching an agreement on treaties.

\subsubsection{Strength and form of national commitments}

Buys et al. (2009) construct a model to predict national level support for a strong global treaty based on both the climatic and economic risks that parties to the treaty face domestically; however Buys et al. do not test the model empirically. Their model distinguishes between vulnerabilities to climate impacts and climate policy restrictions with respect to carbon emissions and implies that countries would be most supportive of strong national commitments when they are highly vulnerable to climate impacts and their emitting sectors are not greatly affected by stringent policy measures.

Victor (2011) analyzes the structure of the commitments themselves, or what Hafner-Burton et al. (2012) call rational design choices. Victor suggests that while policymakers have considerable control over the carbon intensity of their economies, they have much less control over the underlying economic growth of their country. As a result, there is greater uncertainty on the magnitude of emissions reductions, which depends on both factors, than on the reductions in carbon intensity. Victor suggests that this could account for the reluctance by many countries to make binding commitments with respect to emissions reductions. Consistent with this reasoning, Thompson (2010) examined negotiations within the UNFCCC and found that greater uncertainty with respect to national emissions was associated with a decrease in support for a national commitment to a global treaty.

Webster et al. (2010) examined whether uncertainty with respect to national emissions increases the potential for individual countries to hedge by joining an international trade agreement. They found that hedging had a minor impact compared to the other effects of international trade, namely burden sharing and wealth transfer. These findings may have relevance for structuring a carbon market to reduce emissions by taking advantage of disparities in marginal abatement costs across different countries. In theory, the right to trade emission permits or credits could lessen the uncertainties associated with any given country's compliance costs compared to the case where no trading were possible. Under a trading scheme, if a country discovered its own compliance costs to be exceptionally high, for example, it could purchase credits on the market.

\subsubsection{Design of measurement, verification regimes, and treaty compliance}

A particularly important issue in climate treaty formation and compliance is uncertainty with respect to actual emissions from industry and land use. Measurement, reporting, and verification (MRV) regimes have the potential to set incentives for participation in a treaty and still be stringent, robust, and credible with respect to compliance. The effects of strategies for managing GHG emissions are uncertain because the magnitude of the emissions of carbon dioxide and other GHG gases, such as methane, often cannot be detected given the error bounds associated with the measurement process. This is especially the case in the agriculture, forestry, and other land-use (AFOLU) sectors.

In the near term, an MRV regime that met the highest standards could require stock and flow data for carbon and other GHGs. These 
data are currently available only in wealthy countries, thus precluding developing countries from participating (Oliveira et al., 2007). By contrast, there are design options for MRV regimes that are less accurate, but which still provide data on the drivers of emissions so that the developing countries could be part of the system. By being more inclusive, these options could be a more effective way to actually reduce aggregate emissions, at least in the near term (Bucki et al., 2012). In the longer term, robust and harmonized estimation of GHG flows-emissions and their removal-in agriculture and forestry requires investment in monitoring and reporting capacity, especially in developing countries (Böttcher et al., 2009; Romijn et al., 2012). Reflecting this need for an evolving MRV regime to match data availability, the 2006 Guidelines for National Greenhouse Gas Inventories, prepared by an IPCC working group, suggested three hierarchical tiers of data for emission and carbon stock change factors with increasing levels of data requirements and analytical complexity. Tier 1 uses IPCC default values of high uncertainty; Tier 2 uses countryspecific data; and Tier 3 uses higher spatial resolution, models, and inventories. In 2008, only Brazil, India and Mexico had the capacity to use Tier 2 and no developing country was able to use tier 3 (Hardcastle and Baird, 2008). Romijn et al. (2012) focused on 52 tropical countries and found that four of them had a very small capacity gap regarding the monitoring of their forests through inventories, while the remaining 48 had limited or no ability to undertake this monitoring process.

In order to overcome the gaps and uncertainties associated with lower tier approaches, different principles can be applied to form pools (Böttcher et al., 2008). For example, a higher level of aggregation by including soil, litter and harvested products in addition to a biomass pool as part of the MRV regime decreases relative uncertainty: the losses in one pool (e.g., biomass) are likely to be offset by gains in other pools (e.g., harvested products) (Böttcher et al., 2008). Researchers have suggested that the exclusion of a pool (e.g., soil) in an MRV regime should be allowed only if there is adequate documentation that the exclusion provides a more conservative estimate of emissions (Grassi et al., 2008). They also suggest that an international framework needs to create incentives for investments. In this respect, overcoming initialization costs and unequal access to monitoring technologies would be crucial for implementation of an integrated monitoring system, and fostering international cooperation (Böttcher et al., 2009).

\subsubsection{Choice and design of policy instruments}

Whether motivated primarily by a binding multilateral climate treaty or by some other set of factors, there is a growing set of policy instruments that countries have implemented or are considering to deal with climate change. Typically, these instruments will influence the decisions of firms and private individuals, so that policymakers try to anticipate how these agents will react to them.
Some policy instruments operate by mandating particular kinds of behaviour, such as the installation of pollution control technology or limits on emissions from particular sources. There is an extensive literature in political science demonstrating that the effects of these instruments are fairly predictable (Shapiro and McGarity, 1991) and are insensitive to market or regulatory uncertainties, simply because they prescribe particular technologies or practices which must be strictly adhered to. There is a literature in economics, however, suggesting that their very inflexibility makes them inefficient (Malueg, 1990; Jaffe and Stavins, 1995).

In the presence of substantial technological uncertainty, no matter what policy instrument is employed, interventions that shift investment behaviour from currently low cost to currently high cost technologies run the risk of increasing short-term costs and energy security concerns for consumers (Del Rio and Gual, 2007; Frondel et al., 2008, 2010). In some cases, long-term costs may be higher or lower, depending on how different technologies evolve over time (Williges et al., 2010; Reichenbach and Requate, 2012). This section is structured by considering two broad classes of interventions for targeting the energy supply: interventions that focus on emissions, by placing a market price or tax on $\mathrm{CO}_{2}$ or other greenhouse gases; and interventions that promote Research, Development, Deployment, and Diffusion (RDD\&D) of particular technologies. In both types of interventions, policy choices can be sensitive to uncertainties in technology costs, markets, and the state of regulation in other jurisdictions and over time. In the case of technology-oriented policy, choices are also sensitive to the risks that particular technologies present. We then describe instruments for reducing energy demand by focusing on lifestyle choice and energy efficient products and technologies. Finally, we briefly contrast the effects of uncertainties in the realm of climate change adaptation with climate change mitigation, recognizing that more detail on adaptation can be found in the WGII AR5.

\subsubsection{Instruments creating market penalties for GHG emissions}

Market-based instruments increase the cost of energy derived from fossil fuels, potentially leading firms involved in the production and conversion of energy to invest in low carbon technologies. Considerable research prior to AR4 identified the differences between two such instruments - carbon taxes and cap-and-trade regimes - with respect to uncertainty. Since AR4, research has examined the effects of regulatory risk and market uncertainty on one instrument or the other by addressing the following question: how is the mitigation investment decision affected by uncertainty with respect to whether and to what extent a market instrument and well-enforced regulations will be in place in the future?

Much of this research has focused on uncertainty with respect to carbon prices under a cap-and-trade system. A number of factors influence the relationship between the size of the cap and the market price that 
includes fossil fuel prices, consumer demand for energy, and economic growth more generally. Each of these factors can lead to volatility in carbon market prices (Alberola et al., 2008; Carraro et al., 2009; Chevallier, 2009). Vasa and Michaelowa (2011) assessed the impact of policy uncertainty on carbon markets and found that the possibility of easily creating and destroying carbon markets leads to extreme short-term rent-seeking behaviour and high volatility in market prices. Experience so far with the most developed carbon market-the European Emissions Trading System (ETS) - reveals high volatility marked by not-infrequent decreases of the price of carbon to very low values (Feng et al., 2011).

Numerous modelling studies have shown that regulatory uncertainty reduces the effectiveness of market-based instruments. More specifically, a current or expected carbon price induces a decrease in investment into lower carbon infrastructure and hence less technological learning, when there is uncertainty as to future market conditions, compared to the case where future conditions are known (Yang et al., 2008; Fuss et al., 2009; Oda and Akimoto, 2011). In order to compensate and maintain a prescribed level of change in the presence of uncertainty, carbon prices would need to be higher. Estimates of the additional macroeconomic costs range from 16-37\% (Blyth et al., 2007) to as much as $50 \%$ (Reinelt and Keith, 2007), depending on the particular type of investment under consideration. The precise instrument design details can affect investment behaviour. Patiño-Echeverri et al. $(2007,2009)$, for example, found that less frequent but larger regulatory policy changes had less of a negative interactive effect with uncertainty, while Zhao (2003) found a greater impact of uncertainty on the performance of a carbon tax than on a cap-and-trade system. Fan et al. (2010) added to this analysis by examining the sensitivity of these results to increasing risk aversion, under two alternative carbon market designs: one in which carbon allowances were auctioned by the government to firms, and a second in which existing firms received free allowances due to a grandfathering rule.

Under an auctioned system for carbon allowances, increasing risk aversion leads to greater investments in low carbon technologies. In contrast, under a grandfathered market design, increasing risk aversion combined with uncertainty pushes investment behaviour closer to what it would be in the absence of the carbon market: more investment in coal. The intuition behind this finding is that the grandfathered scheme would create a situation of windfall profits (since the freely allocated permits have a value to the firms receiving them), and riskaverse investors would be more influenced by the other, less desirable state of the world, the absence of carbon markets. Fan et al., (2012) replicated these results using a broader range of technological choices than in their earlier paper. Whereas these latter two papers used a game-theoretic model, Fuss et al., (2012) employed a real options theory model to arrive at qualitatively the same conclusions.

One option for reducing carbon price volatility is to set a cap or floor for that price to stabilize investment expectations (Jacoby and Ellerman, 2004; Philibert, 2009). Wood and Jotzo (2011) found that setting a price floor increased the effectiveness of the carbon price in stimulat- ing investments in low carbon technologies, given a particular expectation of macroeconomic drivers (e. g., economic growth and fossil fuel prices that influence the degree to which a carbon cap is a constraint on emissions). Szolgayova et al., (2008), using a real options model to examined the value of waiting for information, found the cap stabilized expectations. In the process, the cap lessened the effectiveness of an expected carbon price at altering investment behaviour, as many investments in low carbon technologies are undertaken only because of the possibility of very high carbon prices in the future. In another study assuming rational actor behaviour, Burtraw et al. (2010) found that a symmetric safety valve that sets both a floor and a ceiling price outperforms a single-sided safety valve in terms of both emissions reduction and economic efficiency. Murray et al. (2009) suggested that a reserve allowance for permits outperforms a simple safety valve in this regard.

Empirical research on the influence of uncertainty on carbon market performance has been constrained by the small number of functioning markets, thus making it difficult to infer the effects of differences in market design. The few studies to date suggest that the details of market design can influence the perception of uncertainty, and in turn the performance of the market. More specifically, investment behaviour into the Clean Development Mechanism (CDM) has been influenced by uncertainties in terms of what types of projects are eligible (Castro and Michaelowa, 2011), as well as the actual number of Certified Emissions Reductions (CERs) that can be acquired from a given project (Richardson, 2008).

Looking at the European Union's Emission Trading System (ETS), researchers have observed that expected carbon prices do affect investment behaviour, but primarily for investments with very short amortization periods. High uncertainty with respect to the longer-term market price of carbon has limited the ETS from having an impact on longer-term investments such as R\&D or new power plant construction (Hoffmann, 2007). Blyth and Bunn (2011) found that uncertainty for post-2012 targets was a major driver of ETS prices, with an effect of suppressing those prices. The literature suggests that prices have not been high enough to drive renewable energy investment in the absence of feed-in tariffs (Blanco and Rodrigues, 2008). Barbose et al. (2008) examined a region - the western United States-where no ETS was functioning but many believed that it would, and found that most utilities did consider the possibility of carbon prices in the range of USD 4 to USD 22 a ton. At the same time, the researchers could not determine whether this projection of carbon prices would have an actual effect on utilities' decisions, were an actual ETS in place, because they were unable to document the analysis underlying the utilities' investment decisions.

\subsubsection{Instruments promoting technological RDD\&D}

Several researchers suggest that future pathways for RDD\&D will be the determining factor for emissions reductions (Prins and Rayner, 2007; Lilliestam et al., 2012). Policy instruments can provide an incentive for firms not only to alter their investment portfolio towards low 
carbon technologies, but also to devote resources towards innovation (Baker et al., 2008). Because instruments differ in terms of how they influence behaviour, such as whether or not they create an immediate incentive or one that accrues over the lifetime of the investment, their relative effectiveness can be sensitive to relevant market uncertainties.

The literature reviewed in the previous section reveals that in the presence of substantial regulatory uncertainty, market-based instruments do a poor job of promoting RDD\&D. This has given rise to policy proposals to supplement a pure-market system with another instrument-such as a cap, floor, or escape valve-to reduce price volatility and stabilize expectations. By contrast, combining a market-based instrument with specific technology support can lead to greater volatility in the carbon price, even when there is very little uncertainty about which technologies will be assisted in the coming years (Blyth et al., 2009).

Several empirical studies with a focus on risk and uncertainty have compared the effectiveness of market instruments with other instruments such as feed-in tariffs or renewable quota systems, in stimulating low carbon investments and R\&D. Butler and Neuhoff (2008) compared the feed-in tariff in Germany with the quota system in the United Kingdom, and found the German system outperformed the UK system on two dimensions: stimulating overall investment quantity, and reducing costs to consumers. The primary driver was the effectiveness of the feed-in tariff in reducing risks associated with future revenues from the project investment, therefore making it possible to lower the cost of project financing. Other researchers replicate this finding using other case studies (Mitchell et al., 2006; Fouquet and Johansson, 2008). Lüthi and Wüstenhagen (2012) surveyed investors with access to a number of markets, and found that they steered their new projects to those markets with feed-in tariff systems, as it was more likely than other policy instruments to reduce their risks. Lüthi (2010) compared policy effectiveness across a number of jurisdictions with feed-in tariffs, and found that above a certain level of return, risk-related factors did more to influence investment than return-related factors.

Looking at the early stages in the technology development process, Bürer and Wüstenhagen (2009) surveyed 'green' tech venture capitalists in the United States and Europe using a stated preference approach to identify which policy instrument or instruments would reduce the perceived risks of investment in a particular technology. They identified a strong preference in both continents, but particularly Europe, for feed-in tariffs over cap-and-trade and renewable quota systems, because of the lower risks to return on investment associated with the former policy instrument. Moreover, venture capital investors typically look for short- to medium-term returns on their investment, for which the presence of feed-in tariffs has the greatest positive effect.

Held et al. (2006) identified patterns of success across a wide variety of policy instruments to stimulate investment in renewable energy technologies in Europe. They found that long-term regulatory consistency was vital for new technology development. Other studies have shown that regulatory inconsistency with respect to subsidy programs-such as feed-in tariffs in Spain or tax credits in the United States - can lead to temporarily overheated markets, pushing up investment costs and consumer prices, and reducing the pressure for technological development (Del Rio and Gual, 2007; Sáenz de Miera et al., 2008; Barradale, 2010).

In contrast to the large literature looking at the overall effects of uncertainty, there have only been a few empirical papers documenting the particular risks that concern investors the most. Leary and Esteban (2009) found regulatory uncertainty - particularly with respect to issues of siting - to concern investors in wave- and tide-based energy projects. Komendantova et al. (2012) examined perceptions among European investors in solar projects in North Africa, and found concerns about regulatory change and corruption were much greater than concerns about terrorism and technology risks. The same researchers modelled the sensitivity of required state subsidies for project development in response to these risks, and found the subsidies required to stimulate a given level of solar investment rose by a factor of three, suggesting large benefits from stemming corruption and stabilizing regulations (Komendantova et al., 2011). Meijer et al. (2007) examined the perceived risks for biogas project developers in the Netherlands, and found technological, resource, and political uncertainty to be their most important concerns. These studies are useful by documenting policymakers' concerns so they can address these issues in the future.

Table 2.3 synthesizes the modelling and empirical results on renewable quota systems and feed-in tariffs, as well as with results for cap-andtrade systems from the previous sub-section. The table highlights the

Table 2.3 | Uncertainties affecting the effectiveness of alternative policy instruments.

\begin{tabular}{|c|c|c|c|}
\hline Instrument & Uncertainty & Investor fears & $\begin{array}{c}\text { Effect on low carbon } \\
\text { technology }\end{array}$ \\
\hline \multirow{4}{*}{ Allowance trading market } & Technological systems & Other low carbon technologies will prove more cost-effective & Dampened investment \\
\hline & Market behaviour & Growth in energy demand will decline & Dampened investment \\
\hline & Market behaviour & Fossil fuel prices will fall & Dampened investment \\
\hline & Regulatory actions & Governments will increase the number of allowances & Dampened investment \\
\hline \multirow{2}{*}{ Renewable quotas } & Technological systems & Other low carbon technologies will prove more cost-effective & Dampened investment \\
\hline & Market behaviour & Supply for renewable energy will rise faster than the quota & Dampened investment \\
\hline Subsidies and feed-in tariffs & Regulatory actions & Subsidy for this particulartechnology will decline & Overheated market \\
\hline
\end{tabular}


effects of three of the classes of uncertainties identified earlier in this chapter, namely with respect to technological systems, market behaviour, and the future regulatory actions of governments.

\subsubsection{Energy efficiency and behavioural change}

As pointed out in Section 2.6.5.2 and earlier sections, one way to mitigate climate risk is to encourage RD\&D with respect to providing energy from renewable sources, such as wind and solar, as well as to promote low energy use products. For firms to undertake these investments, there needs to be some guarantee that a market for their products will exist. Currently consumers are reluctant to adopt energy efficient measures, such as compact fluorescent bulbs, energy efficient refrigerators, boilers and cooling systems, as well as new technologies such as solar installations and wind power. This can be attributed to the uncertainties associated with future energy prices and consumption of energy coupled with misperceptions of the products' benefits and an unwillingness to incur the upfront costs of these measures as discussed in Section 2.4.3.2.

Gardner and Stern (2008) identified a list of energy efficient measures that could reduce North American consumers' energy consumption by almost $30 \%$ but found that individuals were not willing to invest in them because they have misconceptions about the measures' effectiveness. Other studies show that the general public has a poor understanding of energy consumption associated with familiar activities (Sterman and Sweeney, 2007). A national online survey of 505 participants by Attari et al. (2010) revealed that most respondents felt that measures such as turning off the lights or driving less were much more effective as energy efficient improvements than experts' viewed them to be.

There are both behavioural and economic factors described in Section 2.4.3.2 that can explain the reluctance of households to incur the upfront costs of these energy efficient measures. Due to a focus on short-term horizons, individuals may underestimate the savings in energy costs from investing in energy efficient measures. In addition they are likely to discount the future hyperbolically so that the upfront cost is perceived to be greater than expected discounted reduction in energy costs (Dietz et al., 2013; Kunreuther et al., 2013b). Coupled with these descriptive models or choices that are triggered by intuitive thinking, households may have severe budget constraints that discourage them from investing in these energy efficient measures. If they intend to move in several years and feel that the investment in the energy efficient measure will not be adequately reflected in an increase in their property value, then it is inappropriate for them not to invest in these measures if they undertake deliberative thinking.

To encourage households to invest in energy efficient measures, messages that communicate information on energy use and savings from undertaking these investments need to be conveyed (Abrahamse et al., 2005). Recent research has indicated the importance of highlighting indirect and direct benefits (e.g., being 'green', energy independence, saving money) in people's adoption of energy efficiency measures to address the broad range and heterogeneity in people's goals and values that contribute to the subjective utility of different courses of action (Jakob, 2006). One also needs to recognize the importance of political identity considerations when choosing the nature of these messages, as different constituencies have different associations to options that mitigate climate change and labels that convey potential benefits from adopting energy efficient measures (Hardisty et al., 2010; Gromet et al., 2013).

The advent of the 'smart' grid in Western countries, with its 'smart' metering of household energy consumption and the development of 'smart' appliances will make it feasible to provide appliance-specific feedback about energy use and energy savings to a significant number of consumers within a few years. A field study involving more than 1,500 households in Linz, Austria revealed that feedback on electricity consumption corresponded with electricity savings of $4.5 \%$ for the average household in this pilot group (Schleich et al., 2013).

To deal with budget constraints, the upfront costs of these measures need to be spread over time so the measures are viewed as economically viable and attractive. The Property Assessed Clean Energy (PACE) programme in the United States is designed to address the budget constraint problem. Participants in this programme receive financing for improvements that is repaid through an assessment on their property taxes for up to 20 years. Financing spreads the cost of energy improvements over the expected life of measures such as weather sealing, energy efficient boilers and cooling systems, and solar installations and allows for the repayment obligation to transfer automatically to the next property owner if the property is sold. The program addresses two important barriers to increased adoption of energy efficiency and small-scale renewable energy: high upfront costs and fear that project costs will not be recovered prior to a future sale of the property (Kunreuther and Michel-Kerjan, 2011).

Social norms that encourage greater use of energy efficient technology at the household level can also encourage manufacturers to invest in the R\&D for developing new energy efficient technologies and public sector actions such as well-enforced standards of energy efficiency as part of building sale requirements, (Dietz et al., 2013).

\subsubsection{Adaptation and vulnerability reduction}

Compared to mitigation measures, investments in adaptation appear to be more sensitive to uncertainties in the local impacts associated with the damage costs of climate change. This is not surprising for two reasons. First, while both mitigation and adaptation may result in lower local damage costs associated with climate impacts, the benefits of adaptation flow directly and locally from the actions taken (Prato, 2008). Mitigation measures in one region or country, by contrast, deliver benefits that are global; however, they are contingent on the 
actions of people in other places and in the future, rendering their local benefits more uncertain. One cannot simply equate marginal local damage costs with marginal mitigation costs, and hence the importance of uncertainty with respect to the local damage costs is diminished (Webster et al., 2003).

Second, politically negotiated mitigation targets, such as the $2{ }^{\circ} \mathrm{C}$ threshold appear to have been determined by what is feasible and affordable in terms of the pace of technological diffusion, rather than by an optimization of mitigation costs and benefits (Hasselmann et al., 2003; Baker et al., 2008; Hasselmann and Barker, 2008). Hence, mitigation actions taken to achieve a temperature target would not be changed if the damage costs (local or global) were found to be somewhat higher or lower. This implies that mitigation measures will be insensitive to uncertainty of these costs associated with climate change. Adaptation decisions, in contrast, face fewer political and technical constraints, and hence can more closely track what is needed in order to minimize local expected costs and hence will be more sensitive to the uncertainties surrounding future damage costs from climate change (Patt et al., 2007, 2009).

There are two situations where decisions on adaptation policies and actions may be largely insensitive to uncertainties about the potential impacts of climate change on future damage. The first is where adaptation is constrained by the availability of finance, such as international development assistance. Studies by the World Bank, OECD, and other international organizations have estimated the financing needs for adaptation in developing countries to be far larger than funds currently available (Agrawala and Fankhauser, 2008; World Bank, 2010; Patt et al., 2010). In this case, adaptation actions are determined by decisions with respect to the allocation of available funds in competing regions rather than the local impacts of climate change on future damage (Klein et al., 2007; Hulme et al., 2011). Funding decisions and political constraints at the national level can also constrain adaptation so that choices no longer are sensitive to uncertainties with respect to local impacts (Dessai and Hulme, 2004, 2007).

The other situation is where adaptation is severely constrained by cultural norms and/or a lack of local knowledge and analytic skill as to what actions can be taken (Brooks et al., 2005; Füssel and Klein, 2006; O'Brien, 2009; Jones and Boyd, 2011). In this case, adaptive capacity could be improved through investments in education, development of local financial institutions and property rights systems, women's rights, and other broad-based forms of poverty alleviation. There is a growing literature to suggest that such policies bring substantial benefits in the face of climate change that are relatively insensitive to the precise nature and extent of local climate impacts (Folke et al., 2002; World Bank, 2010; Polasky et al., 2011). These policies are designed to reduce these countries' vulnerability to a wide range of potential risks rather than focusing on the impacts of climate change (Thornton et al., 2008; Eakin and Patt, 2011).

\subsubsection{Public support and opposition to climate policy}

In this section, we review what is known about public support or opposition to climate policy, climate-related infrastructure, and climate science. In all three cases, a critical issue is the role that perceptions of risks and uncertainties play in shaping support or opposition. Hence, the material presented here complements the discussion of perceptions of climate change risks and uncertainties (see Section 2.4.6). Policy discussions on particular technologies often revolve around the health and safety risks associated with technology options, transition pathways, and systems such as nuclear energy (Pidgeon et al., 2008; Whitfield et al., 2009), coal combustion (Carmichael et al., 2009; Hill et al., 2009), and underground carbon storage (Itaoka et al., 2009; Shackley et al., 2009). There are also risks to national energy security that have given rise to political discussions advocating the substitution of domestically produced renewable energy for imported fossil fuels (Eaves and Eaves, 2007; Lilliestam and Ellenbeck, 2011).

\subsubsection{Popular support for climate policy}

There is substantial empirical evidence that people's support or opposition to proposed climate policy measures is determined primarily by emotional factors and their past experience rather than explicit calculations as to whether the personal benefits outweigh the personal costs. A national survey in the United States found that people's support for climate policy also depended on cultural factors, with regionally differentiated worldviews playing an important role (Leiserowitz, 2006), as did a cross-national comparison of Britain and the United States (Lorenzoni and Pidgeon, 2006), and studies comparing developing with developed countries (Vignola et al., 2012).

One of the major determinants of popular support for climate policy is whether people have an underlying belief that climate change is dangerous. This concern can be influenced by both cultural factors and the methods of communication (Smith, 2005; Pidgeon and Fischhoff, 2011). Leiserowitz (2005) found a great deal of heterogeneity linked to cultural effects with respect to the perception of climate change in the United States. The use of language used to describe climate change - such as the distinction between 'climate change' and 'global warming' - play a role in influencing perceptions of risk, as well as considerations of immediate and local impacts (Lorenzoni et al., 2006). The portrayal of uncertainties and disagreements with respect to climate impacts was found to have a weak effect on whether people perceived the impacts as serious, but a strong effect on whether they felt that the impacts deserved policy intervention (Patt, 2007). Studies in China (Wang et al., 2012) and Austria (Damm et al., 2013) found that people's acceptance of climate-related policies was related to their underlying perceptions of risk but also to their beliefs about government responsibility. 
An important question related to climate change communication is whether the popular reporting of climate change through disaster scenarios has the effect of energizing people to support aggressive policy intervention, or to become dismissive of the problem. A study examining responses to fictionalized disaster scenarios found them to have differential effects on perceptions and support for policy. They reduced people's expectation of the local impacts, while increasing their support for global intervention (Lowe et al., 2006). Other studies found interactive effects: those with a low awareness of climate change became concerned about being exposed to disaster scenarios, while those with a high awareness of climate change were dismissive of the possible impacts (Schiermeier, 2004).

Finally, the extent to which people believe it is possible to actually influence the future appears to be a major determinant of their support for both individual and collective actions to respond to climate change. In the case of local climate adaptation, psychological variables associated with self-empowerment were found to have played a much larger role in influencing individual behaviour than variables associated with economic and financial ability (Grothmann and Patt, 2005; Grothmann and Reusswig, 2006). With respect to mitigation policy, perceptions concerning the barriers to effective mitigation and beliefs that it was possible to respond to climate change were found to be important determinants of popular support (Lorenzoni et al., 2007).

\subsubsection{Local support and opposition to infrastructure projects}

The issue of local support or opposition to infrastructure projects in implementing climate policy is related to the role that perceived technological risks play in the process. This has been especially important with respect to nuclear energy, but is of increasing concern for carbon storage and renewable energy projects, and has become a major issue when considering expansion of low carbon energy technologies (Ellis et al., 2007; Van Alphen et al., 2007; Zoellner et al., 2008).

In the case of renewable energy technologies, a number of factors appear to influence the level of public support or opposition, factors that align well with a behavioural model in which emotional responses are highly contextual. One such factor is the relationship between project developers and local residents. Musall and Kuik (2011) compared two wind projects, where residents feared negative visual impacts. They found that their fear diminished, and public support for the projects increased when there was co-ownership of the development by the local community. A second factor is the degree of transparency surrounding project development. Dowd et al. (2011) investigated perceived risks associated with geothermal projects in Australia. Using a survey instrument, they found that early, transparent communication of geothermal technology and risks tended to increase levels of public support.

A third such factor is the perception of economic costs and benefits that go hand-in-hand with the perceived environmental risks. Zoellner et al. (2008) examined public acceptance of three renewable technologies (grid-connected PV, biomass, and wind) and found that perceived economic risks associated with higher energy prices were the largest predictor of acceptance. Concerns over local environmental impacts, including visual impacts, were of concern where the perceived economic risks were high. Breukers and Wolsink (2007) also found that that the visual impact of wind turbines was the dominant factor in explaining opposition against wind farms. Their study suggests that public animosity towards a wind farm is partly reinforced by the planning procedure itself, such as when stakeholders perceive that norms of procedural justice are not being followed.

Many studies have assessed the risks and examined local support for carbon dioxide capture and storage (CCS). According to Ha-Duong et al. (1997), the health and safety risks associated with carbon dioxide capture and transportation technologies differ across causal pathways but are similar in magnitude to technologies currently supported by the fossil-fuel industry. Using natural analogues, Roberts et al. (2011) concluded that the health risks of natural $\mathrm{CO}_{2}$ seepage in Italy was significantly lower than many socially accepted risks. For example, it were three orders of magnitude lower than the probability of being struck by lightning.

Despite these risk assessments, there is mixed evidence of public acceptance of $\mathrm{CO}_{2}$ storage. For example, a storage research project was authorized in Lacq, France, but another was halted in Barendreich, The Netherlands due to public opposition. On the other hand, Van Alphen et al. (2007) evaluated the concerns with CCS among important stakeholders, including government, industry, and NGO representatives and found support if the facility could be shown to have a low probability of leakage and was viewed as a temporary measure.

Wallquist et al. (2012) used conjoint analysis to interpret a Swiss survey on the acceptability of CCS and found that concerns over local risks and impacts dominated the fears of the long-term climate impacts of leakage. The local concerns were less severe, and the public acceptance higher, for CCS projects combined with biomass combustion, suggesting that positive feelings about removing $\mathrm{CO}_{2}$ from the atmosphere, rather than simply preventing its emission into the atmosphere, influences perceptions of local risks. Terwel et al. (2011) found that support for CCS varied as a function of the stakeholders promoting and opposing it, in a manner similar to the debate on renewable energy. Hence, there was greater support of CCS when its promoters were perceived to be acting in the public interest rather than purely for profit. Those opposing CCS were less likely to succeed when they were perceived to be acting to protect their own economic interests, such as property values, rather than focusing on environmental quality and the public good.

In the period between the publication of AR4 and the accident at the Fukushima power plant in Japan in March 2011, the riskiness of nuclear power as a climate mitigation option has received increasing attention. Socolow and Glaser (2009) highlight the urgency of taking 
steps to reduce these risks, primarily by ensuring that nuclear fuels and waste materials are not used for weapons production. A number of papers examine the public's perceived risks of nuclear power. In the United States, Whitfield et al. (2009) found risk perceptions to be fairly stable over time, with those people expressing confidence in 'traditional values' perceiving nuclear power to be less risky than others. In the United Kingdom, Pidgeon et al. (2008) found a willingness to accept the risks of nuclear power when it was framed as a means of reducing the risks of climate change, but that this willingness largely dissipated when nuclear power was suggested as an alternative to renewable energy for accomplishing this same objective.

\subsection{Gaps in knowledge and data}

The interface between science and policy is affected by epistemic uncertainty or uncertainty due to lack of information or knowledge for characterizing phenomena. Below we characterize suggested areas for future research that may enable us to reduce epistemic uncertainty.

\section{Perceptions and responses to risk and uncertainty:}

- Examine cross-cultural differences in human perception and reaction to climate change and response options.

- Understand the rebound effect induced by adopting mitigation measures for reducing the impact of climate change (e.g., increased driving when switching to a more fuel efficient car).

- Consider the design of long-term mitigation and adaptation strategies coupled with short-term economic incentives to overcome myopic behaviour (e.g., loans for investing in energy efficient technologies so yearly payments are lower than the reduction in the annual energy bill).

- Encourage deliberative thinking in the design of policies to overcome biases such as a preference for the current state of affairs or business-as-usual.

- Understand judgment and choice processes of key decision makers in firms and policymakers, especially in a climate change response context.

- Use descriptive models and empirical studies to design strategies for climate change negotiations and implementation of treaties.

Tools and decision aids for improving choices related to climate change:

- Characterize the likelihood of extreme events and examine their impact on the design of climate change policies.

- Study how robust decision making can be used in designing climate policy options when there is uncertainty with respect to the likelihood of climate change and its impacts.
- Examine how integrated assessment models can quantify the value of new climate observing systems.

- Empirically study how decision makers could employ intuitive and deliberative thinking to improve decisions and climate policy choices.

- Study the effectiveness of experiential methods like simulations, games, and movies in improving public understanding and perception of climate change processes.

- Consider the role of structured expert judgment in characterizing the nature of uncertainties associated with climate change and the design of mitigation and adaptation policies for addressing this risk.

\section{Managing uncertainty risk and learning:}

- Exploit the effectiveness of social norms in promoting mitigation and adaptation.

- Quantify the environmental and societal risks associated with new technologies.

- Consider the special challenges faced by developing countries in dealing with risk and uncertainty with respect to climate change policies.

- Measure investor rankings of different risks associated with new technologies.

- Examine impact of government policy on mitigation decisions by firms and households.

- Determine what risks and uncertainties matter the most in developing policy instruments for dealing with climate change.

- Examine the risks to energy systems, energy markets, and the security of energy supply stemming from mitigation policies.

- Integrate analysis of the effects of interrelated policy decisions, such as how much to mitigate, what policy instruments to use for promoting climate change mitigation, and adaptation investment under conditions of risk and uncertainty.

\subsection{Frequently Asked Questions}

\section{FAQ 2.1 When is uncertainty a reason to wait and learn rather than acting now in relation to climate policy and risk management strategies? [Section 2.6.3]}

Faced with uncertainty, policymakers may have a reason to wait and learn before taking a particular action rather than taking the action now. Waiting and learning is desirable when external events are likely to generate new information of sufficient importance as to suggest that the planned action would be unwise. Uncertainty may not be a reason to delay when the action itself generates new information and knowledge. 
Uncertainty may also be a reason to avoid actions that are irreversible and/or have lock-in effects, such as making long-term investments in fossil-fuel based energy systems when climate outcomes are uncertain. This behaviour would reflect the precautionary principle for not undertaking some measures or activities.

While the above criteria are fairly easy to understand, their application can be complicated because a number of uncertainties relevant to a given decision may reinforce each other or may partially cancel each other out (e. g., optimistic estimates of technological change may offset pessimistic estimates of climate damages). Different interested parties may reach different conclusions as to whether external information is likely or not to be of sufficient importance as to render the original action/inaction regrettable.

A large number of studies examine the act-now-or-wait-and-see question in the context of climate change mitigation. So far, most of these analyses have used integrated assessment models (IAMs). At the national level, these studies examine policy strategies and instruments to achieve mitigation targets; at the firm or individual level the studies examine whether one should invest in a particular technology.

A truly integrated analysis of the effects of multiple types of uncertainty on interrelated policy decisions, such as how much to mitigate, with what policy instruments, promoting what investments, has yet to be conducted. The probabilistic information needed to support such an analysis is currently not available.

\section{FAQ 2.2 How can behavioural responses and tools for improving decision making impact on climate change policy? [Section 2.4]}

The choice of climate change policies can benefit from examining the perceptions and responses of relevant stakeholders. Empirical evidence indicates decision makers such as firms and households tend to place undue weight on short-run outcomes. Thus, high upfront costs make them reluctant to invest in mitigation or adaptation measures. Consistent with the theory of loss aversion, investment costs and their associated risks have been shown to be of greater importance in decisions to fund projects that mitigate climate change than focusing on the expected returns associated with the investment.

Policy instruments (e.g., long-term loans) that acknowledge these behavioural biases and spread upfront costs over time so that they yield net benefits in the short-run have been shown to perform quite well. In this context, policies that make investments relatively risk free, such as feed-in tariffs, are more likely to stimulate new technology than those that focus on increasing the expected price such as capand-trade systems.
Human responses to climate change risks and uncertainties can also indicate a failure to put adequate weight on worst-case scenarios. Consideration of the full range of behavioural responses to information will enable policymakers to more effectively communicate climate change risks to stakeholders and to design decision aids and climate change policies that are more likely to be accepted and implemented.

\section{FAQ 2.3 How does the presence of uncertainty affect the choice of policy instruments? [Section 2.6.5]}

Many climate policy instruments are designed to provide decision makers at different levels (e.g., households, firms, industry associations, guilds) with positive incentives (e.g., subsidies) or penalties (e.g., fines) to incentivize them to take mitigation actions. The impact of these incentives on the behaviour of the relevant decision makers depends on the form and timing of these policy instruments.

Instruments such as carbon taxes that are designed to increase the cost of burning fossil fuels rely on decision makers to develop expectations about future trajectories of fuel prices and other economic conditions. As uncertainty in these conditions increases, the responsiveness of economic agents decreases. On the other hand, investment subsidies and technology standards provide immediate incentives to change behaviour, and are less sensitive to long-term market uncertainty. Feed-in tariffs allow investors to lock in a given return on investment, and so may be effective even when market uncertainty is high.

\section{FAQ 2.4 What are the uncertainties and risks that are of particular importance to climate policy in developing countries? [Box 2.1]}

Developing countries are often more sensitive to climate risks, such as drought or coastal flooding, because of their greater economic reliance on climate-sensitive primary activities, and because of inadequate infrastructure, finance, and other enablers of successful adaptation and mitigation. Since AR4, research on relevant risks and uncertainties in developing countries has progressed substantially, offering results in two main areas.

Studies have demonstrated how uncertainties often place low carbon energy sources at an economic disadvantage, especially in developing countries. The performance and reliability of new technologies may be less certain in developing countries than in industrialized countries because they could be unsuited to the local context and needs. Other reasons for uncertain performance and reliability could be due 
to poor manufacturing, a lack of adequate testing in hot or dusty environments, or limited local capacity to maintain and repair equipment. Moreover, a number of factors associated with economic, political, and regulatory uncertainty result in much higher real interest rates in developing countries than in the developed world. This creates a disincentive to invest in technologies with high upfront but lower operating costs, such as renewable energy, compared to fossil-fuel based energy infrastructure.
Given the economic disadvantage of low carbon energy sources, important risk tradeoffs often need to be considered. On the one hand, low-carbon technologies can reduce risks to health, safety, and the environment, such as when people replace the burning of biomass for cooking with modern and efficient cooking stoves. But on the other hand, low-carbon modern energy is often more expensive than its higher-carbon alternatives. There are however, some opportunities for win-win outcomes on economic and risk grounds, such as in the case of off-grid solar power. 


\section{References}

Abrahamse W., L. Steg, C. Vlek, and T. Rothengatter (2005). A review of intervention studies aimed at household energy conservation. Journal of Environmental Psychology 25, 273-291.

$\mathrm{ACl}$ (2004). Impacts of a Warming Arctic-Arctic Climate Impact Assessment. Impacts of a Warming Arctic-Arctic Climate Impact Assessment, by Arctic Climate Impact Assessment, Pp. 144. ISBN 0521617782. Cambridge, UK: Cambridge University Press, December 2004.

Ackerman F., E.A. Stanton, and R. Bueno (2010). Fat tails, exponents, extreme uncertainty: Simulating catastrophe in DICE. Ecological Economics 69, 1657-1665.

Ackerman F., E.A. Stanton, and R. Bueno (2013). Epstein-Zin Utility in DICE: Is Risk Aversion Irrelevant to Climate Policy? Environmental and Resource Economics 56, 73-84. doi: 10.1007/s10640-013-9645-Z, ISSN: 0924-6460, 1573-1502.

Agrawala S., and S. Fankhauser (2008). Economic Aspects of Adaptation to Climate Change: Costs, Benefits and Policy Instruments. OECD Publishing, 139 pp. ISBN: 9789264046030.

Alberola E., J. Chevallier, and B. Cheze (2008). Price drivers and structural breaks in European carbon prices 2005-2007. Energy Policy 36, 787-797. doi: 10.1016/j.enpol.2007.10.029.

Alcott H. (2011). Social norms and energy conservation. Journal of Public Economics 95, 1082-1095.

Ale B.J.M., L.J. Bellamy, R. Van der Boom, J. Cooper, R.M. Cooke, L. H.J. Goossens, A. R. Hale, D. Kurowicka, O. Morales, A. L. C. Roelen, and others (2009). Further development of a Causal model for Air Transport Safety (CATS): Building the mathematical heart. Reliability Engineering \& System Safety 94, 1433-1441.

Allais M. (1953). Le comportement de l'homme rationel devant le risque. Econometrica 21, 503-546.

Van Alphen K., Q. Van Voorst Tot Voorst, M.P. Hekkert, and R. E.H. Smits (2007). Societal acceptance of carbon capture and storage technologies. Energy Policy 35, 4368-4380.

America's Climate Choices: Panel on Advancing the Science of Climate Change; National Research Council (2010). Advancing the Science of Climate Change. The National Academies Press, Washington, D.C., 528 pp. ISBN: 0309145880.

Andonova L., M. Betsill, and H. Bulkeley (2009). Transnational climate governance. Global Environmental Politics 9, 52-73. doi: 10.1162/glep.2009.9.2.52.

Armitage D. (2011). Co-management and the co-production of knowledge: Learning to adapt in Canada's Arctic. Symposium on Social Theory and the Environment in the New World (dis)Order, 21(3), 995-1004.

Aspinall W.P. (1996). Structured elicitation of expert judgment for probabilistic hazard and risk assessment in volcanic eruptions. In: Mader, H. M., Coles, S. G., Connor, C. B. \& Connor, L.J. (eds.) Statistics in Volcanology. Special Publications of IAVCEI. Geological Society, London, pp. 15-30.

Aspinall W.P. (2010). A route to more tractable expert advice. Nature 463, 294-295. doi: 10.1038/463294a, ISSN: 0028-0836.

Athanassoglou S., and A. Xepapadeas (2011). Pollution control with uncertain stock dynamics: When, and how, to be precautious. Journal of Environmental Economics and Management 63, 304-320.
Attari S.Z., M.L. DeKay, C.I. Davidson, and W. B. de Bruin (2010). Public perceptions of energy consumption and savings. Proceedings of the National Academy of Sciences 107, 16054-16059.

Axelrod M. (2011). Climate Change and Global Fisheries Management: Linking Issues to Protect Ecosystems or to Save Political Interests? Global Environmental Politics 11, 64-84. doi: 10.1162/GLEP_a_00069.

Azar C., and K. Lindgren (2003). Catastrophic Events and Stochastic Costbenefit Analysis of Climate Change. Climatic Change 56, 245-255. doi: 10.1023/A:1021743622080, ISSN: 0165-0009.

Bahn O., A. Haurie, and R. Malhamé (2008). A stochastic control model for optimal timing of climate policies. Automatica 44, 1545-1558. doi: 10.1016/j.automatica.2008.03.004, ISSN: 0005-1098.

Baker E. (2005). Uncertainty and learning in a strategic environment: Global climate change. Resource and Energy Economics 27, 19-40.

Baker E., and K. Adu-Bonnah (2008). Investment in risky R\&D programs in the face of climate uncertainty. Energy Economics 30, 465-486. doi: 10.1016/j. eneco.2006.10.003, ISSN: 0140-9883.

Baker E., L. Clarke, and E. Shittu (2008). Technical change and the marginal cost of abatement. Energy Economics 30, 2799-2816.

Baker E., L. Clarke, and J. Weyant (2006). Optimal Technology R\&D in the Face of Climate Uncertainty. Climatic Change 78, 157-179. doi: 10.1007/s10584-0069092-8, ISSN: 0165-0009.

Baker E., and J.M. Keisler (2011). Cellulosic biofuels: Expert views on prospects for advancement. Energy 36, 595-605.

Baker E., and E. Shittu (2006). Profit-maximizing R\&D in response to a random carbon tax. Resource and Energy Economics 28, 160-180. doi: 10.1016/j.reseneeco.2005.08.002, ISSN: 0928-7655.

Baker E., and E. Shittu (2008). Uncertainty and endogenous technical change in climate policy models. Energy Economics 30, 2817-2828.

Bamber J., and W. Aspinall (2013). An expert judgement assessment of future sea level rise from the ice sheets. Nature Climate Change 3, 424-427. Available at: http://cat.inist.fr/?aModele=afficheN\&cpsidt=27221118.

Baranzini A., M. Chesney, and J. Morisset (2003). The impact of possible climate catastrophes on global warming policy. Energy Policy 31, 691-701. doi: 10.101 6/S0301-4215(02)00101-5, ISSN: 0301-4215.

Barbose G., R. Wiser, A. Phadke, and C. Goldman (2008). Managing carbon regulatory risk in utility resource planning: Current practices in the Western United States. Energy Policy 36, 3300-3311. doi: 10.1016/j.enpol.2008.04.023, ISSN: 0301-4215.

Barham B., J.P. Chavas, D. Fitz, V. Rios Salas, and L. Schechter (2014). The Roles of Risk and Ambiguity in Technology Adoption. Journal of Economic Behavior \& Organization 97, 204-218.

Barradale M.J. (2010). Impact of public policy uncertainty on renewable energy investment: Wind power and the production tax credit. Energy Policy 38, 7698-7709. Available at: http://www.sciencedirect.com/science/article/pii/ S0301421510006361.

Barreto I., and D. Patient (2013). Toward a theory of intraorganizational attention based on desirability and feasibility factors. Strategic Management Journal, 34(6), 687-703.

Barrett S. (1994). Self-enforcing international environmental agreements. Oxford Economic Papers 46, 878-894.

Barrett S. (2013). Climate treaties and approaching catastrophes. Journal of Environmental Economics and Management 66, 235-250. 
Barrett S., and A. Dannenberg (2012). Climate negotiations under scientific uncertainty. Proceedings of the National Academy of Sciences 109, 17372-17376. doi: 10.1073/pnas.1208417109, ISSN: 0027-8424, 1091-6490.

Barry J., G. Ellis, and C. Robinson (2008). Cool Rationalities and Hot Air: A Rhetorical Approach to Understanding Debates on Renewable Energy. Global Environmental Politics 8, 67-98. doi: 10.1162/glep.2008.8.2.67, ISSN: 1526-3800.

Battaglini A., J. Lilliestam, A. Haas, and A. Patt (2009). Development of SuperSmart Grids for a more efficient utilisation of electricity from renewable sources. Journal of Cleaner Production 17, 911-918.

Baudry M. (2000). Joint management of emission abatement and technological innovation for stock externalities. Environmental and Resource Economics 16, 161-183. doi: 10.1023/A:1008363207732, ISSN: 0924-6460.

BBC World Service Trust (2009). Research Briefing Ethiopia. BBC World Service Trust, London, UK. Available at: http://r4d.dfid.gov.uk/PDF/Outputs/ MediaBroad/climatebrief-ethopia_web.pdf.

Beck U. (1992). Risk Society: Towards a New Modernity. Sage Publications Ltd, 272 pp. ISBN: 0803983468.

Berkes F., J. Colding, and C. Folke (2000). Rediscovery of traditional ecological knowledge as adaptive management. Ecological Applications 10, 1251-1262.

Berkes F., and D. Jolly (2001). Adapting to climate change: social-ecological resilience in a Canadian western Arctic community. Conservation Ecology 5(2), 18.

Betsill M., and M.J. Hoffmann (2011). The contours of "cap and trade": the evolution of emissions trading systems for greenhouse gases. Review of Policy Research 28, 83-106.

Blackstock J. J., and J. C. Long (2010). The politics of geoengineering. Science 327, 527-527. Available at: http://www.sciencemag.org/content/327/5965/527. short.

Blanco M.I., and G. Rodrigues (2008). Can the future EU ETS support wind energy investments? Energy Policy 36.4, 1509-1520.

Blanford G.J. (2009). R\&D investment strategy for climate change. Energy Economics 31, Supplement 1, S27-S36. doi: 10.1016/j.eneco.2008.03.010, ISSN: 0140-9883.

Blok K. (2006). Special issue: Renewable energy policies in the European Union. Energy Policy 34, 251-375.

Blyth W., R. Bradley, D. Bunn, C. Clarke, T. Wilson, and M. Yang (2007). Investment risks under uncertain climate change policy. Energy Policy 35, 5766-5773. doi: 16/j.enpol.2007.05.030, ISSN: 0301-4215.

Blyth W., and D. Bunn (2011). Coevolution of policy, market and technical price risks in the EU ETS. Energy Policy 39, 4578-4593.

Blyth W., D. Bunn, J. Kettunen, and T. Wilson (2009). Policy interactions, risk and price formation in carbon markets. Energy Policy 37, 5192-5207. doi: 10.1016/j.enpol.2009.07.042, ISSN: 0301-4215.

Boardman A.E., D.H. Greenberg, A.R. Vining, and D.L. Weimer (2005). Cost Benefit Analysis: Concepts and Practice. Prentice Hall, ISBN: 0131435833.

De Boer J., J.A. Wardekker, and J.P. Van Der Sluijs (2010). Frame-based guide to situated decision-making on climate change. Global Environmental Change 20, 502-510.

Bord R.J., R.E. O'Connor, and A. Fisher (2000). In what sense does the public need to understand global climate change? Public Understanding of Science $\mathbf{9}$, 205-218. Available at: http://pus.sagepub.com/content/9/3/205.short.

Bosetti V., C. Carraro, A. Sgobbi, and M. Tavoni (2009). Delayed action and uncertain stabilisation targets. How much will the delay cost? Climatic Change 96, 299-312. doi: 10.1007/s10584-009-9630-2, ISSN: 0165-0009.
Bosetti V., and M. Tavoni (2009). Uncertain R\&D, backstop technology and GHGs stabilization. Energy Economics 31, S18-S26.

Bostrom A., M.G. Morgan, B. Fischhoff, and D. Read (1994). What do people know about global climate change? 1. Mental models. Risk Analysis 14, 959-970. doi: 10.1111/j.1539-6924.1994.tb00065.x, ISSN: 1539-6924.

Böttcher H., K. Eisbrenner, S. Fritz, G. Kindermann, F. Kraxner, I. McCallum, and M. Obersteiner (2009). An assessment of monitoring requirements and costs of "Reduced Emissions from Deforestation and Degradation." Carbon Balance and Management 4, 7.

Böttcher H., A. Freibauer, M. Obersteiner, and E.D. Schulze (2008). Uncertainty analysis of climate change mitigation options in the forestry sector using a generic carbon budget model. Ecological Modelling 213, 45-62.

Bradfield R., G. Wright, G. Burt, G. Cairns, and K. Van Der Heijden (2005). The origins and evolution of scenario techniques in long range business planning. Futures 37, 795-812. Available at: http://www.sciencedirect.com/science/ article/pii/S0016328705000042.

Brent R. J. (2006). Applied Cost-Benefit Analysis. Edward Elgar Publishing.

Breukers S., and M. Wolsink (2007). Wind power implementation in changing institutional landscapes: An international comparison. Energy Policy 35, 2737-2750. ISSN: 0301-4215.

Brooks N., W. N. Adger, and P. M. Kelly (2005). The determinants of vulnerability and adaptive capacity at the national level and the implications for adaptation. Global Environmental Change Part A 15, 151-163.

Bruckner T., and K. Zickfeld (2008). Inverse Integrated Assessment of Climate Change: the Guard-rail Approach. International Conference on Policy Modeling (EcoMod2008).

Brulle R.J., J. Carmichael, and J.C. Jenkins (2012). Shifting public opinion on climate change: an empirical assessment of factors influencing concern over climate change in the U.S., 2002-2010. Climatic Change 114, 169-188. doi: 10.1007/s10584-012-0403-y, ISSN: 0165-0009, 1573-1480.

Bucki M., D. Cuypers, P. Mayaux, F. Achard, C. Estreguil, and G. Grassi (2012) Assessing REDD+ performance of countries with low monitoring capacities: the matrix approach. Environmental Research Letters 7, 014031. doi: 10.1088/174 8-9326/7/1/014031, ISSN: 1748-9326.

Budescu D.V., S. Broomell, and H.-H. Por (2009). Improving communication of uncertainty in the reports of the Intergovernmental Panel on Climate Change. Psychological Science 20, 299-308. doi: 10.1111/j.1467-9280.2009.02284.x.

Bulkeley H. (2010). Cities and the governing of climate change. Annual Review of Environment and Resources 35, 229-253.

Bürer M.J., and R. Wüstenhagen (2009). Which renewable energy policy is a venture capitalist's best friend? Empirical evidence from a survey of international cleantech investors. Energy Policy 37, 4997-5006. doi: 10.1016/j. enpol.2009.06.071, ISSN: 0301-4215.

Burtraw D., K. Palmer, and D. Kahn (2010). A symmetric safety valve. Energy Policy 38, 4921-4932. doi: 10.1016/j.enpol.2010.03.068, ISSN: 0301-4215.

Butler L., and K. Neuhoff (2008). Comparison of feed-in tariff, quota and auction mechanisms to support wind power development. Renewable Energy 33, 1854-1867. doi: 10.1016/j.renene.2007.10.008, ISSN: 0960-1481.

Buys P., U. Deichmann, C. Meisner, T. Ton-That, and D. Wheeler (2009). Country stakes in climate change negotiations: two dimensions of vulnerability. Climate Policy 9, 288-305. 
Cabantous L., D. Hilton, H. Kunreuther, and E. Michel-Kerjan (2011). Is imprecise knowledge better than conflicting expertise? Evidence from insurers' decisions in the United States. Journal of Risk and Uncertainty 42, 211-232. Available at: http://link.springer.com/article/10.1007/s11166-011-9117-1.

Cabré M.M. (2011). Issue-linkages to climate change measured through NGO participation in the UNFCCC. Global Environmental Politics 11, 10-22. doi: 10.1162/GLEP_a_00066, ISSN: 1526-3800.

Camerer C. F. (2000). Prospect Theory in the wild. In: Choice, Values, and Frames. D. Kahneman, A. Tversky, eds. Cambridge University Press, New York.

Camerer C.F., and H. Kunreuther (1989). Decision processes for low probability events: Policy implications. Journal of Policy Analysis and Management 8, 565-592. doi: 10.2307/3325045, ISSN: 1520-6688.

Caney S. (2011). Climate Change, Energy Rights and Equality. Climate Change. In: The Ethics of Global Climate Change. D. Arnold, (ed.), Cambridge University Press, pp. 77-103.

De Canio S.J., and A. Fremstad (2013). Game theory and climate diplomacy. Ecological Economics 85, 177-187. Available at: http://www.sciencedirect. com/science/article/pii/S0921800911001698.

Carmichael G.R., B. Adhikary, S. Kulkarni, A. D'Allura, Y. Tang, D. Streets, Q. Zhang, T. C. Bond, V. Ramanathan, A. Jamroensan, and P. Marrapu (2009). Asian aerosols: Current and year 2030 distributions and implications to human health and regional climate change. Environ. Sci. Technol. 43, 5811-5817. doi: 10.1021/es8036803, ISSN: 0013-936X.

Carraro C., V. Bosetti, E. De Cian, R. Duval, E. Massetti, and M. Tavoni (2009). The incentives to participate in and the stability of international climate coalitions: a game theoretic approach using the WITCH Model. Working Papers.

Castro P., and A. Michaelowa (2011). Would preferential access measures be sufficient to overcome current barriers to CDM projects in least developed countries? Climate and Development 3, 123-142.

Chan G.L., L. Diaz Anadon, M. Chan, and A. Lee (2010). Expert Elicitation of Cost, Performance, and RD\&D Budgets for Coal Power with CCS. Working Paper, Energy Technology Innovation Policy Research Group, Belfer Center for Science and International Affairs, Harvard Kennedy School.

Charlesworth M., and C. Okereke (2010). Policy responses to rapid climate change: An epistemological critique of dominant approaches. Global Environmental Change 20, 121-129. Available at: http://www.sciencedirect. com/science/article/pii/S0959378009000727.

Charnes A., and W.W. Cooper (1959). Chance-Constrained Programming. Management Science 6, 73-79. doi: 10.1287/mnsc.6.1.73.

Chevallier J. (2009). Carbon futures and macroeconomic risk factors: A view from the EU ETS. Energy Economics 31, 614-625. doi: 10.1016/j.eneco.2009.02.008, ISSN: 0140-9883.

Chichilnisky G., and G. Heal (1993). Global environmental risks. The Journal of Economic Perspectives 7, 65-86. ISSN: 0895-3309.

Ciriacy-Wantrup S.V. (1971). The economics of environmental policy. Land Economics 47, 36-45.

Clarke H.R., and W.J. Reed (1994). Consumption/pollution tradeoffs in an environment vulnerable to pollution-related catastrophic collapse. Journal of Economic Dynamics and Control 18, 991-1010. doi: 10.1016/0165-1889(94)900 42-6, ISSN: 0165-1889.

Cohen M.D., J.G. March, and J.P. Olsen (1972). A garbage can model of organizational choice. Administrative Science Quarterly 17, 1-25. doi: 10.2307/2392088, ISSN: 0001-8392.
Collins H.M. (1985). Changing Order: Replication and Induction in Scientific Practice. Sage Publications, 208 pp. ISBN: 9780803997578.

De Coninck H., C. Fischer, R.G. Newell, and T. Ueno (2008). International technology-oriented agreements to address climate change. Energy Policy 36, 335-356.

Conliffe A. (2011). Combating ineffectiveness: climate change bandwagoning and the UN Convention to Combat Desertification. Global Environmental Politics $11,44-63$.

Cooke R. M. (1991). Experts in Uncertainty: Opinion and Subjective Probability in Science. Oxford University Press, USA, 321 pp.

Cooke R.M. (2012). Model uncertainty in economic impacts of climate change: Bernoulli versus Lotka Volterra dynamics. Integrated Environmental Assessment and Management, n/a-n/a. doi: 10.1002/ieam.1316, ISSN: 1551-3793.

Cooke R.M., and L.L.H.J. Goossens (2008). TU Delft expert judgment data base. Reliability Engineering \& System Safety 93, 657-674.

Cooper R.N. (1989). International cooperation in public health as a prologue to macroeconomic cooperation. In: Can Nations Agree? R. N. Cooper, et al. (eds.). Brookings Institution, Washington, DC, pp. 178-254.

Corner A., and U. Hahn (2009). Evaluating science arguments: Evidence, uncertainty, and argument strength. Journal of Experimental Psychology: Applied 15, 199. Available at: http://psycnet.apa.org/journals/xap/15/3/199/.

Cronin M., C. Gonzalez, and J. Sterman (2009). Why don't well-educated adults understand accumulation? A challenge to researchers, educators and citizens. Organizational Behavior and Human Decision Processes 108, 116-130.

Crost B., and C.P. Traeger (2013). Optimal climate policy: Uncertainty vs Monte Carlo. Economics Letters 120, 552-558. Available at: http://www.sciencedirect. com/science/article/pii/S0165176513002565.

Cullen H. (2010). The Weather of the Future: Heat Waves, Extreme Storms, and Other Scenes from a Climate-Changed Planet. HarperCollins, 358 pp. ISBN: 9780061726880.

Curtright A.E., M.G. Morgan, and D.W. Keith (2008). Expert assessments of future photovoltaic technologies. Environmental Science and Technology 42, 9031-9038.

Cyert R., and J. March (1963). A Behavioral Theory of the Firm. Prentice Hall, Englewood Cliffs, $364 \mathrm{pp}$.

Damm A., K. Eberhard, J. Sendzimir, and A. Patt (2013). Perception of landslides risk and responsibility: a case study in eastern Styria, Austria. Natural Hazards, 1-19. doi: 10.1007/s11069-013-0694-y, ISSN: 0921-030X.

Dechezleprêtre A., M. Glachant, I. Haščič, N. Johnstone, and Y. Ménière (2011). Invention and transfer of climate change-mitigation technologies: A global analysis. Review of Environmental Economics and Policy 5, 109-130.

Dessai S., and M. Hulme (2004). Does climate adaptation policy need probabilities. Climate Policy 4, 107-128.

Dessai S., and M. Hulme (2007). Assessing the robustness of adaptation decisions to climate change uncertainties: A case study on water resources management in the East of England. Global Environmental Change 17, 59-72. doi: 16/j. gloenvcha.2006.11.005, ISSN: 0959-3780.

Dietz S. (2011). High impact, low probability? An empirical analysis of risk in the economics of climate change. Climate Change 108 (3), 519-541.

Dietz T., P. Stern, and E.U. Weber (2013). Reducing carbon-based energy consumption through changes in household behavior. Daedalus, 142.1: 78-79. 
Ding D., E.W. Maibach, X. Zhao, C. Roser-Renouf, and A. Leiserowitz (2011). Support for climate policy and societal action are linked to perceptions about scientific agreement. Nature Climate Change 1, 462-466. Available at: http://www. nature.com/nclimate/journal/vaop/ncurrent/full/nclimate1295.html.

Dinner I., E.J. Johnson, D.G. Goldstein, and K. Liu (2011). Partitioning default effects: Why people choose not to choose. Journal of Experimental Psychology: Applied 17, 332. Available at: http://psycnet.apa.org/journals/xap/17/4/332/.

Dodgson J. S., M. Spackman, A. Pearman, and L.D. Phillips (2009). Multi-Criteria Analysis: A Manual. Department for Communities and Local Government: London, Available at: http://eprints.Ise.ac.uk/12761/1/Multi-criteria_Analysis. pdf.

Dowd A.M., N. Boughen, P. Ashworth, and S. Carr-Cornish (2011). Geothermal technology in Australia: Investigating social acceptance. Energy Policy 39, 6301-6307.

Dumas P., and M. Ha-Duong (2005). An Abrupt Stochastic Damage Function to Analyze Climate Policy Benefits. Advances in Global Change Research. In: The Coupling of Climate and Economic Dynamics. A. Haurie, L. Viguier, (eds.), Springer Netherlands, pp. 97-111. ISBN: 978-1-4020-3425-1.

Durand-Lasserve 0., A. Pierru, and Y. Smeers (2010). Uncertain long-run emissions targets, $\mathrm{CO}_{2}$ price and global energy transition: A general equilibrium approach. Energy Policy 38, 5108-5122. Available at: http://www. sciencedirect.com/science/article/pii/S0301421510003150.

Dutt V. (2011). Why do we want to defer actions on climate change? A psychological perspective. Carnegie Mellon University. Available at: http://www.hss.cmu. edu/departments/sds/ddmlab/papers/GonzalezDutt2011_psychreview.pdf.

Dutt V., and C. Gonzalez (2011). Human control of climate change. Climatic Change 111, 497-518. Available at: http://www.springerlink. com/index/8351601768q73873.pdf.

Dutt V., and C. Gonzalez (2013). Climate Risk Communication: Effects of cost, timing, and probability of climate consequences in decisions from description and experience. In: Psychology of Policy Making. Nova Science Publishers, Hauppauge, New York.

Eakin H.C., and A. Patt (2011). Are adaptation studies effective, and what can enhance their practical impact? Wiley Interdisciplinary Reviews: Climate Change 2, 141-153.

Eaves J., and S. Eaves (2007). Renewable corn-ethanol and energy security. Energy Policy 35, 5958-5963. doi: 10.1016/j.enpol.2007.06.026, ISSN: 0301-4215.

ECLACS (2011). The Economics of Climate Change in the Caribbean. Summary Report 2011. UNECLAC/ POS.

Ehrhardt-Martinez K., and J.A. Laitner (2010). Rebound, technology and people: Mitigating the rebound effect with energy-resource management and peoplecentered initiatives. Proceedings of the 2010 ACEEE Summer Study on Energy Efficiency in Buildings, 76-91. Available at: http://rste040vlmp01.blackmesh. com/files/proceedings/2010/data/papers/2142.pdf.

Eisner M.J., R.S. Kaplan, and J.V. Soden (1971). Admissible Decision Rules for the E-Model of Chance-Constrained Programming. Management Science 17, 337-353. ISSN: 0025-1909.

Ellis G., J. Barry, and C. Robinson (2007). Many ways to say no, different ways to say yes: Applying Q-Methodology to understand public acceptance of wind farm proposals. Journal of Environmental Planning and Management 50, 517-551. ISSN: 0964-0568.

Ellsberg D. (1961). Risk, Ambiguity, and the Savage Axioms. The Quarterly Journal of Economics 75, 643-669. doi: 10.2307/1884324, ISSN: 0033-5533.
Den Elzen M., and D. van Vuuren (2007). Peaking profiles for achieving long-term temperature targets with more likelihood at lower costs. Proceedings of the National Academy of Sciences 104, 17931-17936. doi: 10.1073/pnas.0701598104.

Engle-Warnick J., and S. Laszlo (2006). Learning-by-Doing in an Ambiguous Environment. CIRANO Working Papers 2006s-29, CIRANO.

Fan L., B. F. Hobbs, and C.S. Norman (2010). Risk aversion and $\mathrm{CO}_{2}$ regulatory uncertainty in power generation investment: Policy and modeling implications. Journal of Environmental Economics and Management 60, 193-208. doi: 10.1016/j.jeem.2010.08.001, ISSN: 0095-0696.

Fan L., C. S. Norman, and A. Patt (2012). Electricity capacity investment under risk aversion: A case study of coal, gas, and concentrated solar power. Energy Economics 34, 54-61. doi: 10.1016/j.eneco.2011.10.010, ISSN: 0140-9883.

Farzin Y.H., and P. M. Kort (2000). Pollution Abatement Investment When Environmental Regulation Is Uncertain. Journal of Public Economic Theory 2, 183-212. Available at: http://ideas.repec.org/a/bla/jpbect/v2y2000i2p183-212.html.

Feltovich P.J., M.J. Prietula, and K.A. Ericsson (2006). Studies of expertise from psychological perspectives. In: The Cambridge Handbook of Expertise and Expert Performance. K.A. Ericsson, N. Charness, P.J. Feltovich, R.R. Hoffman, (eds.), Cambridge University Press, Available at: http://psycnet.apa.org/ psycinfo/2006-10094-004.

Feng Z.H., L.L. Zou, and Y.M. Wei (2011). Carbon price volatility: Evidence from EU ETS. Applied Energy 88, 590-598.

Figner B., and E.U. Weber (2011). Who takes risks when and why? Current Directions in Psychological Science 20, 211-216.

Finucane M. L., A. Alhakami, P. Slovic, and S. M. Johnson (2000). The affect heuristic in judgments of risks and benefits. Journal of Behavioral Decision Making $13,1-17$.

Fischer C., and R.G. Newell (2008). Environmental and technology policies for climate mitigation. Journal of Environmental Economics and Management 55, 142-162. Available at: http://www.sciencedirect.com/science/article/pii/ S0095069607001064.

Fisher A.C., and U. Narain (2003). Global warming, endogenous risk, and irreversibility. Environmental and Resource Economics 25, 395-416. doi: 10.1023/A:1025056530035, ISSN: 0924-6460.

Fleming S.M., C.L. Thomas, and R.J. Dolan (2010). Overcoming status quo bias in the human brain. Proceedings of the National Academy of Sciences 107, 6005-6009. Available at: http://www.pnas.org/content/107/13/6005.short.

Flynn J., P. Slovic, and H. Kunreuther (2001). Risk Media and Stigma: Understanding Public Challenges to Modern Science and Technology. Earthscan, London UK. Folke C., S. Carpenter, T. Elmqvist, L. Gunderson, C.S. Holling, and B. Walker (2002). Resilience and sustainable development: building adaptive capacity in a world of transformations. AMBIO: A Journal of the Human Environment 31 437-440.

Fouquet D., and T.B. Johansson (2008). European renewable energy policy at crossroads-Focus on electricity support mechanisms. Energy Policy 36, 4079-4092. doi: 10.1016/j.enpol.2008.06.023, ISSN: 0301-4215.

Frondel M., N. Ritter, and C. M. Schmidt (2008). Germany's solar cell promotion: Dark clouds on the horizon. Energy Policy Energy Policy 36, 4198-4204. ISSN 0301-4215.

Frondel M., N. Ritter, C.M. Schmidt, and C. Vance (2010). Economic impacts from the promotion of renewable energy technologies: The German experience. Energy Policy 38, 4048-4056. ISSN: 0301-4215. 
Funke M., and M. Paetz (2011). Environmental policy under model uncertainty: a robust optimal control approach. Climatic Change 107, 225-239. doi: 10.1007/ s10584-010-9943-1, ISSN: 0165-0009.

Funtowicz S. O., and J.R. Ravetz (1992). Three Types of Risk Assessment and the Emergence of Post Normal Science. In: Social Theories of Risk. S. Krimsky, D. Golding, (eds.),Westport, pp. 251-273.

Fuss S., D. Johansson, J. Szolgayova, and M. Obersteiner (2009). Impact of climate policy uncertainty on the adoption of electricity generating technologies. Energy Policy 37, 733-743. doi: 10.1016/j.enpol.2008.10.022, ISSN: 03014215.

Fuss S., J. Szolgayová, N. Khabarov, and M. Obersteiner (2012). Renewables and climate change mitigation: Irreversible energy investment under uncertainty and portfolio effects. Energy Policy 40, 59-68. ISSN: 0301-4215.

Füssel H.M., and R.J.. Klein (2006). Climate change vulnerability assessments: an evolution of conceptual thinking. Climatic Change 75, 301-329.

Gardner G.T., and P.C. Stern (2008). The short list: The most effective actions US households can take to curb climate change. Environment: Science and Policy for Sustainable Development 50, 12-25.

Gearheard S., M. Pocernich, R. Stewart, J. Sanguya, and H.P. Huntington (2009). Linking Inuit knowledge and meteorological station observations to understand changing wind patterns at Clyde River, Nunavut. Climatic Change 100, 267-294. Available at: http://www.springerlink.com/index/ $337542 v 5715 \mathrm{~m} 32 \mathrm{k} 5 . \mathrm{pdf}$.

Gibbons M. (1994). The New Production of Knowledge: The Dynamics of Science and Research in Contemporary Societies. SAGE, 196 pp. ISBN: 9780803977945.

Gilson R.J., and M.J. Roe (1993). Understanding the Japanese keiretsu: Overlaps between corporate governance and industrial organization. Yale Law Journal, 871-906. Available at: http://www.jstor.org/stable/10.2307/796835.

Gjerde J., S. Grepperud, and S. Kverndokk (1999). Optimal climate policy under the possibility of a catastrophe. Resource and Energy Economics 21, 289-317. doi: 10.1016/S0928-7655(99)00006-8, ISSN: 0928-7655.

Goeschl T., and G. Perino (2009). On backstops and boomerangs: Environmental R\&D under technological uncertainty. Energy Economics 31, 800-809. Available at: http://www.sciencedirect.com/science/article/pii/ S014098830900036X.

Goldstein N.J., R. B. Cialdini, and V. Griskevicius (2008). A room with a viewpoint: Using social norms to motivate environmental conservation in hotels. Journal of Consumer Research 35, 472-482. Available at: http://www.jstor. org/stable/10.1086/586910.

Gollier C., B. Jullien, and N. Treich (2000). Scientific progress and irreversibility: an economic interpretation of the "Precautionary Principle." Journal of Public Economics 75, 229-253. doi: 10.1016/S0047-2727(99)00052-3, ISSN: 00472727.

Gollier C., and N. Treich (2003). Decision-making under scientific uncertainty: the economics of the precautionary principle. Journal of Risk and Uncertainty 27, 77-103.

Gong M., J. Baron, and H. Kunreuther (2009). Group cooperation under uncertainty. Journal of Risk and Uncertainty 39, 251-270.

Gonzalez C., and V. Dutt (2011). Instance-based learning: Integrating sampling and repeated decisions from experience. Psychological Review 118, 523-551. Available at: http://psycnet.apa.org/journals/rev/118/4/523/.
Goodnough A. (2006). As hurricane season looms, state aim to scare. The New York Times. Available at: http://www.nytimes.com/2006/05/31/us/31 prepare. html?pagewanted=print\&_r $=0$.

Goossens L.H.J., F.T. Harper, B.C.P. Kraan, and H. Métivier (2000). Expert judgement for a probabilistic accident consequence uncertainty analysis. Radiation Protection Dosimetry 90, 295-301. Available at: http://rpd.oxfordjournals. org/content/90/3/295.abstract.

Government of India, Ministry of Finance (2012). Economic Survey 2012-13.

Grassi G., S. Monni, S. Federici, F. Achard, and D. Mollicone (2008). Applying the conservativeness principle to REDD to deal with the uncertainties of the estimates. Environmental Research Letters 3, 035005.

Green D., J. Billy, and A. Tapim (2010). Indigenous Australians' knowledge of weather and climate. Climatic Change 100, 337-354. Available at: http://www. springerlink.com/index/u04024q252848663.pdf.

Green D., and G. Raygorodetsky (2010). Indigenous knowledge of a changing climate. Climatic Change 100, 239-242. Available at: http://www.springerlink. com/index/27kg6682148j0670.pdf.

Greene D.L., J. German, and M.A. Delucchi (2009). Fuel economy: The case for market failure. In: Reducing climate impacts in the transportation sector. Springer, pp. 181-205. Available at: http://link.springer.com/chapter/ 10.1007/978-1-4020-6979-6_11/fulltext.html.

Gromet D.M., H. Kunreuther, and R.P. Larrick (2013). Political ideology affects energy-efficiency attitudes and choices. Proceedings of the National Academy of Sciences 110, 9314-9319. Available at: http://www.pnas.org/ content/110/23/9314.short.

Gross M. (2010). Ignorance and Surprise: Science, Society, and Ecological Design. MIT Press, 255 pp. ISBN: 9780262013482.

Grothmann T., and A. Patt (2005). Adaptive capacity and human cognition: the process of individual adaptation to climate change. Global Environmental Change Part A 15, 199-213.

Grothmann T., and F. Reusswig (2006). People at risk of flooding: Why some residents take precautionary action while others do not. Natural Hazards $\mathbf{3 8}$, 101-120.

Grubb M. (1997). Technologies, energy systems and the timing of $\mathrm{CO}_{2}$ emissions abatement: An overview of economic issues. Energy Policy 25, 159-172. doi: 10.1016/S0301-4215(96)00106-1, ISSN: 0301-4215.

Grubler A., and K. Riahi (2010). Do governments have the right mix in their energy R\&D portfolios? Carbon 1, 79-87.

Guston D.H. (2001). Boundary Organizations in Environmental Policy and Science. Sage Publications, $133 \mathrm{pp}$.

Ha-Duong M. (1998). Quasi-option value and climate policy choices. Energy Economics 20, 599-620. doi: 10.1016/S0140-9883(98)00011-5, ISSN: 0140-9883.

Ha-Duong M., M.J. Grubb, and J.C. Hourcade (1997). Influence of socioeconomic inertia and uncertainty on optimal $\mathrm{CO}_{2}$-emission abatement. Nature 389, $270-273$.

Ha-Duong M., and N. Treich (2004). Risk aversion, intergenerational equity and climate change. Environmental and Resource Economics 28, 195-207. doi: 10.1 023/B:EARE.0000029915.04325.25, ISSN: 0924-6460.

Hafner-Burton E.M., D. G. Victor, and Y. Lupu (2012). Political science research on International Law. American Journal of International Law 106, 47-97.

Haigh M. S., and J.A. List (2005). Do professional traders exhibit myopic loss aversion? An experimental analysis. The Journal of Finance 60, 523-534. Available at: http://onlinelibrary.wiley.com/doi/10.1111/j.1540-6261.2005.00737.x/full. 
Hall J.W., R.J. Lempert, K. Keller, A. Hackbarth, C. Mijere, and D. J. McInerney (2012). Robust climate policies under uncertainty: A comparison of robust decision making and info-gap methods. Risk Analysis 32, 1657-72. Available at: http://onlinelibrary.wiley.com/doi/10.1111/j.1539-6924.2012.01802.x/full.

Hammond J.S., R.L. Keeney, and H. Raiffa (1999). Smart Choices: A Practical Guide to Making Better Decisions. Harvard Business Press, 244 pp.

Hardcastle P.D., and D. Baird (2008). Capability and Cost Assessment of the Major Forest Nations to Measure and Monitor Their Forest Carbon. LTS International, Penicuick, UK.

Hardisty D. J., E. J. Johnson, and E. U. Weber (2010). A dirty word or a dirty world? Attribute framing, political affiliation, and query theory. Psychological Science 21, 86-92. Available at: http://pss.sagepub.com/content/21/1/86.short.

Hasselmann K., and T. Barker (2008). The Stern Review and the IPCC Fourth Assessment Report: Omplications for interaction between policymakers and climate experts. An editorial essay. Climatic Change 89, 219-229.

Hasselmann K., M. Latif, G. Hooss, C. Azar, O. Edenhofer, C.C. Jaeger, O.M. Johannessen, C. Kemfert, M. Welp, and A. Wokaun (2003). The challenge of long-term climate change. Science 302, 1923-1925.

Heal G. M., and H. Kunreuther (2012). Tipping Climate Negotiations. In Common Sense and Climate Change: Essays in Honor of Thomas Schelling, edited by Robert Hahn and Alistair Ulph, Oxford University Press.

Heath C., and A. Tversky (1991). Preference and belief: Ambiguity and competence in choice under uncertainty. Journal of Risk and Uncertainty 4, 5-28. doi: 10.1007/BF00057884, ISSN: 0895-5646, 1573-0476.

Heidegger M. (1962). Being and Time (J. Macquarrie and E. Robinson, Trans.). Harper \& Row, New York, NY.

Held H., E. Kriegler, K. Lessmann, and O. Edenhofer (2009). Efficient climate policies under technology and climate uncertainty. Energy Economics 31, S50-S61.

Held H., M. Ragwitz, and R. Haas (2006). On the success of policy strategies for the promotion of electricity from renewable energy sources in the EU. Energy \& Environment 17, 849-868.

Hill J., S. Polasky, E. Nelson, D. Tilman, H. Huo, L. Ludwig, J. Neumann, H. Zheng, and D. Bonta (2009). Climate change and health costs of air emissions from biofuels and gasoline. Proceedings of the National Academy of Sciences 106, 2077-2082. doi: 10.1073/pnas.0812835106.

Hirst E., D. White, and R. Goeltz (1985). Indoor temperature changes in retrofit homes. Energy 10, 861-870. Available at: http://www.sciencedirect.com/ science/article/pii/0360544285901197.

Hof A. F., D.P. van Vuuren, and M. G. J. den Elzen (2010). A quantitative minimax regret approach to climate change: Does discounting still matter? Ecological Economics 70, 43-51. doi: 16/j.ecolecon.2010.03.023, ISSN: 0921-8009.

Hoffmann V.H. (2007). EU ETS and investment decisions: The case of the german electricity industry. European Management Journal 25, 464-474.

Hoffmann M. J. (2011). Climate Governance at the Crossroads. Experimenting with a Global Response after Kyoto. Oxford University Press.

Holling C. S. (Ed.) (1978). Adaptive Environmental Assessment and Management. Wiley \& Sons.

Hope C.W. (2008). Optimal carbon emissions and the social cost of carbon over time under uncertainty. Integrated Assessment 8, 107-122. ISSN: 1389-5176.

Hope C.W. (2009). How deep should the deep cuts be? Optimal $\mathrm{CO}_{2}$ emissions over time under uncertainty. Climate Policy 9, 3-8. doi: 10.3763/cpol.2008.0583a, ISSN: 1469-3062.
Hora S.C. (2004). Probability judgments for continuous quantities: Linear combinations and calibration. Management Science 50, 597-604.

Van den Hove S. (2007). A rationale for science-policy interfaces. Futures 39, 807-826. Available at: http://www.sciencedirect.com/science/article/pii/ S0016328706002060.

Hulme M., S.J. O'Neill, and S. Dessai (2011). Is weather event attribution necessary for adaptation funding? Science 334, 764-765.

IISD (2012). Fossil-Fuel Subsidy Reform in India: Cash Transfers for PDS Kerosene and Domestic LPG. International Institute for Sustainable Development, Available at: http://www.iisd.org/gsi/sites/default/files/ffs_india_teri_rev.pdf.

IPCC (2007). Summary for Policymakers. In: Climate Change 2007: The Physical Science Basis. Contribution of Working Group I to the Fourth Assessment Report of the Intergovernmental Panel on Climate Change [S. Solomon, D. Qin, M. Manning, M. Marquis, K. Averyt, M. M. B. Tignor, H.L. Miller, Z. Chen (eds.)]. Cambridge University Press, Cambridge, United Kingdom and New York, NY, USA, 18 pp. Available at: http://www.ipcc.ch/pdf/assessment-report/ ar4/wg1/ar4-wg1-spm.pdf.

IPCC (2012). Managing the Risks of Extreme Events and Disasters to Advance Climate Change Adaption. A Special Report of Working Groups I and II of the Intergovernmental Panel on Climate Change [Field, C. B., V. Barros, T.F. Stocker, D. Qin, D.J. Dokken, K. L. Ebi, M.D. Mastrandrea, K.J. Mach, G.-K. Plattner, S.K. Allen, M. Tignor, and P.M. Midgley (eds.)] Cambridge University Press, Cambridge, UK, and New York, NY, USA, 582 pp.

Itaoka K., Y. Okuda, A. Saito, and M. Akai (2009). Influential information and factors for social acceptance of CCS: The 2nd round survey of public opinion in Japan. Energy Procedia 1, 4803-4810. doi: 10.1016/j.egypro.2009.02.307, ISSN: 1876-6102.

Iverson T., and C. Perrings (2012). Precaution and proportionality in the management of global environmental change. Global Environmental Change 22, 161-177. Available at: http://www.sciencedirect.com/science/article/pii/ S0959378011001440.

Jacoby H.D., and A.D. Ellerman (2004). The safety valve and climate policy. Energy Policy 32, 481-491. doi: 10.1016/S0301-4215(03)00150-2, ISSN: 0301 4215.

Jaffe A., and R. Stavins (1995). Dynamic incentives of environmental regulations: The effects of alternative policy instruments on technology diffusion. Journal of Environmental Economics and Management 29, 43-63.

Jakob M. (2006). Marginal costs and co-benefits of energy efficiency investments: The case of the Swiss residential sector. Energy Policy 34, 172-187. Available at: http://www.sciencedirect.com/science/article/pii/S030142150400271X.

James W. (1878). Remarks on Spencer's Definition of Mind as Correspondence. The Journal of Speculative Philosophy XII, 1-18. Available at: http://www.jstor org/stable/25666067?seq=1.

Jasanoff S. (1990). The Fifth Branch: Science Advisers As Policymakers. Harvard University Press, Cambridge, 322 pp. ISBN: 9780674300620.

Jasanoff S. (2005a). Designs on Nature: Science And Democracy in Europe And the United States. Princeton University Press, New York, 392 pp. ISBN: 9780691130422

Jasanoff S. (2005b). Judgment under Siege: The Three-Body Problem of Expert Legitimacy. In: Democratization of Expertise?: Exploring Novel Forms of Scientific Advice in Political Decision-Making (S. Maasen and peter weingart, Eds.). Springer Science \& Business, 256 pp. ISBN: 9781402037535. 
Jasanoff S. (2010). Testing time for climate science. Science 328, 695-696. doi: 10.1126/science.1189420, ISSN: 0036-8075, 1095-9203.

Jinnah S. (2011). Marketing linkages: Secretariat governance of the climate-biodiversity interface. Global Environmental Politics 11, 23-43.

Johansson D.J.A., U.M. Persson, and C. Azar (2008). Uncertainty and learning: implications for the trade-off between short-lived and long-lived greenhouse gases. Climatic Change 88, 293-308. Available at: http://www.springerlink. com/index/K2052K4611313K26.pdf.

Johnson E.J., and D.G. Goldstein (2013). Decisions By Default. In: Behavioral Foundations of Policy. E. Shafir, (ed.), Princeton University Press, Princeton, NJ.

Johnson E.J., G. Häubl, and A. Keinan (2007). Aspects of endowment: a query theory of value construction. Journal of Experimental Psychology: Learning, Memory, and Cognition 33, 461. Available at: http://psycnet.apa.org/journals/ $\mathrm{xIm} / 33 / 3 / 461 /$.

Jones L., and E. Boyd (2011). Exploring social barriers to adaptation: Insights from Western Nepal. Global Environmental Change 21, 1262-1274.

Jones R.N., and B.L. Preston (2011). Adaptation and risk management. Wiley Interdisciplinary Reviews: Climate Change 2, 296-308.

Joyce L.A., G.M. Blate, S. G. McNulty, C.I. Millar, R.P. Neilson, R.P. Neilson, and D.L. Peterson (2009). Managing for multiple resources under climate change: National forests. Environmental Management 44, 1022-1032. ISSN: 0364-152X.

Kahn H., and A.J. Wiener (1967). The Year 2000: A Framework for Speculation on the Next Thirty-Three Years. New York.

Kahnemann D. (2003). A psychological perspective on economics. The American Economic Review 93, 162-168.

Kahneman D. (2011). Thinking, Fast and Slow. Macmillan, 511 pp. ISBN: 9780374275631

Kahneman D., and A. Tversky (1979). Prospect theory: An analysis of decision under risk. Econometrica 47, 263-291. doi: 10.2307/1914185, ISSN: 0012-9682.

Kasperson R.E., O. Renn, P. Slovic, H.S. Brown, J. Emel, R. Goble, J.X. Kasperson, and S. Ratick (1988). The social amplification of risk: A conceptual framework. Risk Analysis 8, 177-187.

Kaufman N. (2012). The bias of integrated assessment models that ignore climate catastrophes. Climatic Change 110, 575-595. Available at: http://link.springer. com/article/10.1007/s10584-011-0140-7.

Keeney R.L. (1993). Decision analysis: An overview. Operations Research 30, 803-838.

Keller K., B.M. Bolker, and D.F. Bradford (2004). Uncertain climate thresholds and optimal economic growth. Journal of Environmental Economics and Management 48, 723-741. doi: 10.1016/j.jeem.2003.10.003, ISSN: 0095-0696.

Kelly D.L., and C.D. Kolstad (1999). Bayesian learning, growth, and pollution. Journal of Economic Dynamics and Control 23, 491-518. Available at: http://www.sciencedirect.com/science/article/pii/\$0165188998000347.

Keohane R., and D.G. Victor (2011). The Regime of Climate Change. Perspectives on Politics 9, 7-23.

Klein R.J.., S.E.. Eriksen, L. O. Naess, A. Hammill, T.M. Tanner, C. Robledo, and K.L. O'Brien (2007). Portfolio screening to support the mainstreaming of adaptation to climate change into development assistance. Climatic Change $84,23-44$.
Kleindorfer P.R., H.C. Kunreuther, and P. Schoemaker (1993). Decision Sciences: An Integrative Perspective. Cambridge University Press, Available at: http://books.google.com/books?hl=en\&lr=\&id=IN4fXDap37MC\&oi=fnd\&p $\mathrm{g}=$ PR7\&dq=Decision+Sciences, + An+Integrated+Perspective+(with+Paul+ Kleindorfer+and+Paul+Schoemaker).+Cambridge+University+Press.+(1993).\& ots=ipLgqDwpfM\&sig=sjUix58NuM3Xpqu0d-r35wRCZyY.

Kloeckner C.A. (2011). Towards a psychology of climate change. Climate Change Management. In: The Economic, Social and Political Elements of Climate Change. pp. 153-173. Available at: http://www.springerlink.com/index/ K17H385232021072.pdf.

Klügel J.U. (2008). Seismic hazard analysis—Quo vadis? Earth-Science Reviews $88,1-32$.

Knutti R., G. Abramowitz, M. Collins, V. Eyring, P. Glecker, B. Hewitson, and L. Mearns (2010). Good Practice Guidance Paper on Assessing and Combining Multi Model Climate Projections. In: Meeting Report of the Intergovernmental Panel on Climate Change Expert Meeting on Assessing and Combining Multi Model Climate Projections [T.F. Stocker, D. Qin, G.-K. Plattner, M. Tignor, P. M. Midgley, (eds.)]. IPCC Working Group I Technical Support Unit, University of Bern, Bern, Switzerland.

Knutti R., M.R. Allen, P. Friedlingstein, J.M. Gregory, G.C. Hegerl, G. Meehl, M. Meinshausen, J.M. Murphy, G.-K. Plattner, S.C. B. Raper, T.F. Stocker, P.A. Stott, H. Teng, and T.M.L. Wigley (2008). A review of uncertainties in global temperature projections over the twenty-first century. Journal of Climate 21, 2651-2663.

Knutti R., D. Masson, and A. Gettelman (2013). Climate model genealogy: Generation CMIP5 and how we got there. Geophysical Research Letters 40, 1194-1199. doi: 10.1002/grl.50256.

Kolstad C.D. (1994). George Bush versus Al Gore: Irreversibilities in greenhouse gas accumulation and emission control investment. Energy Policy 22, 771-778. doi: 10.1016/0301-4215(94)90053-1, ISSN: 0301-4215.

Kolstad C.D. (1996a). Fundamental irreversibilities in stock externalities. Journal of Public Economics 60, 221-233. Available at: http://www.sciencedirect. com/science/article/pii/0047272795015213.

Kolstad C.D. (1996b). Learning and stock effects in environmental regulation: the case of greenhouse gas emissions. Journal of Environmental Economics and Management 31, 1-18. Available at: http://are.berkeley. edu/courses/ARE263/fall2008/paper/Learning/KolstadLearning\%20JEEM.pdf.

Kolstad C. D. (2007). Systematic uncertainty in self-enforcing international environmental agreements. Journal of Environmental Economics and Management 53, 68-79. Available at: http://ideas.repec.org/a/eee/jeeman/v53y2007i1p68-79. html.

Kolstad C.D., and A. Ulph (2011). Uncertainty, learning and heterogeneity in international environmental agreements. Environmental and Resource Economics 50, 389-403.

Komendantova N., A. Patt, L. Barras, and A. Battaglini (2012). Perception of risks in renewable energy projects: The case of concentrated solar power in North Africa. Energy Policy 40, 103-109. Available at: http://www. sciencedirect.com/science/article/pii/S0301421509009458.

Komendantova N., A. Patt, and K. Williges (2011). Solar power investment in North Africa: Reducing perceived risks. Renewable and Sustainable Energy Reviews.

Krantz D.H., and H.C. Kunreuther (2007). Goals and plans in decision making. Judgment and Decision Making 2, 137-168. 
Krosnick J.A., A.L. Holbrook, L. Lowe, and P.S. Visser (2006). The origins and consequences of democratic citizens' policy agendas: A study of popular concern about global warming. Climatic Change 77, 7-43. Available at: http://www.springerlink.com/index/WU4K81W185X1V576.pdf.

Kunreuther H., R. Ginsberg, L. Miller, P. Sagi, P. Slovic, B. Borkin, and N. Katz (1978). Disaster Insurance Protection: Public Policy Lessons. Wiley and Sons, New York, 400 pp.

Kunreuther H., G. Heal, M. Allen, O. Edenhofer, C.B. Field, and G. Yohe (2013a). Risk management and climate change. Nature Climate Change 3, 447-450. Available at: http://www.nber.org/papers/w18607.

Kunreuther H., R. Hogarth, and J. Meszaros (1993). Insurer ambiguity and market failure. Journal of Risk and Uncertainty 7, 71-87.

Kunreuther H., R. Meyer, and E. Michel-Kerjan (2013b). Overcoming Decision Biases to Reduce Losses from Natural Catastrophes. In: The Behavioral Foundations of Policy, E. Shafir (ed.). Princeton University Press, New Jersey, USA, pp. 398-425. ISBN: 9780691137568.

Kunreuther H., and E. Michel-Kerjan (2011). People get ready: Disaster preparedness. Issues in Science and Technology XXVIII, 1-7. Available at: http://www. issues.org/28.1/kunreuther.html.

Kunreuther H., N. Novemsky, and D. Kahneman (2001). Making low probabilities useful. Journal of Risk and Uncertainty 23, 103-20. Available at: http://econpapers.repec.org/article/kapjrisku/v_3a23_3ay_3a2001_3ai_3a2_3ap_ 3a103-20.htm.

Kunreuther H., M. Pauly, and S. McMorrow (2013c). Insurance and Behavioral Economics: Improving Decisions in the Most Misunderstood Industry. New York: Cambridge University Press.

Kunreuther H., G. Silvasi, E.T. Bradlow, and D. Small (2009). Bayesian analysis of deterministic and stochastic prisoner's dilemma games. Judgment and Decision Making 4, 363-384.

Labriet M., A. Kanudia, and R. Loulou (2012). Climate mitigation under an uncertain technology future: a TIAM-WORLD analysis. Energy Economics 34, S366-S377. Available at: http://www.sciencedirect.com/science/article/pii/ S0140988312000461.

Labriet M., R. Loulou, and A. Kanudia (2010). Modeling uncertainty in a large scale integrated energy-climate model. International Series in Operations Research \& Management Science. In: Uncertainty and Environmental Decision Making. Springer, pp. 51-77. Available at: http://link.springer.com/chapter/ 10.1007/978-1-4419-1129-2_2.

Laibson D. (1997). Golden eggs and hyperbolic discounting. The Quarterly Journal of Economics 112, 443-478.

Laidler G. J. (2006). Inuit and scientific perspectives on the relationship between sea ice and climate change: the ideal complement? Climatic Change 78, 407-444. Available at: http://www.springerlink.com/index/M72813263P4U2380.pdf.

Lange A., and N. Treich (2008). Uncertainty, learning and ambiguity in economic models on climate policy: some classical results and new directions. Climatic Change 89, 7-21.

Larrick R.P., and J.B. Soll (2008). The MPG illusion. Science 320, 1593-1594.

Lawler J. J., T.H. Tear, C. Pyke, R. M. Shaw, P. Gonzales, P. Kareiva, L. Hansen, L. Hannah, K. Klausmeyer, A. Aldous, C. Bienz, and S. Pearsall (2008). Resource management in a changing and uncertain climate. Frontiers in Ecology and the Environment 8, 35-43.

Lawlor K., E. Weinthal, and L. Olander (2010). Institutions and policies to protect rural livelihoods in REDD+ regimes. Global Environmental Politics 10, 1-11.
Leach A. J. (2007). The climate change learning curve. Journal of Economic Dynamics and Control 31, 1728-1752. Available at: http://www.sciencedirect. com/science/article/pii/S0165188906001266.

Leary D., and M. Esteban (2009). Climate Change and renewable energy from the ocean and tides: Calming the sea of regulatory uncertainty. The International Journal of Marine and Coastal Law 24, 617-651. doi: 10.1163/092735209X1 2499043518269

Lee K.N. (1993). Compass and Gyroscope: Integrating Science and Politics for the Environment. Island Press. Washington, DC, USA, 255 pp.

Lefale P. (2010). Ua 'afa le Aso Stormy weather today: traditional ecological knowledge of weather and climate. The Samoa experience. Climatic Change 100, 317-335. doi: 10.1007/s10584-009-9722-z.

Leiserowitz A. (2005). American risk perceptions: Is climate change dangerous? Risk Analysis 25, 1433-1442.

Leiserowitz A. (2006). Climate change risk perception and policy preferences: The role of affect, imagery, and values. Climatic Change 77, 45-72.

Leiserowitz A., and K. Broad (2008). Florida: Public Opinion on Climate Change. A Yale University/University of Miami/Columbia University Poll. New Haven, CT: Yale Project on Climate Change.

Leiserowitz A., E. Maibach, and C. Roser-Renouf (2008). Global Warming's" Six America": An Audience Segmentation. Yale School of Forestry and Environmental Studies and George Mason University Center for Climate Change Communication.

Leiserowitz A. and E. Maibach, C. Roser-Renouf, and J. Hmielowski (2012). Extreme, weather, climate and preparedness in the American mind. Yale Project on Climate Change Communication.

Lempert R.J., D.G. Groves, S.W. Popper, and S.C. Bankes (2006). A General, Analytic Method for Generating Robust Strategies and Narrative Scenarios. Management Science 52, 514-528. doi:10.1287/mnsc.1050.0472.

Letson D., C.E. Laciana, F.E. Bert, E.U. Weber, R.W. Katz, X.I. Gonzalez, and G.P. Podestá (2009). Value of perfect ENSO phase predictions for agriculture: evaluating the impact of land tenure and decision objectives. Climatic Change 97, 145-170.

Li Y., E. J. Johnson, and L. Zaval (2011). Local warming. Psychological Science 22, 454-459. doi: 10.1177/0956797611400913.

Lilliestam J., A. Battaglini, C. Finlay, D. Fürstenwerth, A. Patt, G. Schellekens, and P. Schmidt (2012). An alternative to a global climate deal may be unfolding before our eyes. Climate and Development 4, 1-4.

Lilliestam J., and S. Ellenbeck (2011). Energy security and renewable electricity trade-Will Desertec make Europe vulnerable to the "energy weapon"? Energy Policy 39, 3380-3391. doi: 10.1016/j.enpol.2011.03.035, ISSN: 0301-4215.

Little C.M., N. M. Urban, and M. Oppenheimer (2013). Probabilistic framework for assessing the ice sheet contribution to sea level change. Proceedings of the National Academy of Sciences 110, 3264-3269. Available at: http://www.pnas. org/content/110/9/3264.short.

Loewenstein G., and J. Elster (1992). Choice Over Time. Russell Sage Foundation, 434 pp. ISBN: 9780871545589.

Loewenstein G. F., E. U. Weber, C. K. Hsee, and N. Welch (2001). Risk as feelings. Psychological Bulletin 127, 267.

Lorenz A., E. Kriegler, H. Held, and M. G. Schmidt (2012a). How to measure the importance of climate risk for determining optimal global abatement policies? Climate Change Economics 3, 01-28. Available at: http://www.worldscientific. com/doi/pdf/10.1142/s2010007812500042. 
Lorenz A., M. Schmidt, E. Kriegler, and H. Held (2012b). Anticipating Climate Threshold Damages. Environmental Modeling and Assessment 17, 163-175. doi: 10.1007/s10666-011-9282-2, ISSN: 1420-2026.

Lorenzoni I., A. Leiserowitz, M.D.. Doria, W. Poortinga, and N.F. Pidgeon (2006). Cross-national comparisons of image associations with "global warming" and "climate change" among laypeople in the United States of America and Great Britain. Journal of Risk Research 9, 265-281.

Lorenzoni I., S. Nicholson-Cole, and L. Whitmarsh (2007). Barriers perceived to engaging with climate change among the UK public and their policy implications. Global Environmental Change 17, 445-459.

Lorenzoni I., and N. F. Pidgeon (2006). Public views on climate change: European and USA perspectives. Climatic Change 77, 73-95.

Lowe T., K. Brown, S. Dessai, M. de França Doria, K. Haynes, and K. Vincent (2006). Does tomorrow ever come? Disaster narrative and public perceptions of climate change. Public Understanding of Science 15, 435-457.

Lüthi S. (2010). Effective deployment of photovoltaics in the Mediterranean countries: Balancing policy risk and return. Solar Energy 84, 1059-1071.

Lüthi S., and R. Wüstenhagen (2012). The price of policy risk-Empirical insights from choice experiments with European photovoltaic project developers. Energy Economics 34, 1001-1011.

Malueg D.A. (1990). Welfare consequences of emission credit trading programs. Journal of Environmental Economics and Management 18, 66-77. ISSN: 00950696.

Manne A. S., and R. G. Richels (1991). Buying greenhouse insurance. Energy Policy 19, 543-552. doi: 10.1016/0301-4215(91)90034-L, ISSN: 0301-4215.

Martin T. G., M.A. Burgmann, F. Fidler, P. M. Kuhnert, S. Low-Choy, M. McBride, and K. Mengersen (2012). Eliciting expert knowledge in conservation science. Conservation Biology 26, 29-38.

Maslow A. H. (1954). Motivation and Personality. Harper (New York), Available at: http://www.getcited.org/pub/101181741.

Mastrandrea M., C. Field, T. Stocker, O. Edenhofer, K. Ebi, D. Frame, H. Held, E. Kriegler, K. Mach, P. Matschoss, and others (2010). Guidance note for lead authors of the IPCC Fifth Assessment Report on consistent treatment of uncertainties. Intergovernmental Panel on Climate Change, Geneva, 5.

Mastrandrea M.D., K.J. Mach, G.-K. Plattner, O. Edenhofer, T. F. Stocker, C. B. Field, K. L. Ebi, and P.R. Matschoss (2011). The IPCC AR5 guidance note on consistent treatment of uncertainties: a common approach across the working groups. Climatic Change 108, 675-691. doi: 10.1007/s10584-011-0178-6, ISSN: 0165-0009, 1573-1480.

McCrimmon K.R. (1968). Descriptive and normative implications of the decisiontheory postulates. In: Risk and Uncertainty. MacMillan, London, pp. 3-24.

McDermott C.L., K. Levin, and B. Cashore (2011). Building the forest-climate bandwagon: REDD+ and the logic of problem amelioration. Global Environmental Politics 11, 85-103.

McInerney D., and K. Keller (2008). Economically optimal risk reduction strategies in the face of uncertain climate thresholds. Climatic Change 91, 29-41. doi: 10.1007/s10584-006-9137-z, ISSN: 0165-0009, 1573-1480.

Meckling J. (2011). The globalization of carbon trading: transnational business coalitions in climate politics. Global Environmental Politics 11, 26-50.

Meijer I.S.M., M.P. Hekkert, and J.F.M. Koppenjan (2007). The influence of perceived uncertainty on entrepreneurial action in emerging renewable energy technology; biomass gasification projects in the Netherlands. Energy Policy 35, 5836-5854. doi: 10.1016/j.enpol.2007.07.009, ISSN: 0301-4215.
Meinshausen M., S.J. Smith, K. Calvin, J.S. Daniel, M.L.T. Kainuma, J-F. Lamarque, K. Matsumoto, S.A. Montzka, S. C. B. Raper, K. Riahi, A. Thomson, G. J.M. Velders, and D.P.P van Vuuren (2011). The RCP greenhouse gas concentrations and their extensions from 1765 to 2300. Climatic Change 109, 213-241. ISSN: 0165-0009.

Mendonça M. (2007). Feed-in Tariffs: Accelerating the Deployment of Renewable Energy. Earthscan, 173 pp. ISBN: 9781844074662.

Michel-Kerjan E., S. Lemoyne de Forges, and H. Kunreuther (2012). Policy tenure under the U.S. National Flood Insurance Program (NFIP). Risk Analysis 32(4), 644-658. doi: 10.1111/j.1539-6924.2011.01671.x, ISSN: 1539-6924.

Milinski M., R.D. Sommerfeld, H.J. Krambeck, F.A. Reed, and J. Marotzke (2008). The collective-risk social dilemma and the prevention of simulated dangerous climate change. Proceedings of the National Academy of Sciences 105, 2291.

Miller C. (2001). Hybrid management: boundary organizations, science policy, and environmental governance in the climate regime. Science, Technology \& Human Values 26, 478-500. Available at: http://sth.sagepub.com/content/26/4/478. short.

Mitchell C., D. Bauknecht, and P.M. Connor (2006). Effectiveness through risk reduction: a comparison of the renewable obligation in England and Wales and the feed-in system in Germany. Energy Policy 34, 297-305. doi: 10.1016/j. enpol.2004.08.004, ISSN: 0301-4215.

Morgan M.G., and M. Henrion (1990). Uncertainty: A Guide to Dealing with Uncertainty in Quantitative Risk and Policy Analysis. Cambridge University Press, 354 pp. ISBN: 9780521427449 paperback, 0-521-36542-2 hardback.

Morgan M.G., and D.W. Keith (1995). Subjective judgements by climate experts. Environmental Science \& Technology 29, 468-476.

Moser S.C. (2007). In the long shadows of inaction: The quiet building of a climate protection movement in the United States. Global Environmental Politics 7, 124-144.

Moser S.C. (2010). Communicating climate change: history, challenges, process and future directions. Wiley Interdisciplinary Reviews: Climate Change 1, 31-53. Available at: http://onlinelibrary.wiley.com/doi/10.1002/wcc.11/full.

Mozumder P., E. Flugman, and T. Randhir (2011). Adaptation behavior in the face of global climate change: Survey responses from experts and decision makers serving the Florida Keys. Ocean \& Coastal Management 54, 37-44.

Murray B.C., R.G. Newell, and W.A. Pizer (2009). Balancing cost and emissions certainty: An allowance reserve for cap-and-trade. Review of Environmental Economics and Policy 3, 84-103.

Musall F. D., and O. Kuik (2011). Local acceptance of renewable energy-A case study from southeast Germany. Energy Policy 39(6), 3252-3260.

Myers T.A., M.C. Nisbet, E.W. Maibach, and A.A. Leiserowitz (2012). A public health frame arouses hopeful emotions about climate change. Climatic Change 113, 1105-1112. Available at: http://www.springerlink. com/index/B0072M7777772K7R.pdf.

Von Neumann J., and O. Morgenstern (1944). Theory of Games and Economic Behavior. Princeton University Press, Princeton, NJ.

Nietzsche F. (2008). The Birth of Tragedy. Oxford University Press, 224 pp.

Nilsson M. (2005). The role of assessments and institutions for policy learning: a study on Swedish climate and nuclear policy formation. Policy Sciences 38, 225-249. Available at: http://link.springer.com/article/10.1007/s11077-006-9006-7. 
Nordhaus W.D. (1994). Expert opinion on climatic change. American Scientist 82, $45-51$.

Nordhaus W.D., and D. Popp (1997). What is the value of scientific knowledge? An application to global warming using the PRICE model. The Energy Journal, 1-45. Available at: http://www.jstor.org/stable/10.2307/41322716.

Nowotny H., P. Scott, and M. Gibbons (2001). Re-Thinking Science: Knowledge and the Public in an Age of Uncertainty. Polity, 292 pp. ISBN: 9780745626086.

O'Brien K. (2009). Do values subjectively define the limits to climate change adaptation? In: Adapting to Climate Change. W. Adger, I. Lorenzoni, K. O'Brien, (eds.), Cambridge University Press., Cambridge, UK, pp. 164-180.

O'Hagan A., E. Caitlin, C.E. Buck, A. Daneshkhah, J.R. Eiser, P. H. Garthwaite, D. J. Jenkinson, J.E. Oakley, and T. Rakow (2006). Uncertainty Judgements: Eliciting Experts' Probabilities. John Wiley \& Sons Inc, ISBN: 0-470-02999-4.

O'Neill B.C., and M. Oppenheimer (2002). Dangerous climate impacts and the Kyoto Protocol. Science 296, 1971-1972. Available at: http://www.sciencemag. org/content/296/5575/1971.short.

O'Neill B., and W. Sanderson (2008). Population, uncertainty, and learning in climate change decision analysis. Climatic Change 89, 87-123. doi: 10.1007/s105 84-008-9419-8, ISSN: 0165-0009.

Obersteiner M., C. Azar, P. Kauppi, K. Möllersten, J. Moreira, S. Nilsson, P. Read, K. Riahi, B. Schlamadinger, and Y. Yamagata (2001). Managing climate risk. Science 294, 786-787. Available at: http://webarchive.iiasa. ac.at/Admin/PUB/Documents/IR-01-051.pdf.

Oda J., and K. Akimoto (2011). An analysis of CCS investment under uncertainty. Energy Procedia 4, 1997-2004. Available at: http://www.sciencedirect. com/science/article/pii/S1876610211002785.

Oliveira P.J.., G.P. Asner, D.E. Knapp, A. Almeyda, R. Galván-Gildemeister, S. Keene, R. F. Raybin, and R. C. Smith (2007). Land-use allocation protects the Peruvian Amazon. Science 317, 1233-1236.

Orlove B., C. Roncoli, and A. Majugu (2009). Indigenous climate knowledge in Southern Uganda: the multiple components of a dynamic regional system. Climatic Change 100(2), 243-265. doi: 10.1007/s10584-009-9586-2.

Patiño-Echeverri D., P. Fischbeck, and E. Kriegler (2009). Economic and environmental costs of regulatory uncertainty for coal-fired power plants. Environmental Science and Technology 43, 578-584. doi: 10.1021/es800094h, ISSN: 0013-936X.

Patiño-Echeverri D., B. Morel, J. Apt, and C. Chen (2007). Should a coal-fired power plant be replaced or retrofitted? Environmental Science and Technology 41, 7980-7986. doi: 10.1021/es0711009, ISSN: 0013-936X.

Patt A. (2007). Assessing model-based and conflict-based uncertainty. Global Environmental Change 17, 37-46.

Patt A., and S. Dessai (2005). Communicating uncertainty: lessons learned and suggestions for climate change assessment. Comptes Rendus Geoscience 337, 425-441. Available at: http://www.sciencedirect.com/science/article/pii/ S1631071304002822.

Patt A., R.J.. Klein, and A. de la Vega-Leinert (2005). Taking the uncertainty in climate-change vulnerability assessment seriously. Comptes Rendus Geosciences 337, 411-424.

Patt A., L. Ogallo, and M. Hellmuth (2007). Learning from 10 years of climate outlook forums in Africa. Science 318, 49-50. doi: 10.1126/science.1147909, ISSN: 0036-8075, 1095-9203.
Patt A., M. Tadross, P. Nussbaumer, K. Asante, M. Metzger, J. Rafael, A. Goujon, and G. Brundrit (2010). Estimating least-developed countries' vulnerability to climate-related extreme events over the next 50 years. Proceedings of the National Academy of Sciences 107, 1333-1337. doi: 10.1073/pnas.0910253107, ISSN: 0027-8424, 1091-6490.

Patt A., D.P. van Vuuren, F. Berkhout, A. Aaheim, A. F. Hof, M. Isaac, and R. Mechler (2009). Adaptation in integrated assessment modeling: where do we stand? Climatic Change 99, 383-402. doi: 10.1007/s10584-009-9687-y, ISSN: 0165-0009, 1573-1480.

Patt A., and E.U. Weber (2014). Perceptions and communications strategies for the many uncertainty relevant for climate policy. Wiley Interdisciplinary Reviews: Climate Change 5(2), 219-232.

Patt A., and R. Zeckhauser (2000). Action bias and environmental decisions. Journal of Risk and Uncertainty 21, 45-72.

Payne J.W., J.R. Bettman, and E.J. Johnson (1988). Adaptive strategy selection in decision making. Journal of Experimental Psychology: Learning, Memory, and Cognition 14, 534.

Peck S.C., and T.J. Teisberg (1993). Global warming uncertainties and the value of information: an analysis using CETA. Resource and Energy Economics 15, $71-97$.

Peck S.C., and T.J. Teisberg (1994). Optimal carbon emissions trajectories when damages depend on the rate or level of global warming. Climatic Change 28, 289-314. doi: 10.1007/BF01104138, ISSN: 0165-0009.

Peck S.C., and T.J. Teisberg (1995). Optimal $\mathrm{CO}_{2}$ control policy with stochastic losses from temperature rise. Climatic Change 31, 19-34. doi: 10.1007/BF01092979, ISSN: 0165-0009.

Percival R.V., and A. Miller (2011). Resolving conflicts between green technology transfer and intellectual property law. University of Maryland School of Law Working Paper No. 2011-27.

Peters E., P. Slovic, J.H. Hibbard, and M. Tusler (2006). Why worry? Worry, risk perceptions, and willingness to act to reduce medical errors. Health Psychology; Health Psychology 25, 144. Available at: http://psycnet.apa.org/journals/ hea/25/2/144/.

Philibert C. (2009). Assessing the value of price caps and floors. Climate Policy 9 , 612-633.

Pichert D., and K.V. Katsikopoulos (2008). Green defaults: Information presentation and pro-environmental behaviour. Journal of Environmental Psychology $28,63-73$.

Pidgeon N., and B. Fischhoff (2011). The role of social and decision sciences in communicating uncertain climate risks. Nature Climate Change 1,35-41.Available at: http://www.nature.com/nclimate/journal/v1/n1/full/nclimate1080.html?WT. ec_id=NCLIMATE-201104.

Pidgeon N., I. Lorenzoni, and W. Poortinga (2008). Climate change or nuclear power-No thanks! A quantitative study of public perceptions and risk framing in Britain. Global Environmental Change 18, 69-85. doi: 10.1016/j.gloenvcha.2007.09.005, ISSN: 09593780.

Pierotti R. (2011). The World According to Is'a: Combining Empiricism and Spiritual Understanding in Indigenous Ways of Knowing. Wiley-Blackwell Press.

Pindyck R.S. (2011). Fat tails, thin tails, and climate change policy. Review of Environmental Economics and Policy 5, 258-274.

Pindyck R.S. (2013). Climate Change Policy: What Do the Models Tell Us? National Bureau of Economic Research, Available at: http://www.nber. org/papers/w19244. 
Pizer W.A. (1999). The optimal choice of climate change policy in the presence of uncertainty. Resource and Energy Economics 21, 255-287. doi: 10.1016/5092 8-7655(99)00005-6.

Polasky S., S.R. Carpenter, C. Folke, and B. Keeler (2011). Decision-making under great uncertainty: Environmental management in an era of global change. Trends in Ecology \& Evolution 26, 398-404. doi: 10.1016/j.tree.2011.04.007, ISSN: 01695347

Pope D.G., and M.E. Schweitzer (2011). Is Tiger Woods loss averse? Persistent bias in the face of experience, competition, and high stakes. The American Economic Review 101, 129-157. Available at: http://www.ingentaconnect. com/content/aea/aer/2011/00000101/00000001/art00009.

Prato T. (2008). Accounting for risk and uncertainty in determining preferred strategies for adapting to future climate change. Mitigation and Adaptation Strategies for Global Change 13, 47-60.

Prins G., and S. Rayner (2007). Time to ditch Kyoto. Nature 449, 973-975.

Pycroft J., L. Vergano, C. Hope, D. Paci, and J.C. Ciscar (2011). A tale of tails: Uncertainty and the social cost of carbon dioxide. Economics: The Open-Access, Open-Assessment E-Journal. doi: 10.5018/economics-ejournal.ja.2011-22, ISSN: 1864-6042.

Quiggin J. (1993). Generalized Expected Utility Theory: The Rank-Dependent Model. Springer.

Ramsey F.P. (1926). Truth and probability. In: The Foundations of Mathematics and Other Logical Essays. Kegan, Paul, Trench, Trubner \& Co, London, pp. 156-198.

Rasch P.J., S. Tilmes, R.P. Turco, A. Robock, L. Oman, C.-C. (Jack) Chen, G. L. Stenchikov, and R.R. Garcia (2008). An overview of geoengineering of climate using stratospheric sulphate aerosols. Philosophical Transactions of the Royal Society A: Mathematical, Physical and Engineering Sciences 366, 4007-4037. doi: 10.1098/rsta.2008.0131.

Rasmussen N. (1975). Reactor Safety Study. U.S. Nuclear Regulatory Commission, Washington, DC,

Rayner S. (1993). Introduction. Global Environmental Change 3, 7-11. doi: 10.101 6/0959-3780(93)90011-9, ISSN: 0959-3780.

Rayner S. (2007). The rise of risk and the decline of politics. Environmental Hazards 7, 165-172. Available at: http://www.sciencedirect.com/science/article/ pii/S1747789107000142.

Rayner S., and E.L. Malone (2001). Climate change, poverty, and intragenerational equity:the national level. International Journal of Global Environmental Issues 1, 175-202. Available at: http://inderscience.metapress.com/index/vhdj0r6pbgr09fqe.pdf.

Reichenbach J., and T. Requate (2012). Subsidies for renewable energies in the presence of learning effects and market power. Resource and Energy Economics 34, 236-254. ISSN: 0928-7655.

Reilly J.M., J.A. Edmonds, R.H. Gardner, and A.L. Brenkert (1987). Uncertainty analysis of the IEA/ORAU $\mathrm{CO}_{2}$ emissions model. The Energy Journal 8, 1-29. ISSN: 0195-6574.

Reinelt P.S., and D.W. Keith (2007). Carbon capture retrofits and the cost of regulatory uncertainty. The Energy Journal 28, 101.

Richardson J. (2008). Needful things. Trading Carbon 2, 30-32.

Del Rio P., and M.. Gual (2007). An integrated assessment of the feed-in tariff system in Spain. Energy Policy 35, 994-1012. ISSN: 0301-4215.

Roberts J.J., R.A. Wood, and R.S. Haszeldine (2011). Assessing the health risks of natural $\mathrm{CO}_{2}$ seeps in Italy. Proceedings of the National Academy of Sciences 108, 16545-16548. doi: 10.1073/pnas.1018590108.
Robock A., M. Bunzl, B. Kravitz, and G. L. Stenchikov (2010). A test for geoengineering? Science 327, 530-531. doi: 10.1126/science.1186237.

Romijn E., M. Herold, L. Kooistra, D. Murdiyarso, and L. Verchot (2012). Assessing capacities of non-Annex I countries for national forest monitoring in the context of REDD+. Environmental Science \& Policy 19-20, 33-48. doi: 10.1016/j.envsci.2012.01.005, ISSN: 1462-9011.

Roncoli C. (2006). Ethnographic and participatory approaches to research on farmers' responses to climate predictions. Climate Research 33, 81. Available at: http://www.int-res.com/abstracts/cr/v33/n1/p81-99/.

Roser-Renouf C., E.W. Maibach, A. Leiserowitz, and X. Zhao (2011). The genesis of climate change activism: From key beliefs to political advocacy. In Press.

Rothlisberger J.D., D.C. Finnoff, R.M. Cooke, and D.M. Lodge (2012). Shipborne nonindigenous species diminish great lakes ecosystem services. Ecosystems 15, 1-15.

Rothlisberger J.D., D.M. Lodge, R.M. Cooke, and D.C. Finnoff (2009). Future declines of the binational Laurentian Great Lakes fisheries: the importance of environmental and cultural change. Frontiers in Ecology and the Environment $8,239-244$.

Roy A.D. (1952). Safety first and the holding of assets. Econometrica: Journal of the Econometric Society 20, 431-449.

Rozenberg J., S. Hallegatte, A. Vogt-Schilb, O. Sassi, C. Guivarch, H. Waisman, and J.-C. Hourcade (2010). Climate policies as a hedge against the uncertainty on future oil supply. Climatic Change 101, 663-668. doi: 10.1007/s1058 4-010-9868-8, ISSN: 0165-0009.

Ryan J.J.C.H., T.A. Mazzuchi, D. J. Ryan, J. Lopez de la Cruz, and R.M. Cooke (2012). Quantifying information security risks using expert judgment elicitation. Computers \& Operations Research 39, 774-784. doi: 10.1016/j. cor.2010.11.013, ISSN: 0305-0548.

Sáenz de Miera G., P. del Río González, and I. Vizcaíno (2008). Analysing the impact of renewable electricity support schemes on power prices: The case of wind electricity in Spain. Energy Policy 36, 3345-3359. Available at: http://www.sciencedirect.com/science/article/pii/S0301421508001882.

Sagar A. D., and B. van der Zwaan (2006). Technological innovation in the energy sector: R\&D, deployment, and learning-by-doing. Energy Policy 34, 2601-2608. doi: 10.1016/j.enpol.2005.04.012, ISSN: 0301-4215.

Samuelson W., and R. Zeckhauser (1988). Status quo bias in decision making. Journal of Risk and Uncertainty 1, 7-59.

Sanquist T. F., H. Orr, B. Shui, and A.C. Bittner (2012). Lifestyle factors in US residential electricity consumption. Energy Policy 42, 354-364. Available at: http://www.sciencedirect.com/science/article/pii/S0301421511009906.

Sarewitz D. (2010). Curing climate backlash. Nature 464, 28. doi: 10.1038/ 464028a, ISSN: 1476-4687.

Savage L.J. (1954). The Foundations of Statistics. Courier Dover Publications, 356 pp. ISBN: 9780486623498.

Schiermeier Q. (2004). Disaster movie highlights transatlantic divide. Nature 431, 4-4.

Schleich J., M. Klobasa, S. Gölz, and M. Brunner (2013). Effects of feedback on residential electricity demand-Findings from a field trial in Austria. Energy Policy 61, 1097-1106. Available at: http://www.sciencedirect.com/science/ article/pii/S0301421513003443.

Schmeidler D. (1989). Subjective probability and expected utility without additivity. Econometrica: Journal of the Econometric Society 57, 571-587. 
Schmidt M.G.W., A. Lorenz, H. Held, and E. Kriegler (2011). Climate targets under uncertainty: challenges and remedies. Climatic Change 104, 783-791. Available at: http://www.springerlink.com/index/607010683813VU36.pdf.

Schoemaker P. (1995). Scenario planning: A tool for strategic thinking. Sloan Management Review 4, 25-40.

Schoemaker P.J.H., and J.E. Russo (2001). Winning Decisions: Getting It Right the First Time. Crown Business, 352 pp. Available at: http://books.google. com/books?hl=en\&lr=\&id=iHG_2i4Z0wYC\&oi=fnd\&pg=PR7\&dq=Russo, + J.+ Edward+\%26+Paul+Schoemaker.+Winning+Decisions:+Getting+it+Right+the +First+Time\&ots=th9D50nH3f\&sig=ULqGHHsV4kDFyfOMZUdlfskMT14.

Scott M.J., R.D. Sands, J. Edmonds, A.M. Liebetrau, and D.W. Engel (1999). Uncertainty in integrated assessment models: modeling with MiniCAM 1.0. Energy Policy 27, 855-879. doi: 10.1016/S0301-4215(99)00057-9, ISSN: 03014215.

Shackley S., D. Reiner, P. Upham, H. de Coninck, G. Sigurthorsson, and J. Anderson (2009). The acceptability of $\mathrm{CO}_{2}$ capture and storage (CCS) in Europe: An assessment of the key determining factors: Part 2. The social acceptability of CCS and the wider impacts and repercussions of its implementation. International Journal of Greenhouse Gas Control 3, 344-356. doi: 10.1016/j. ijggc.2008.09.004, ISSN: 1750-5836.

Shah T., and U. Lele (2011). Climate Change, Food and Water Security in South Asia: Critical Issues and Cooperative Strategies in an Age of Increased Risk and Uncertainty. Synthesis of Workshop Discussions. A Global Water Partnership (GWP) and International Water Management Institute (IWMI) Workshop. Stockholm, Sweden, 1-47 pp.

Shapiro S.A., and T. O. McGarity (1991). Not So Paradoxical: The Rationale for Technology-Based Regulation. Duke LJ, 729. Available at: http://heinonlinebackup. com/hol-cgi-bin/get_pdf.cgi?handle=hein.journals/duklr1991\&section=30.

Simon H.A. (1955). A Behavioral Model of Rational Choice. The Quarterly Journal of Economics 69, 99-118. doi: 10.2307/1884852, ISSN: 0033-5533.

Slovic P. (1987). Perception of risk. Science 236, 280-285. doi: 10.1126/ science. 3563507 .

Smith J. (2005). Dangerous news: Media decision making about climate change risk. Risk Analysis 25, 1471-1482.

Socolow R.H., and A. Glaser (2009). Balancing risks: nuclear energy \& climate change. Daedalus 138, 31-44. doi: 10.1162/daed.2009.138.4.31, ISSN: 00115266.

Spence A., W. Poortinga, C. Butler, and N. F. Pidgeon (2011). Perceptions of climate change and willingness to save energy related to flood experience. Nature Climate Change 1, 46-49. doi: 10.1038/nclimate1059, ISSN: 1758-678X.

Sterman J.D. (2008). Risk communication on climate: Mental models and Mass Balance. Science 322, 532-533. doi: 10.1126/science.1162574, ISSN: 0036$8075,1095-9203$.

Sterman J.D., and L.B. Sweeney (2007). Understanding public complacency about climate change: Adults' mental models of climate change violate conservation of matter. Climatic Change 80, 213-238. doi: 10.1007/s10584-006-910 7-5, ISSN: 0165-0009, 1573-1480.

Stern N.H. (2007). The Economics of Climate Change: The Stern Review. Cambridge University Press, 713 pp. ISBN: 9780521700801.

Stevenson M.A. (2010). Framing anthropogenic environmental change in public health terms. Global Environmental Politics 10, 152-157. doi: 10.1162/glep.2010.10.1.152, ISSN: 1526-3800.
Stirling A. (2007). Risk, precaution and science: towards a more constructive policy debate. Talking point on the precautionary principle. EMBO Reports 8, 309-315. doi: 10.1038/sj.embor.7400953, ISSN: 1469-221X.

Sunstein C.R. (2006). The availability heuristic, intuitive cost-benefit analysis, and climate change. Climatic Change 77, 195-210. doi: 10.1007/s10584-006-9073y, ISSN: 0165-0009, 1573-1480.

Swim J.K., P.C. Stern, T.J. Doherty, S. Clayton, J.P. Reser, E. U. Weber, R. Gifford, and G.S. Howard (2011). Psychology's contributions to understanding and addressing global climate change. American Psychologist 66, 241. Available at: http://psycnet.apa.org/journals/amp/66/4/241/.

Syri S., A. Lehtilä, T. Ekholm, I. Savolainen, H. Holttinen, and E. Peltola (2008). Global energy and emissions scenarios for effective climate change mitigation-Deterministic and stochastic scenarios with the TIAM model. International Journal of Greenhouse Gas Control 2, 274-285. Available at: http://www.sciencedirect.com/science/article/pii/S1750583608000029.

Szolgayova J., S. Fuss, and M. Obersteiner (2008). Assessing the effects of $\mathrm{CO}_{2}$ price caps on electricity investments-A real options analysis. Energy Policy 36 , 3974-3981. doi: 10.1016/j.enpol.2008.07.006, ISSN: 0301-4215.

Taleb N. N. (2007). The Black Swan: The Impact of the Highly Improbable. Random House Publishing Group, 481 pp. ISBN: 9781588365835.

Tavoni A., A. Dannenberg, G. Kallis, and A. Löschel (2011). Inequality, communication, and the avoidance of disastrous climate change in a public goods game. Proceedings of the National Academy of Sciences. doi: 10.1073/pnas.1102493108.

Terwel B.W., F. Harinck, N. Ellemers, and D.D. Daamen (2011). Going beyond the properties of $\mathrm{CO}_{2}$ capture and storage (CCS) technology: How trust in stakeholders affects public acceptance of CCS. International Journal of Greenhouse Gas Control 5, 181-188. Available at: http://www.sciencedirect. com/science/article/pii/S1750583610001507.

Thaler R.H. (1999). Mental accounting matters. Journal of Behavioral Decision Making 12, 183-206. doi: 10.1002/(SICI)1099-0771(199909)12:3<183::AIDBDM318>3.0.C0;2-F, ISSN: 1099-0771.

Thaler R.H., and C.R. Sunstein (2008). Nudge: Improving Decisions About Health, Wealth, and Happiness. Yale Univ Press, Available at: http://books.google. com/books?hl=en\&lr=\&id=dSJQn8egXvUC\&oi=fnd\&pg=PA17\&dq=thaler+sunstein+nudge\&ots=0cJNMCGnRt\&sig=W0TkD9mBUvN68xjgj5sFwpaW-NU.

Thompson A. (2010). Rational design in motion: Uncertainty and flexibility in the global climate regime. European Journal of International Relations 16 269-296.

Thornton P. K., P. G. Jones, T. Owiyo, R. L. Kruska, M. Herrero, V. Orindi, S. Bhadwal, P. Kristjanson, A. Notenbaert, N. Bekele, and others (2008). Climate change and poverty in Africa: Mapping hotspots of vulnerability. African Journal of Agriculture and Resource Economics 2, 24-44.

Tol R.S.J. (1999). Safe policies in an uncertain climate: an application of FUND. Global Environmental Change, Part A: Human and Policy Dimensions 9 221-232.

Tol R. S.J. (2003). Is the uncertainty about climate change too large for expected cost-benefit analysis? Climatic Change 56, 265-289.

Toubia O., E. Johnson, T. Evgeniou, and P. Delquié (2013). Dynamic experiments for estimating preferences: An adaptive method of eliciting time and risk parameters. Management Science 59, 613-640. Available at: http://mansci. journal.informs.org/content/59/3/613.short. 
Tsur Y., and A. Zemel (1996). Accounting for global warming risks: Resource management under event uncertainty. Journal of Economic Dynamics and Control 20, 1289-1305. doi: 10.1016/0165-1889(95)00900-0, ISSN: 0165-1889.

Tsur Y., and A. Zemel (2009). Endogenous discounting and climate policy. Environmental and Resource Economics 44, 507-520. doi: 10.1007/s10640-009-9298 -0, ISSN: 0924-6460.

Tuomisto J.T., A. Wilson, J.S. Evans, and M. Tainio (2008). Uncertainty in mortality response to airborne fine particulate matter: Combining European air pollution experts. Reliability Engineering \& System Safety 93, 732-744.

Turner N. J., and H. Clifton (2009). "It's so different today": Climate change and indigenous lifeways in British Columbia, Canada. Global Environmental Change 19, 180-190. Available at: http://www.sciencedirect.com/science/article/ pii/S0959378009000223.

Tversky A., and D. Kahneman (1973). Availability: A heuristic for judging frequency and probability. Cognitive Psychology 5, 207-232. doi: 10.1016/0010 -0285(73)90033-9, ISSN: 0010-0285.

Tversky A., and D. Kahneman (1992). Advances in prospect theory: Cumulative representation of uncertainty. Journal of Risk and Uncertainty 5, 297-323. doi: 10.1007/BF00122574, ISSN: 0895-5646, 1573-0476.

Tyshenko M. G., S. ElSaadany, T. Oraby, S. Darshan, W. Aspinall, R. M. Cooke, A. Catford, and D. Krewski (2011). Expert elicitation for the judgment of prion disease risk uncertainties. Journal of Toxicology and Environmental Health, Part A 74, 261-285.

Ulph A., and D. Ulph (1997). Global warming, irreversibility and learning. The Economic Journal 107, 636-650.

UNDP (2007). Human Development Report 2007/2008: Fighting Climate Change: Human Solidarity in a Divided World. United Nations Development Programme, New York, 384 pp. Available at: http://hdr.undp.org/en/media/HDR_20072008_ EN_Complete.pdf.

UNFCCC (2007). Vulnerability and Adaptation To Climate Change In Small Island Developing States. UNFCC, 38 pp. Available at: http://unfccc.int/files/ adaptation/adverse_effects_and_response_measures_art_48/application/pdf/ 200702_sids_adaptation_bg.pdf.

U.S. Environmental Protection Agency (2005). Guidelines for Carcinogen Risk Assessment. Washington, DC, Available at: http://cfpub.epa. gov/ncea/cfm/recordisplay.cfm?deid=116283.

U. S. NRC (1983). PRA Procedures Guide. A Guide to the Performance of Probabilistic Risk Assessments for Nuclear Power Plants. Final Report. NUREG/CR-2300. U.S. NRC (U.S. Nuclear Regulatory Commission). Available at: Available from: http://www.nrc.gov/reading-rm/doc-ollections/nuregs/contract/cr2300/vol2/ cr2300v2-a.pdf.p. 12-12).

Vasa A., and A. Michaelowa (2011). Uncertainty in Climate Policy-Impacts on Market Mechanisms. In: Climate Change and Policy. G. Gramelsberger, J. Feichter, (eds.), Springer Berlin Heidelberg, pp. 127-144. ISBN: 978-3-642-17699-9, 978-3-642-17700-2.

Victor D.G. (2011). Global Warming Gridlock: Creating More Effective Strategies for Protecting the Planet. Cambridge University Press, Cambridge, UK, 392 pp. ISBN: 97805218650120521865018.

Vignola R., S. Klinsky, J. Tam, and T. McDaniels (2012). Public perception, knowledge and policy support for mitigation and adaption to Climate Change in Costa Rica: Comparisons with North American and European studies. Mitigation and Adaptation Strategies for Global Change 18, 1-21. doi: 10.1007/s110 27-012-9364-8, ISSN: 1381-2386.
Vlek C. (2010). Judicious management of uncertain risks: I. Developments and criticisms of risk analysis and precautionary reasoning. Journal of Risk Research 13, 517-543. Available at: http://www.tandfonline.com/doi/abs/ 10.1080/13669871003629887.

Van Vuuren D.P., J. Edmonds, M. Kainuma, K. Riahi, A. Thomson, K. Hibbard, G. C. Hurtt, T. Kram, V. Krey, J. F. Lamarque, T. Masui, M. Meinshausen, N. Nakicenovic, S.J. Smith, and S.K. Rose (2011). The representative concentration pathways: An overview. Climatic Change 109, 5-31.

Wakker P.P. (2010). Prospect Theory: For Risk and Ambiguity. Cambridge University Press, Cambridge; New York, 606 pp. ISBN: 97805217650150521765013 97805217486810521748682.

Wallquist L., S. L. Seigo, V.H.. Visschers, and M. Siegrist (2012). Public acceptance of CCS system elements: A conjoint measurement. International Journal of Greenhouse Gas Control 6, 77-83.

Wallsten T.S., D.V. Budescu, A. Rapoport, R. Zwick, and B. Forsyth (1986). Measuring the vague meanings of probability terms. Journal of Experimental Psychology: General 115, 348. Available at: http://psycnet.apa.org/journals/ xge/115/4/348/.

Walters C.J., and R. Hilborn (1978). Ecological optimization and adaptive management. Annual Review of Ecology and Systematics 9, 157-188.

Wang M., C. Liao, S. Yang, W. Zhao, M. Liu, and P. Shi (2012). Are People Willing to Buy Natural Disaster Insurance in China? Risk Awareness, Insurance Acceptance, and Willingness to Pay. Risk Analysis 32, 1717-1740. doi: 10.1111/j.153 9-6924.2012.01797.x, ISSN: 1539-6924.

Weber E.U. (1997). Perception and expectation of climate change: Precondition for economic and technological adaptation. In: M. Bazerman, D. Messick, A. Tenbrunsel, \& K. Wade-Benzoni (eds.), Psychological Perspectives to Environmental and Ethical Issues in Management. Jossey-Bass, San Francisco, CA, pp. 314-341.

Weber E.U. (2006). Experience-based and description-based perceptions of longterm risk: Why global warming does not scare us (yet). Climatic Change 77, 103-120. doi: 10.1007/s10584-006-9060-3, ISSN: 0165-0009, 1573-1480.

Weber E.U. (2011). Climate change hits home. Nature Climate Change 1, 25-26. doi: doi:10.1038/nclimate1070.

Weber E.U. (2013). Doing the right thing willingly: Behavioral decision theory and environmental policy. In: The Behavioral Foundations of Policy. E. Shafir, (ed.), Princeton University Press., Princeton, NJ, pp. pp. 380-397.

Weber E.U., and D.J. Hilton (1990). Contextual effects in the interpretations of probability words: Perceived base rate and severity of events. Journal of Experimental Psychology: Human Perception and Performance 16, 781. Available at: http://psycnet.apa.org/journals/xhp/16/4/781/.

Weber E.U., and C. Hsee (1998). Cross-cultural differences in risk perception, but cross-cultural similarities in attitudes towards perceived risk. Management Science, 1205-1217.

Weber E.U., and E.J. Johnson (2009). Decisions under uncertainty: Psychological, economic, and neuroeconomic explanations of risk preference. In: Neuroeconomics: Decision Making and the Brain. P. Glimcher, C.F. Camerer, E. Fehr, R. Poldrack, (eds.), Elsevier, New York, pp. 127-144.

Weber E.U., E.J. Johnson, K. F. Milch, H. Chang, J.C. Brodscholl, and D. G. Goldstein (2007). Asymmetric discounting in intertemporal choice. Psychological Science 18, 516-523. doi: 10.1111/j.1467-9280.2007.01932.x. 
Weber E.U., and P. G. Lindemann (2007). From intuition to analysis: Making decisions with our head, our heart, or by the book. In: Intuition in Judgment and Decision Making. H. Plessner, C. Betsch, T. Betsch, (eds.), Lawrence Erlbaum, Mahwah, NJ, pp. 191-208.

Weber E.U., S. Shafir, and A.-R. Blais (2004). Predicting risk sensitivity in humans and lower animals: Risk as variance or coefficient of variation. Psychological Review 111, 430-445. doi: 10.1037/0033-295X.111.2.430, ISSN: 1939-1471 (ELECTRONIC); 0033-295X (PRINT).

Weber E.U., and P.C. Stern (2011). Public understanding of climate change in the United States. American Psychologist 66, 315-328. doi: 10.1037/a0023253, ISSN: 1935-990X, 0003-066X.

Webster M.D. (2008). Uncertainty and the IPCC. An editorial comment. Climatic Change 92, 37-40. doi: 10.1007/s10584-008-9533-7, ISSN: 0165-0009.

Webster M.D., M. Babiker, M. Mayer, J.M. Reilly, J. Harnisch, R. Hyman, M.C. Sarofim, and C. Wang (2002). Uncertainty in emissions projections for climate models. Atmospheric Environment 36, 3659-3670. doi: 10.1016/S1352-2 310(02)00245-5, ISSN: 1352-2310.

Webster M.D., C. Forest, J. Reilly, M. Babiker, D. Kicklighter, M. Mayer, R. Prinn, M. Sarofim, A. Sokolov, P. Stone, and C. Wang (2003). Uncertainty analysis of climate change and policy response. Climatic Change 61, 295-320. doi: 10.1023/B:CLIM.0000004564.09961.9f, ISSN: 0165-0009.

Webster M.D., L. Jakobovits, and J. Norton (2008). Learning about climate change and implications for near-term policy. Climatic Change 89(1-2), 67-85.

Webster M.D., S. Paltsev, and J. Reilly (2010). The hedge value of international emissions trading under uncertainty. Energy Policy 38, 1787-1796. doi: 10.1016/j.enpol.2009.11.054, ISSN: 0301-4215.

Weitzman M.L. (2001). Gamma discounting. American Economic Review 91, 260-271.

Weitzman M.L. (2009). On modeling and interpreting the economics of catastrophic climate change. The Review of Economics and Statistics 91, 1-19.

Weitzman M.L. (2011). Fat-tailed uncertainty in the economics of catastrophic climate change. Review of Environmental Economics and Policy 5, 275-292.

Whitfield S.C., E.A. Rosa, A. Dan, and T. Dietz (2009). The Future of nuclear power: Value orientations and risk perception. Risk Analysis 29, 425-437. doi: 10.1111/j.1539-6924.2008.01155.x, ISSN: 1539-6924.

Whitmarsh L. (2008). Are flood victims more concerned about climate change than other people? The role of direct experience in risk perception and behavioural response. Journal of Risk Research 11, 351-374. Available at: http://www. tandfonline.com/doi/abs/10.1080/13669870701552235.
Williges K., J. Lilliestam, and A. Patt (2010). Making concentrated solar power competitive with coal: The costs of a European feed-in tariff. Energy Policy 38, 3089-3097.

Wiser R., K. Porter, and R. Grace (2005). Evaluating experience with renewables portfolio standards in the United States. Mitigation and Adaptation Strategies for Global Change 10, 237-263. doi: 10.1007/s11027-005-6573-4, ISSN: 1381-2386, 1573-1596.

Wood P. J., and F. Jotzo (2011). Price floors for emissions trading. Energy Policy 39, 1746-1753. doi: 10.1016/j.enpol.2011.01.004, ISSN: 0301-4215.

World Bank (2010). Economics of Adaptation to Climate Change: Social Synthesis Report. World Bank. The International Bank for Reconstruction and Development.

Yang M., W. Blyth, R. Bradley, D. Bunn, C. Clarke, and T. Wilson (2008). Evaluating the power investment options with uncertainty in climate policy. Energy Economics 30, 1933-1950. doi: 10.1016/j.eneco.2007.06.004, ISSN: 01409883.

Yohe G., N. Andronova, and M. Schlesinger (2004). To hedge or not against an uncertain climate future? Science 306, 416-417. doi: 10.1126/science. 1101170.

Yohe G., and R. Wallace (1996). Near term mitigation policy for global change under uncertainty: Minimizing the expected cost of meeting unknown concentration thresholds. Environmental Modeling \& Assessment 1, 47-57. Available at: http://link.springer.com/article/10.1007/BF01874846.

Young O.R. (1994). International Governance: Protecting the Environment in a Stateless Society. Cornell University Press, 244 pp. ISBN: 9780801481765.

De Zeeuw A., and A. Zemel (2012). Regime shifts and uncertainty in pollution control. Journal of Economic Dynamics and Control 36, 939-950. doi: 10.1016/j.jedc.2012.01.006, ISSN: 0165-1889.

Zhao J. (2003). Irreversible abatement investment under cost uncertainties: tradable emission permits and emissions charges. Journal of Public Economics 87, 2765-2789.

Zickfeld K., M.G. Morgan, D.J. Frame, and D.W. Keith (2010). Expert judgments about transient climate response to alternative future trajectories of radiative forcing. Proceedings of the National Academy of Sciences. doi: 10.1073/pnas.0908906107.

Zoellner J., P. Schweizer-Ries, and C. Wemheuer (2008). Public acceptance of renewable energies: Results from case studies in Germany. Energy Policy 36, 4136-4141. 
